THE INTERNATIONAL

REVIIEW OF RESEARCH IN

OPEN AND DISTANCE LEARNING

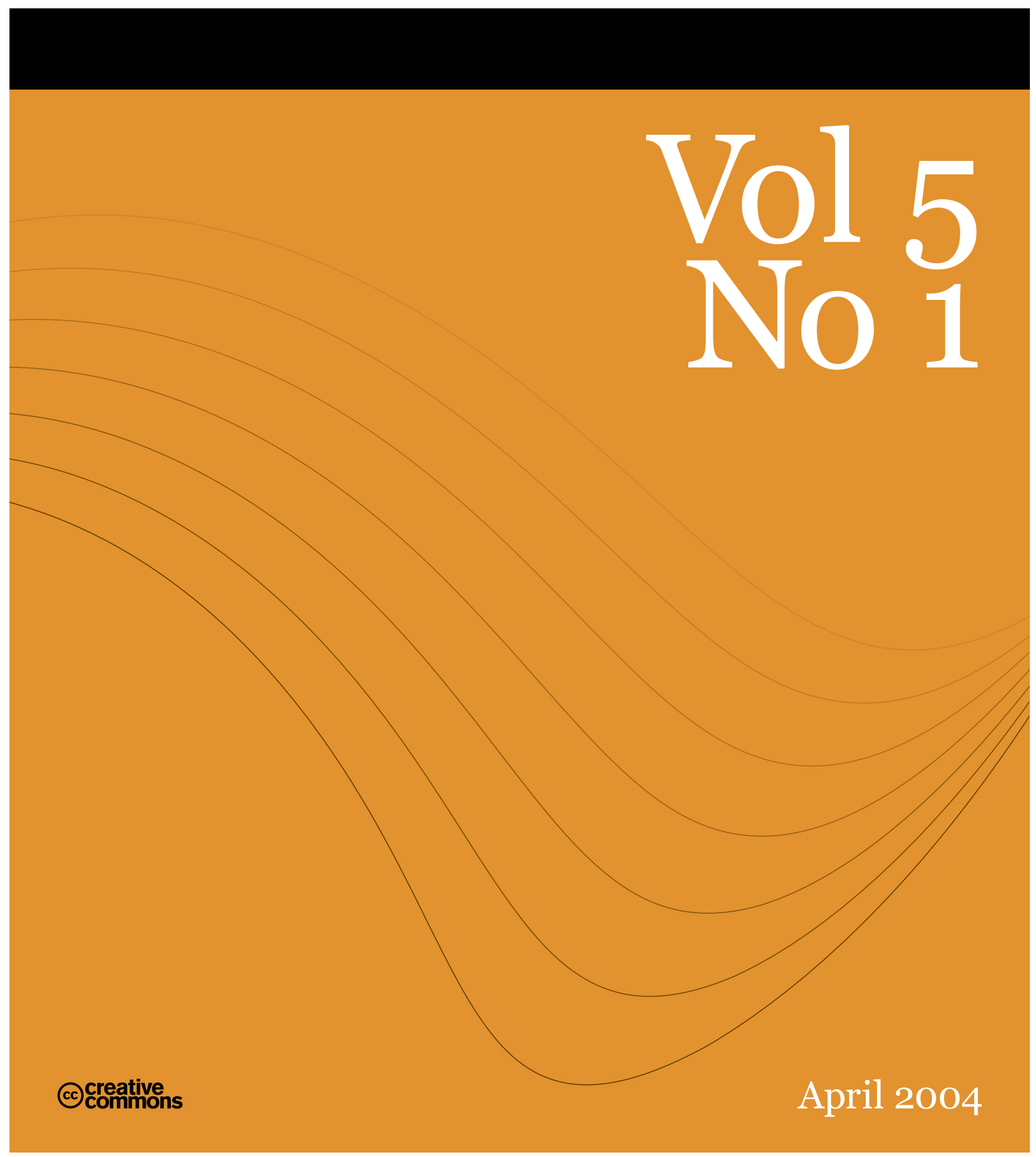


April - 2004

\title{
Guest Editorial - Low Cost Distance Education Strategies: The use of appropriate information and communication technologies
}

\author{
Thomas Hülsmann \\ Carl von Ossietzky University \\ Germany
}

\section{Introduction}

The argument for distance education (including e-learning) in developing countries could be imagined as a "triple jump." Each leap of the triple jump consists of a theorem and a corollary applying it to developing countries.

Theorem 1: Education is good for development.

Corollary: The demand for education is especially high in the developing world. Traditional education cannot cope with its size and is, in many cases, not the most cost-effective allocation of resources.

Theorem 2: Distance education can help.

Corollary: Distance education is able to deal with large numbers more cost-effectively than traditional education, and has proved to do so also in developing countries.

Theorem 3: E-learning is extending the capabilities of traditional distance education.

Corollary: Given the emerging global information infrastructure, there are a number of cases where e-learning can enhance the capabilities of distance education in the developing world.

Many distance educators would readily subscribe to theorems of leaps 1 and 2 of the triple jump, but argue that the argument collapses at leap 3, especially when it comes to the corollary suggesting that ICT-based distance education could be relevant in the developing world. This paper takes the role of the "devil's advocate" 1 , and will try to cast some doubt on the first two theorems, while intending to strengthen the third leap theorem, the least established argument of the three. 


\section{Education and Development}

General laws in social sciences are rare and tend to be trivial. The law that "on the average the educated earn more than the less educated" is less trivial, and has served as the cornerstone of the "human capital research program" (Blaug, 1992). One line of this research uses the hypothesis that "people invest in themselves" to throw light on decision patterns made in such diverse fields of activities as health, migration, and education (Blaug as cited in Woodhall, 1995). $\stackrel{2}{\text { This }}$ line of research led to the micro-economic approach of calculating "rates of return to education" (Psacharopulos and Woodhall, 1985). The underlying idea is to offset the costs of an additional year of education against the benefits in terms of increased earnings. The finding of this line of research insists that both "private rates of return" as well as "social rates of return" are substantial and especially high in low-income countries (Psacharoupoulos and Patrinos, 2002).

Unfortunately, macro-economic evidence paints a less rosy picture of the relation between investment in education and economic growth. While Post-World War II statistics confirm that the experiment of such a massive investment has been conducted in almost all countries, the reported findings of correlating growth in educational investment and economic growth are sobering.

"[T]he association of growth of educational capital and conventional measures of TFP [= Total Factor Productivity; TH] is large, strongly statistically significant, and negative” (Prichett, 1999).

The reason for this may be sought in the low quality of educational investment in some countries - too low for affecting productivity - but may also result from the fact that the demand for educated labour rose slower than the supply, turning educational investment into a costly "screening exercise." Most disturbing is, however, the piracy metaphor suggests that substantial amounts of education may not have been successfully channelled to productive tasks, but to rent seeking forms of employment. Pritchett (1990) illustrates his piracy metaphor by reporting the case of a country that offered degree holders a place in a civil service department of their choice, and most students opted to work in customs. Education may have shown them the privately most rewarding avenue of activities, albeit adding little to "total factor productivity."를

Investment in education, however, can be justified not only for "efficiency reasons," but also for "evaluative reasons" (for the distinction between "evaluative and effectiveness reasons" (Sen, 1999, p. 4). At least basic education is viewed as a "human right" (or as economists may wish to call it "a merit good"). In a society so deeply shaped by the "typographic system of communication" (Giesecke, 2002), ${ }^{4}$ literacy has become a necessary prerequisite for "appearing in public without shame" (Sen, 1999, p. 71) and fully "functioning" in society.

To sum up: An advocatus diaboli may be able to successfully challenge the claim that education would lead to economic growth. As a consequence, any hopes that educational investment would be self-paying out of added productivity (which would eventually trickle down into the coffers of the ministry of education) seem unfounded. However, education (at least basic education) is increasingly regarded as a "merit good" and should be provided. This means that the conflict between sustained demand for education and restrained budgets to fund it remains and calls for cost-effective resource allocation. Could distance education help to resolve this conflict? 


\section{Distance Education}

The second leap of the triple jump is the theorem, generally upheld by distance educators (Daniel, 2001), that distance education is able to deal with large numbers of learners in a cost-effective manner. The argument here is different from the traditional rationale for distance education in terms of increased flexibility. Learners who cannot be reached by traditional delivery methods remain a captive market for distance education. However, it has also been claimed that distance education is the more cost-effective means for allocating educational resources, and that it is especially capable of reaching large numbers. The heart of the argument lies in distance education's susceptibility for scale economies.

Theorem 2 is meant to imply that distance education is attractive in developing countries, because it is said to increase access and, at the same time, to be more cost-efficient - i.e. lowers average costs per student. The point is that the "very good thing" of increasing access leads to the "very good thing" of driving down average costs per student. The mechanism behind this is the attractive $\mathrm{AC}$ formula $(\mathrm{AC}=\mathrm{F} / \mathrm{N}+\mathrm{V})$, where $\mathrm{AC}=$ average cost, $\mathrm{F}=$ fixed costs, $\mathrm{N}=$ numbers of students, and $\mathrm{V}=$ variable cost per student. The large fixed costs of course development (embodiment of the academic dignity in traditional distance education ${ }^{\underline{6}}$ ) produce the quality material, which will be available at a prix démocratique because the arrangement welcomes so many people $(\mathrm{N})$ - "the more, the merrier."

The success of this type of distance education cannot be denied. A number of quite successful organizational models have been developed, both supporting formal and informal education at various levels. An international overview of trends and policies is given in UNESCO (2002), Perraton (2000), and Perraton and Creed (2000). However, there are weak points.

Traditional pedagogues lament that distance education does not allow for interactivity between teacher and student, which good quality education would require. In fact, even Rumble, an intimate adept of the world of high quality distance teaching, gives short thrift to claims that, for instance, Holmberg's "guided didactic conversation" could qualify as substitute for an academic discussion (Rumble, 2001)..$^{7}$ As a result, quality distance education is often measured by its investment in student support (mostly contributing to $\mathrm{V}$, the "variable costs per student," parameter, which sets the lower limit, below which average costs per student could not possibly fall). $\cdot$ 
Hulsmann, Vol. 5, No. 1 Editorial

Low Cost Distance Education Strategies: The use of appropriate information and communication technologies

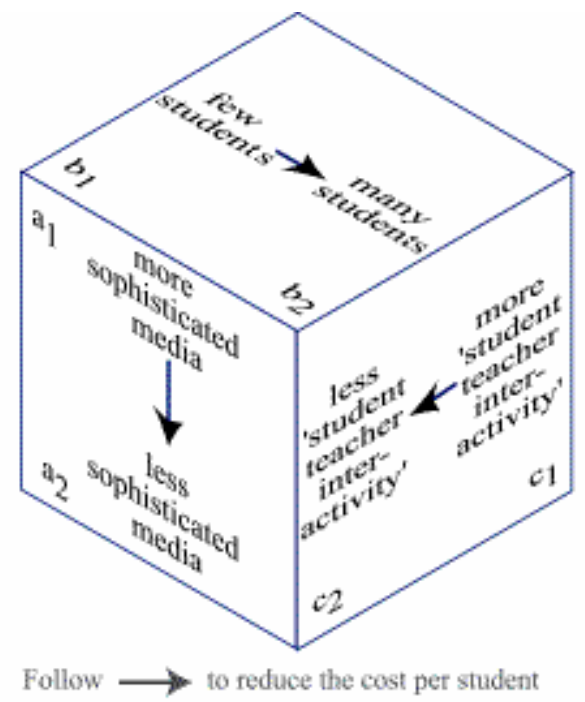

Figure 1. Costing Cube

Before deriving practical policy consequences from the average cost formula, it should be noted that the variables $\mathrm{F}, \mathrm{V}$, and $\mathrm{N}$ are not independent. You cannot reduce $\mathrm{V}$ and increase $\mathrm{N}$ at will. Enrolment level is mediated by market decisions of the clients - i.e., in our case, the students. And given the proliferation of flexible learning options, distance education students are not anymore a captive market. They will opt with their feet. If $\mathrm{V}$ is brought down as part of "walking the efficiency path," (i.e., the path to reduce "cost per student” identified in Perraton's Costing Cube $^{-}$) then many may opt out. Luckily, this means conversely that investment in student support can increase cost-effectiveness by lowering the "costs per graduate" to the extent student support impacts on retention and throughput. (Traditional distance education has been accused of operating with drop-out money (Noble, 1997), which could be seen as an act of piracy, in the sense of Pritchett (1999): the education, which the correspondence school offers, does little in terms of adding value and only "redistributes" students' money into the coffers of the institution.) The AC equation is only half of the story. Enthusiasts of scale economics, who aim at bringing down average costs per student, may loose sight of the fact that total costs $(\mathrm{TC}=\mathrm{F}+\mathrm{VxN})$ nonetheless rise. In many developing countries this means, as Butcher and Roberts (2004) convincingly demonstrate, that the funding stream may be interrupted before the rollout of a project has led to the low average costs per student, the program may have had aimed for. Arguably, the biggest disadvantage of this model is that it needs to restrict the scope of course offerings of an institution. The more courses an institution offers (without being able to proportionally expand its learner base), the more the effect of scale economies is lost. This is one reason why it is difficult to teach specialized courses by distance education.

To sum up: The advocatus diaboli, while not being able to completely damage the case that distance education is able to contribute to coping with large numbers and provide education more cost-effectively, would be able to identify the limitations of the model. Lack of interactivity may be such a weak point, as well as the limited scope of course offerings. In fact that the very advantage of the model, that it is compatible with broad access, may - in a number of contexts turn out to be a weakness since markets, in particular for specialized courses, are likely to be limited. Nonetheless, there are stories of success. Open universities, or in-service teacher training for example, have been found to be potentially successful organizational models. ${ }^{10}$ 


\section{e-Learning}

Full exploitation of the potential of digital learning environments would certainly drive-up both fixed and variable costs. Fixed costs may rise if the multimedia capabilities of the digital learning environment are exploited or when programmes are designed to increase, what Hülsmann (2000) calls "internal interactivity" (ranging from multiple choice questions to computer marked assignments or simulated dialogue in the ELIZA tradition (Weizenbaum, 1976). Media and IT experts are necessary alongside instructional designers to realize such projects in the form of Computer Based Training (CBTs) or Web-Based Training (WBTs). Their development is costly, despite the fact that the cost-structure ${ }^{11}$ may be compatible with Fordist distance education and, in principle, is susceptible to scale economies.

Variable costs per students are likely to increase where enhanced demand for teacher student communication drives up teaching costs. This remains true whatever medium may sustain the line of communication. Increased costs of "external interactivity" (Hülsmannn, 2000) re-establish the link between costs and volume, and thus erodes scale economies.

Fortunately, there are choices. They may be seen as ranging between two poles: (1) the type-i option which emphasizes the information aspect of ICT-based distance education (e-learning), and which puts a premium on the use of multimedia and programmed "internal interactivity;" and (2) the type-c option, which emphasizes the communication aspect of ICT and puts a premium on communication (both between teacher and students, and among peers). ${ }^{12}$ On an adequately equipped computer, both types of e-learning can be realized. This is why the problem of media selection in e-learning differs from the problem of media selection in traditional distance education (for the latter see Bates, 1995, in his chapter "Selecting [educational] technologies" where he develops the ACTIONS model of media selection). While in traditional distance education selection of technologies has implications for costs and pedagogy, standard e-learning environments - such as learning management systems (LMS) - enable realization of educational scenarios of a highly different nature, both with respect to cost-structure and with regard to teaching and learning, on the same platform. So CBTs (WBTs), which epitomize the type-i variant of e-learning, may just be sent to students (or access via the Internet) without further tutorial support being given. In some contexts such an option may look cost-efficient, for instance if it is possible to reach large cohorts of learners. In corporate training environments, this is often seen as an attractive option (see Whalen and Wright, 1999).

On the other pole, there is the "virtual seminar," which illustrates the type-c variant. This variant can be seen as driving horses through the classical layout of a distance education institution. Its extensive use of teacher-student communication, e.g., in the form of asynchronous communication, re-establishes the link between costs and volume of activities (number of students to be taught) and is little susceptible for scale economies. It also calls into question the need for specialized course development altogether. Why write new courses when one can cherry-pick from an increasingly large repository of knowledge, which is already there? Why reinventing the wheel? Once the infrastructure is in place, such a virtual seminar option can be rather "low cost." To some extent, this option can be seen as enabling a response to the problem of scope (the demand for a more diversified set of specialized course offerings). 
It is important to realize that in this type-c variant of e-learning, personnel costs are the decisive cost drivers (Rumble, 2001). Once the infrastructure is in place, not the technology costs but instead the personnel costs (e.g., teachers/ tutors) are the main cost drivers.

We can relate this observation to Orivel's argument against the computers in schools in developing countries (Orivel, 2000). Orivel distinguishes between (1) costs that depend on a global world market, and (2) locally driven costs. Costs for computer equipment fall in the former, costs for tutors and teachers fall in the latter category. This leads Orivel to conclude that even if computers were introduced with the aim of substituting teachers, $\underline{\underline{13}}$ they are unlikely to lead to lower costs since world market gadgets (such as computers) are generally more expensive than services, such as those provided by teachers, bought on local markets. While this does not mean that tutorial support in the developing world will be inexpensive, it may help to put things into perspective. Given the infrastructure in place, linking wireless local loop (WLL) to vocational training centres in Ethiopia may lead to much lower costs than would be incurred in an industrialized country. $\underline{\underline{14}}$

There are ways to recover efficiencies lost in e-learning (lost due to its possibly higher fixed costs together with its possibly less scale economies in e-learning). Hülsmann (2004) points out that elearning allows, in principle, better re-use of developed material (keywords: "re-purposing, learning objects") which allows to depreciate "nuggets" (i.e., learning objects which had been costly to develop such as climate simulations) not only horizontally along the shelf life of a course, but also vertically - i.e. across various courses where such nuggets could be re-used.

A second way to recover lost efficiencies is cooperation. Hülsmann (2004) quotes Rumble and Latchem, (2004) pointing out:

Technology and e-business approaches make it possible for integrated processes of open and distance education to be disintegrated into their constituent parts: curriculum development; content development; learner acquisition and support; learning delivery; assessment and advising; articulation; and credentialing. These processes can then be managed by different organizations (p. 134).

The fact that distance teaching is a complex system, requiring a number of components being in place in order to function properly, does not imply that all components have to be housed at the same institution. E-learning, in principle, not only allows easier sharing of resources, it also facilitates the process of co-operation at a distance.

To sum up: The advocatus diaboli may point out that: 1) cost-effectiveness arguments against elearning in developing countries are often biased when high infrastructure costs are charged to elearning projects; fair comparison is only possible on the basis of operating costs. If infrastructure is not in place, the question is: Will governments opt for rolling out the required ICT infrastructure or not? This is a different debate, which would need to include the "opportunity costs” for not doing so (Mansell and Wehn, 1998, p.7). 2) Infrastructure will, albeit unevenly, percolate in remote areas of developing countries, especially by means of wireless technology i.e., either using satellite transmissions, or hooking up WLL to Mbones (multicast backbone) linking major centres. 3) When infrastructure is in place, personnel costs are the main cost drivers in a number of e-learning options. Personnel costs are dependent on local markets and therefore comparatively lower than in the industrialized world. 4) E-learning facilitates sharing of resources 
Hulsmann, Vol. 5, No. 1 Editorial

Low Cost Distance Education Strategies: The use of appropriate information and communication technologies

and cooperation. Hence, there are a number of avenues to recover lost efficiencies, which are in line with cultural traditions in developing countries.

\section{The Contributions}

In this issue, Rashid Aderinoye's and Kester Ojokheta's contribution unequivocally supports the above theorems 1 and 2. They say that: "Clearly, education is the key to human development and progress" and they cite both "effectiveness and evaluative reasons" (Sen, 1999, p.4) for this. They ground their contribution on a line of reasoning about education ranging from human capital theory (citing Schultz, 1977), to the more recent approach by Sen (1999) who sees education as capability, "expanding the real freedom that people enjoy."

Traditional distance education works for and contributes to development. Among the numerous examples is the National Teachers' Institute (NTI), a dedicated distance teaching institution, which has contributed to upgrade and train more than 300,000 teachers since it was officially established in 1978. The authors point out the "ripple effect" this contribution had for the development of the country. Distance education may serve outreach programmes of the university including the University Village Association Rural Literacy Programme, which has been also supported by the British Council. Moreover, NTI has established a Preventive Education Unit addressing, as the first academic institution in West Africa, the issue of HIV/ AIDS using open and distance learning methods.

That international cooperation can create synergies is demonstrated by cooperation between Nigerian distance teaching institutions and international agencies such as the Commonwealth of Learning (COL), UNESCO and, more regionally, the Sudan Open Learning Organization (SOLO).

But there are also moves towards including e-learning, interestingly mentioned in two different, but both important contexts. First, tele-centres have been established within less privileged communities are reported. Second, ICT is used to recruit back the African intellectuals lost due to brain drain (e-Africa). Optimistically the authors see a change away from the former "brain drain" situation, to one where African professionals having gained experience abroad, return home to become a veritable "brain trust" for Africa to draw from.

Lentell and O'Rourke address a key issue of open and distance learning: the scalability of student support. This is an issue for traditional distance education where quality has often been measured by close tutorial support ('of Oxbridge type') is provided. To the extent the rationale for distance education to be expected as cost-effective as being based on scale economies, the scalability of quality tutorial support is, indeed, a key issue. Moreover, the emergence of e-learning does not make the issue go away, but puts it more firmly on the agenda since e-learning facilitates communication with the teacher, and therefore tends to drive variable costs per student up.

The authors put forward a number of propositions, which go beyond the traditional suggestion of labour-for-labour substitution. These propositions include better targeting of support, unbundling issues of academic support, and more generalized need for counselling, making use of local mentors, and more effectively organizing peer support. All these propositions are of great relevance for e-learning contexts. 
Alvana Maria Bof reports on a large-scale project that, at the same time, is innovative in terms of its organizational approach. Proformação is a programme aimed at qualifying 27,000 uncertified teachers in different Brazilian States. The programme is innovative in terms of organization since it operates not from a big institutional base, but by leveraging support from several institutions which are close to the learners where necessary. The approach recalls what Moore calls "vertical

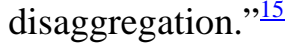

However, in the distance education field, it is not only the strategic alliance, but also the vertical disaggregation form of network that is likely to be of greater interest in the future. Vertical disaggregation is the process developed in the manufacturing industry to deal with shortening product life cycles, by which large firms outsource the production of various components of the product to smaller suppliers. As in manufacturing, in the knowledge industries too it looks as if vertical disaggregation will become the means of reducing product life cycles and improving efficiency and quality. What that means in distance education is outsourcing some of design and a lot of the product development of course materials. It means devolving learner support services to local points of contact and specialized services. It means drawing in instructor resources from wherever they may be located, rather than solely on the faculty on campus (Moore, 2003, p. 4).

Proformação operates on three different levels: 1) the federal level; 2) the state level; and the 3) municipal level. While the design of the curriculum was planned on the federal level, where also the small management unit of the project is located, there is state level coordination of the training agencies (TAs) that conduct the training at the municipal level. The upper two layers make extensive use of telecommunication technologies, while tutoring is done on the local municipal level close to learners.

The last contribution by Mason and Rennie is about development, although not about a developing country. We may recall here that the partition of the world into countries, which could be classified as "industrialized" or "underdeveloped," is increasingly becoming obsolete. There are pockets of underdevelopment in the US for example, whereas China has pockets of leading edge industrial development. The impact of the emerging global information and communication infrastructure may restructure the geography of development further.

It is not the first time that ideas tried in the remote areas of the developed world have been used as an organizational template for developing countries. The Canadian Farm Radio Forum "that ran in the 1940s with the motto "Read, listen, discuss, act"” (Perraton, 2000, p. 17) has served as a model for a number of programmes in developing countries, such as the radiophonic programmes including Acción Comunal Popular (ACPO) in Columbia, the African Medical and Research Foundation (AMREF), and the Institut Africain pour le Developpement Economique et Social (INADES) in Africa. The idea of tele-centres had its origins in the mid-1980s in Scandinavia. It then spread to Western Europe, Australia, and North America, and is now taking root in the former Eastern Bloc countries as well as in Africa, Asia, and Latin America” (Oestman and Dymond, 2001, p. viii).

The Western Isles of Scotland are truly remote areas in an industrialized country. The installation of broadband services ${ }^{16}$ in a remote and rather isolated part of the country may lead to some 
Hulsmann, Vol. 5, No. 1 Editorial

Low Cost Distance Education Strategies: The use of appropriate information and communication technologies

interesting lessons. One principal lesson underlines the dilemma, which is due to the complementarities between technology and social context $t^{17}$. If there is not infrastructure in place, neither appreciation not demand for a new technology is likely to develop. Without expressed demand and awareness from the local communities on the other hand, the interest to rollout the necessary infrastructure will be limited. Mason and Rennie decide that, in the final analysis, introducing broadband is "inevitably a technology-led operation."

The identified demand relates to job opportunities, community services, and access to e-learning. E-learning applications are not the primary reasons for introducing broadband at home, but "will piggyback on a range of applications." The authors suggest that there is a "convergence between working and learning," and that e-learning providers "need to lead the way in working through the implications of theses changes."

There is a section applying the lessons learned to rural e-learning in developing countries. According to Mason and Rennie, it is essential to take into consideration both aspects: technological infrastructure as well as pedagogical readiness. They warn against over-optimism about wireless technology, allowing developing nations to leapfrog ahead of developed nations. They believe that the use of tele-centres could play an important role. ${ }^{18}$

\section{Changing Contexts}

In the final analysis, much of what influences one's stance towards e-learning in the developing world depends on how one gauges the profoundness of the changes of the last twenty years. Are we undergoing "revolutionary changes" comparable to those triggered by the invention of the printing press or the introduction of writing? Or do these comparisons completely overrate the impact of the emerging Global Information Infrastructure (GII)? Those who believe the latter, point out that the introduction of writing had undoubtedly a profound cognitive effect (Goody, 1977; Ong, 1982) while using computers, the new "intellectual tool," shows no comparable features. Similarly, the introduction of the printing press not only contributed in generalizing the cognitive effects on the individual, but also established a completely "new system of communication,” which Gisecke $(1991,2002)$ refers to as "typographeum.” Some, on the other hand, are convinced that the typographic age is rapidly crumbling and soon to be substituted by what some call "informationalism" (Castells, 2000) and others, more euphorically, refer to as a "knowledge society" (Mansell and Wehn, 1998), then it would not be possible to dismiss the use of ICT for development (including e-learning) as a mere fad. When today it is hardly possible to "appear in the public without shame" as Sen puts it, as an illiterate tomorrow, one might not able to function fully in society without a solid grounding as an e-literate.

Are we moving away from the typographeum towards informationalism is a question difficult to answer, being in the thick of the process. The difficulty is apparent once we reflect on the all pervasive influence of writing on individual cognition, and the printing press as a system of communication. The typographic age has generated its proper epistemology, impinging strongly also on our understanding of knowledge (e.g., it being largely of propositional form and ideally organized as a theory). This may make us run into the difficulty exposed in Menon, where Socrates suggests that it is not possible to search for things that are new, since either they are profoundly new, then we do not know what we are looking for, or, if we know what to look for, the things are not really new ${ }^{\underline{19}}$. Either we tend not to see the changes at all, or we fail to see what is new, since it hides behind our old categories. 


\section{References}

Bates, A. W. (1995). Technology, open learning and distance education. London: Routledge.

Blaug, M. (1992). The Methodology of Economics (Second Ed.). Cambridge: Cambridge University Press.

Butcher, N. and Roberts, N. (2004). Costs, effectiveness, efficiency. In H. Perraton and H. Lentell (Eds.) Policy for Open and Distance Learning. London: RoutledgeFalmer.

Castells, M. (2000). The Information Age: Economy, society and culture - Vol. I: The rise of the network society. Oxford: Blackwell.

Daniel J. (2001). Technology and Education: Adventures in the eternal triangle. Paper presented at the LearnTec, Karlsruhe, January.

Giesecke, M. (2002). Von den Mythen der Buchkultur zu den Visionen der Informationsgesellschaft. Frankfurt a. M.: Suhrkamp.

Giesecke, M. (1991). Der Buchdruck in der Frühen Neuzeit Eine historische Fallstudie über die Durchsetzung neuer Informations und Kommunikationstechnologien. Frankfurt a.M.: Suhrkamp.

Goody, J. (1977). The Domestication of the Savage Mind. Cambridge: Cambridge University Press.

Heeks, R. (1999). Indian Software Labour: Cost breakdown and comparison. IDPM, University of Manchester: Manchester, UK. Retrieved May, 28, 2003, from: http://idpm.man.ac.uk/rsc/is/isi/isicost.shtml

Hülsmann, T. (2000). The Costs of Open Learning: a handbook (Vol. 2). Oldenburg: Bibliotheksund Informationssystem der Universität Oldenburg.

Hülsmann, T. (2003). Book Review of Trends, Policy and Strategy Considerations, UNESCO Report (2002). Open Learning 18(3), 303 - 311.

Hülsmann, T. (2004). The Two-pronged Attack on Learner Support: costs and the centrifugal forces of convergence. Paper presented at The Third EDEN Research Workshop and International Conference: Supporting the Learner in Distance Education and ELearning, March 2-4, Oldenburg, Germany.

Jones, S. (1997). Kommunikation, das Internet und Elekromagnetismus, Mythos Internet. Frankfurt a.M.: edition suhrkamp.

Mace, J. (1984). The Economics of Education: a revisionist's view. Higher Education Review, 16(3), $39-55$. 
Mansell, R., and Wehn, U. (Ed.). (1998). Knowledge Societies: information technology for sustainable development. Oxford: Oxford University Press.

Mills, R. (2003). The Centrality of Learner Support in Open and Distance Learning: a paradigm shift in thinking. In A. Tait and R. Mills (Eds.) Rethinking Learner Support in Distance Education: change and continuity in an international context (p. 102-113). London, New York: RoutledgeFalmer.

Moore, M. G. (2003). Network Systems: the emerging organizational paradigm. Editorial. The American Journal of Distance Education, 17(1), 1 - 5.

Noble, D. F. (1997). Digital Diploma Mills, Part I: The Automation of Higher Education. Retrieved October 29, 2001, from: http://www.communication.ucsd.edu/dl/ddm1.html

Oestmann, S., and Dymond, A. C. (2001). Telecenters - experiences, lessons and trends. In C. Latchem and D. Walker (Eds.) Telecentres: Case studies and key issues. Vancouver: Commonwealth of Learning.

Olson, D. (1994). The World on Paper. Cambridge: Cambridge University Press.

Orivel, F. (2000). Finance, costs and economics. In C. Yates, and J. Bradley (Eds.) Basic Education at a Distance. London: Routledge.

Ong, W. (1982). Orality and Literacy: the technologizing of the word. London: Routledge.

Perraton, H. (2000). Open and Distance Learning in the Developing World. London: Routledge.

Perraton, H., and Creed, C. (2000). Applying New Technologies and Cost-Effective Delivery Systems in Basic Education. IRFOL. Retrieved October 4, 2002, from: http://unesdoc.unesco.org/images/0012/001234/123482e.pdf

Platon. (1992). Menon. Rowohlt.

Pritchett, L. (1999). Where has all the Education Gone? World Bank webpage. Retrieved November 5, 2003, from: http://www.worldbank.org/research/growth/pdfiles/Where_r4.pdf

Psacharopoulos, G., and Patrinos, H. A. (2002). Returns to Investment in Education: A further update. World Bank Policy Research Working Paper, 2881.

Psacharopoulos, G., and Woodhall, M. (1985). Education for Development. Oxford: Oxford University Press.

Rumble, G. (2001). E-education: Whose benefits, whose costs? Inaugural Lecture, Open University UK. Retrieved November 7, 2004 from: http://www.iec.ac.uk/resources/e_education_costs.pdf 
Rumble, G. (2001). The Costs of Providing Online Student Support Services. Paper presented at the 20th World Conference of the International Council for Open and Distance education, April. Düsseldorf, Germany.

Rumble, G., and Latchem, C. (2004). Organisational models for distance and open learning. In H. Perraton and H. Lentell (Eds.) Policy for Open and Distance Learning. London: RoutledgeFalmer.

Schultz, T. W. (1977). Investment in human capital. In J. Karabel and H. Hasley (Eds.) Power and Ideology in Education. New York: Oxford University Press.

Sen, A. (1999). Development as Freedom. Oxford: Oxford University Press.

UNESCO. (2002). Trends, Policy and Strategy Considerations. Paris: UNESCO.

Wade, R. (2001). Development Assistance in the Digital Age. Paper presented at the Joint OECD/UN/UNDP/World Bank Global Forum at the OECD: Exploiting the Digital Opportunities for Poverty Reduction, March. Paris, France.

Weizenbaum, J. (1976). Computer, Power and Human Reason: From judgment to calculation. San Francisco: W. H. Freeman and Company.

Whalen, T., and Wright, D. (1999). Methodology for Cost-Benefit Analysis of Web-Based TeleLearning: Case Study of the Bell. Online Institute. American Journal of Distance Education, 13(1). $22-44$.

Wolf, A. (2002). Does Education Matter? Myths about education and economic growth. London: Penguin books.

Woodhall, M. (1995). Human Capital Concepts. In M. Carnoy (Ed.) International Encyclopaedia of Economics of Education. Oxford: Pergamon.

\section{Endnotes}

1. Cf. Robert Wade: “The Catholic Church has the practice of appointing a "devil”'s advocate" (Advocatus Diaboli) when considering a person for sainthood. The role of the devil's advocate is to ferret out all the reasons why that person should NOT be made a saint, and to present them forcefully in the discussion among the group of cardinals who make the decision.” (Wade, 2001)

2. "The concept of human capital, or "hard core" of the human-capital research programme is the idea that people spend on themselves in diverse ways, not for the sake of present enjoyments, but for the sake of future pecuniary or non-pecuniary returns (Blaug 1976 pp. 829, 850)” (Woodhall, 1995, p. 27)

3. Cf. also Mace (1984) and Wolf (2002) 
4. Giesecke insists that the invention of the printing press has shaped society profoundly. Far from seeing the printing press as a mere technology which does more or less what has been done by hand earlier on, he insists that the invention of the printing press changed the whole "'system of communication," which he gives the name "typographeum."

5. For the concepts of "functionings and capabilities" cf. Sen 1998, p. 75.

6. Mills (2003, p.104)

7. "The argument that it (traditional distance education, T.H.) provides opportunities for "guided didactic conversation” is clearly unconvincing.” (Rumble, 2001, p.3)

8. To reconcile student support with scale is one of the themes discussed in this special edition by Lentell and O’Rourke.

9. The cube is based on Perraton (2000, p. 137). For a discussion of the relation between the AC formula and the cube cf. Hülsmann, 2003, p.304.

10. cf. Aderinoye's and Ojokheta's contribution in this edition.

11. Cost-structure means the composition of total costs in fixed costs and variable costs per student.

12. The distinction is due to Rumble's classification of e-education in Type A and Type B (Rumble, 2001, p.75). It is renamed to make the names more "telling" by relating them to the different aspects of ICT.

13. In general this is not the case since computers are meant for rising quality, which in terms of costing, makes them to add-on costs bound to increase overall expenses.

14. A similar argument can be developed for the type-i variant for some contexts. It has been observed that programming services in India are available at substantially lower costs in India than in the US or Europe (Heeks, 1999).

15. Vertical disaggregation is one of two features (the other being "strategic alliances") of what Michael Moore calls "network systems" and which he sees as the "emerging organizational paradigm” (Moore, 2003).

16. No exact definition of "broadband" is given. It is, however, pointed out that other parameters than communication capacity (speed) such as "always-on connectivity," bandwidth symmetry, and addressability need to be taken into consideration.

17. Steven Jones illustrates this point using the metaphor of an electromagnetic field induced by a current. Like the flow of electricity, which generates an electromagnetic field, the introduction of a new technology induces changes in the social context. This applies also reversibly: social 
Low Cost Distance Education Strategies: The use of appropriate information and communication technologies

changes may invoke technological changes, like a built up of an electromagnetic current induces electricity flow. (Jones, 1997, p. 131-146)

18. Perraton and Creed (2000) point out that professional extension services in health education and agriculture face similar problems. Establishing multipurpose community tele-centres would create synergies in addressing these problems.

19. "Do you realize what a quarrelsome proposition you are putting forward? That it is impossible to search for something, neither for what one knows not for what one does not know. Since you cannot search for what you know because you know it already, neither you can search for what you don't know, because you do not know for what to search.” (my translation; Platon, 1962, p.21)

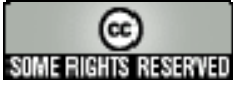




\title{
Open-Distance Education as a Mechanism for Sustainable Development: Reflections on the Nigerian Experience
}

\author{
Rashid Aderinoye and Kester Ojokheta \\ University of Ibadan, Nigeria
}

\begin{abstract}
This article examines open-distance learning in Nigeria and the role it plays in personal, community, and national development. Following consultation with existing literature, a qualitative survey was conducted using questionnaires, interviews, and participatory experience. Although particular emphasis was paid to the Nigerian context, the findings in this article may be regarded as reflective distance education experiences elsewhere in Africa. Clearly, education is the key to human development and progress. It is essential to bring about changes in attitudes, values, and behaviour. Used ethically, distance education may enable people to make informed choices about their present life and future. Moreover, these assertions have been credited to many scholars and institutions at one time or the other. The question here, however, is: To what extent are these assertions true of education, and more especially of those individuals benefiting from open and distance learning in Nigeria? This and more incisive issues constitute the substance of this article.
\end{abstract}

Keywords: distance education; personal development; community development; national development; Nigeria

\section{Background}

The purpose of this article is to introduce readers to the subject of open and distance education and its role in development. From the perspective of Capability Approach Theory, which stresses a developmental approach to education, attention will be paid to the historical antecedents of distance education in Nigeria, the relationship between distance education institutions and the world of work, linkages between open-distance education and development, the intervention of international agencies, and the emergence of the University of South Africa (UNISA), as well as the INADES-Formation Network (http://www.sdnp.undp.org/sdncmr/subweb/cminade4.htm).

\section{Conceptual Issues}

The United Nations Development Programme (1991) describes development as a process that goes beyond the improvement of quality of life: it encompasses better education, higher standards 
Aderinoye \& Ojokheta Open-Distance Education as a Mechanism for Sustainable Development:

Reflections on the Nigerian Experience

of health and nutrition, poverty reduction, cleaner environment, increasing access to and equality of opportunity, greater individual freedom, and the facilitation of a richer cultural life, which are all truly desirable ends in themselves. By breaking the cycles of deprivation and hopelessness that are the first obstacle to every kind of development (United Nations Development Programme, 2003) the UN Development Programme's aims in developing countries is to eradicate extreme poverty and hunger. Schultz (1961) stated that education not only improves individual choices available to mankind, but an educated population provides the type of skilled labour necessary for industrial development and economic growth. Dreze and Sen (1995), however, argued that development should be viewed from various approaches. By contending that a "rights-based approach" to improving access to education provides the basis for a comparative assessment of natural progress, Dreze and Sen succinctly anchored their theoretical approach on human rights and capabilities. They further stated that the intrinsic human value of education, which include the capacity of education to add meaning and value to human lives without discrimination, make it a key component central to universal human rights. In sum, education is the key that unlocks and protects the full spectrum of human rights.

When discussing development from the Capability Approach, we assert that development occurs when people are more able to achieve what makes their lives valuable to them. What people value will vary from one individual to another and may include such ideals as being well fed and nourished, achieving a sense of self-satisfaction and self-respect, being literate, being able to do things better, or earn a better living. Thus, the Capability Approach shifts the goal of development from mere income or economic growth as ends in themselves, to that of growth of people and enhancing the quality of the human condition. Viewing development from this perspective implies that it can be seen as a process of expanding the real freedom that people enjoy. Education, in this larger sense of term, serves as a tool people can use to achieve the level of freedom that they feel is intrinsically valuable, as well as achieving rudimentary levels of knowledge acquisition (e.g., beginning with literacy and basic arithmetic), which serves as a functional key to greater educational development. Education and development policies based on Capability Theory are judged to be successful if they enhance people's individual capabilities, whether or not they directly affect income or economic growth.

\section{Emergence and Transformation of Open-Distance Education in Nigeria}

Calvert (1986) wrote that distance education helps extend the market for education to clientele who have not been previously served. The problem of unsatisfied demand for education versus actual supply of educational services contributed to the acceptance, growth, and implementation of distance education programmes in Nigeria as a means to bridge the gap between demand and supply.

The history of distance education in Nigeria dates back to the practice of correspondence education as a means of preparing candidates for the General Certificate in Education, a prerequisite for the London Matriculation examination. This practice was described by Bell and Tight (1999), and echoed by Alan Tait (2003), who said:

. . . the University of London has been termed the first "Open University," because of this move, students all round the world, but principally within the British Empire and its dominions, were soon looking for tutorial support to supplement the bare syllabus they received on registration wherever they lived (www.undp.org/info21/public/distance/pb-dis2.html). 
In this sense, Nigeria was not left out of the opportunities provided by University of London. Omolewa (1976) reported records that showed a handful of Nigerians, as far back as 1887, enrolled for the first time in the University of London matriculation examination as external students studying through correspondence, and without enjoying any established formal ties to that educational institution. Omolewa (1982) also noted that in 1925 several Nigerians, among them Eyo-Ita and H.O. Davies, passed the London Matriculation Examination. Later, E.O. Ajayi and Alvan Ikoku both obtained University of London degrees in philosophy in 1927 and 1929 respectively, and J.S. Ogunlesi obtained a degree in Philosophy in 1933 (Omolewa, 1982). Access to such educational opportunities at a distance contributed immensely to these individual's productivity, which in turn resonated in the innovations they subsequently demonstrated in their teaching methodology at the St Andrew's Teachers College, Oyo (Aderinoye, 1995). Besides these individuals, a significant number of Nigeria's early educated elites were products of the British correspondence distance education system. Indeed, in spite of the establishment of a University College in Ibadan in 1948, many of its academic staff still passed through the higher degree programmes of the University of London as distance learners, enabling them to combine work with higher degree programmes. They thus acquired the advanced skills and knowledge needed for teaching and research at a time when the College was introducing its own higher degree programmes.

With the emergence of many conventional higher institutions in Nigeria, most of which once were based on purely correspondence modalities, distance education still constitutes an integral part of these institution's educational offerings (Aderinoye, 1992). Institutions in Nigeria that offer distance education include:

- Ahmadu Bello University, which offers a special training programme called: "The Correspondence and Teachers' In-service Programmes (TISEP), established in 1976 to prepare middle level teachers for Nigeria’s primary schools.

- The Correspondence and Open Studies Unit (COSU), now called Distance Learning Institute, which was established in 1974 by the University of Lagos to produce university graduates in disciplines necessary to meet national labour needs (e.g., teachers, nurses, etc.)

- The first independent institution dedicated solely to distance education, the National Teachers' Institute (NTI), which was officially established in 1978 to upgrade unqualified teachers working in the nation's primary schools and to accelerate the preparation of qualified teachers needed for the implementation of the Universal Primary Education programme introduced in 1976 and the Universal Basic Education programme introduced in 1999.

- The External Study Programme (ESP), that later became the Centre for External Studies (CES) and today is called the Distance Learning Centre (DLC), was established by the University of Ibadan's Senate in 1988 under the umbrella of the Nigerian Department of Adult Education to provide opportunities for teachers working in the field to improve their skills and knowledge through on-the-job training. This inservice training enabled them to subsequently raise their status from holders of Nigeria Certificate in Education (NCE) to full-fledged university degree holders.

- To offer similar programs, the University of Abuja established its Centre for Distance Learning and Continuing Education in 1992. 
- After being closed for 16 years, The National Open University was re-opened in 2001 under a new name, the National Open University of Nigeria (NOUN).

- Private entities also engage in providing distance learning that include professional bodies and governmental institutions some of which offer courses in areas such as law, business administration, accounting, and various sciences along with the more commonly found teacher training.

\section{Links Between Open and Distance Education and Development}

Education is inherently a developmental process. Indeed, it can be said that if the expertise necessary for expansion of distance education programmes had not been available, the education policies and developmental issues in place today would have excluded many Nigerians and Africans. Most pioneers of distance education were products of the British correspondence system and the London matriculation exam. In the absence of domestic higher institutions in Nigeria prior to 1948, the nation's first students learned through the distance education modality and eventually graduated to become valuable resource persons whose ground breaking work kickstarted the establishment of Nigeria's first schools and institutes of higher education which, in turn, served as springboards for national development. These "pioneering experts" constituted the original core of administrators and educators that supported educational planning, teacher education, policy formulation, and developmental initiatives.

Archived records from these distance institutions reveal that Nigeria's teaching and educational system, which clearly faced an acute shortage of teachers during the introduction of the Universal Primary Education programme in 1976, and later the Universal Basic Education in 1999, were unquestionably strengthened through the introduction of new teachers produced via ODL modalities. Table 1 shows data gathered through the planning and research department of NTI, which revealed the growing number of graduates produced by that institution alone.

Table 1. NTI Teacher Graduates, 1984 to 1992

\begin{tabular}{|c|c|}
\hline YEAR & NUMBER OF TEACHERS GRADUATED \\
\hline 1984 & 45,150 \\
\hline 1985 & 30,620 \\
\hline 1986 & 35,575 \\
\hline 1987 & 74,131 \\
\hline 1988 & 20,257 \\
\hline 1990 & 12,000 \\
1992 & $+300,000$ \\
\hline
\end{tabular}


Aderinoye \& Ojokheta Open-Distance Education as a Mechanism for Sustainable Development: Reflections on the Nigerian Experience

Over a period of eight years, the total number of primary education teacher graduates rose from 45,150 to over 300,000. In two short years alone, between 1990 and1992, the NTI graduated 21,000 Certificate in Education holders. This figure compares with the combined total of 58,000 teachers graduated by the nation's 58 conventional colleges of education (Aderinoye, 2001). The NTI's Pivotal Teacher Training Programme, designed to support the introduction of the Universal Basic Education scheme introduced in 1999, produced 19,025, 20,800, and 15,587 qualified teachers for years 2000, 2001, and 2002 respectively (NTI, 2003). These activities of NTI have helped to maintain stability, quality, high rates of retention, and have reduced the dropout rates at the basic level of education across the country.

In a follow-up study, which tracked the whereabouts of a randomly selected population External Studies Programme graduates of University of Ibadan $(n=100)$, revealed that 15 graduates went into private business, while 60 remain in active teaching. It was established, during the course of this follow-up investigation, that eight of the 15 graduates are now successful business women, whose children are now enrolled in university. This finding suggests that a solid appreciation of the importance of education plays in personal and community development, has been passed on to these women's children. Five of the seven men went into active politics, two of which are occupying the position of State Commissioners presiding over the affairs of education, local government administration, and chieftaincy matters. While the remaining two men serve as secretaries of community development union. The remaining 25 graduates are engaged in income generation activities, through which they have been able to become employers of others.

Another programme that has contributed to rural transformation through ODL is the University Village Association Rural Literacy Programme. Supported by the British Council, this project provided to the local community audio taped learning materials used to augment outreach programmes delivered to 17 adult learners over a period of 18 months. Three face-to-face sessions each week, two hours in duration, were augmented by these pre-recorded audio tape lessons and distributed to learners, allowing for additional learning to take place at a pace, time, and location convenient to them. These audio taped cassettes provided learners with information on current best practices on how functional literacy (e.g., targeting farmers, governance, women, and health issues) has helped to positively transform the lives of those living in Nigeria's rural areas. While face-to-face literacy lessons were used to provide interaction with facilitators, the use of audio taped cassettes proved to be an important auxiliary learning tool, which were closely monitored for pedagogical effectiveness. When looking at the qualitative aspects made in a 2000 doctoral study, Laoye (2000) revealed that two graduates of the rural literacy programmes served as community association secretaries, while five graduates served as local government councillors, and two served as customary courts judges. In qualitative terms, Laoye's study reveals that, apart from helping elevate their communities' living standards, the personal living standards of these graduates had likewise improved. Moreover, these graduates were monitoring and facilitating progress of their children's education. As such, this developmental "ripple effect" has helped sustain the project, even after the British Council withdrew their support. Today these communities continue to achieve their goals and recruit new pools of learners from the local neighbourhood.

\section{International Agencies and the Development of Open and Distance Educational in Nigeria}

As outlined above, the link between education and development informed the direction and policies of continuing interventions of development agencies like the United Nations Education, 
Aderinoye \& Ojokheta Open-Distance Education as a Mechanism for Sustainable Development:

Reflections on the Nigerian Experience

Scientific, and Cultural Organization (UNESCO), the Commonwealth Of Learning (COL), British Council, Literacy Enhancement Assistance Program (LEAP), and others. These international agencies have assisted Nigeria (and the African region in general) in the development and training of distance education institutions and their staff. It is on record that UNESCO and the COL lent their expertise in the establishment of the NTI, at a time when Nigeria faced an acute shortage of qualified teachers (Ansere, 1982). Institutions in other African nations that have also benefited from international support include: the Sudan Open Learning Organisation (SOLO); various teacher training and tertiary institutions in Gambia, Zambia, Ghana, and Mozambique, through the introduction and use of information and communication technologies (ICTs) for distance learning delivery; and the launch and continuing support for the Virtual University in Kenya. The University Twinning and Networking Scheme (UNITWIN) was established in 1992 following the decision of the General Conference of UNESCO. Today, the UNESCO Chair is the main source of exchange programmes taking place between the developing and developed institutions. Support for various capacity building programmes for distance education institutions across Africa are likewise underway. For example, in 1998 the Department of Adult Education, University of Ibadan, became one of the beneficiaries of the UNESCO Chair on the Application of Information Communication Technology to Adult and Non-Formal Education, which as its official title suggests, is currently focused on the application of ICT to adult and non-formal education. This ongoing work has facilitated the development of the capacity of academic staff of the department. Finally, specific mention must be made of the activities of the following international agencies:

The Commonwealth of Learning (COL) started its intervention through a fellowship programme to staff of African universities. In 1990, to increase his knowledge of ODL, COL sponsored the participation of M. O. Akintayo to the COL/ British Council visiting fellowships programme. Chris Okwudishu of the Centre of Distance Learning, University of Abuja, similarly visited institutions in Canada under the same programme. Some senior officers of various ODL institutions were likewise assisted in the formulation of programme proposals. Among such institutions were:

- University of Abuja, which strengthened its media production capabilities of its Centre for Distance Learning

- Ahmadu Bello University, which developed its distance education teaching programmes used to increase the production and utilization of soy bean crops by rural women

- Imo State University, which improved its media production facilities for its distance education programme and developed an educational broadcasting service in collaboration with the state government (COL, 1994, p. 9).

COL has also assisted in the development of the capacity of West African experts in ODL. In 1992, COL sponsored a training workshop for experts from Gambia, Ghana, Sierra Leone, and Nigeria, with experts from Tanzania and South Africa serving as resource persons. COL also organized another capacity building workshop in programme planning and management for similar group in 1994 in Badagry, Nigeria. With COL's assistance, the West Africa Distance Education Association (WADEA) was likewise inaugurated at NTI, Kaduna, Nigeria (COL, 1994, p. 18).

An early programme of COL for the South African sub-region (Botswana, Namibia, Zambia, Zimbabwe and South Africa) under the expert guidance of Professor Peter Kinyanjui, continues 
Aderinoye \& Ojokheta Open-Distance Education as a Mechanism for Sustainable Development:

Reflections on the Nigerian Experience

to advance distance education in other regions of Africa. This is evident in the reliance of other open and distance learning institutions in other parts of Africa on South African experts.

Similarly, UNESCO, apart from providing technical advice for the establishment of the NTI in 1976, organized a workshop on "course writing" for distance education course developers in Abuja in June 2001, in which more than 300 course developers from the West Africa sub-region participated.

\section{Distance Education Relating to HIV/ AIDS}

The devastating effects of Human Immunodeficiency Virus/ Acquired Immunodeficiency Syndrome (HIV/ AIDS) on Nigeria and other African nations' workforce, and most especially on the region's teachers, not to mention the alarming increase of those living with HIV/ AIDS, necessitated the development of a process of prevention designed to mitigate the impact of this pandemic. To this end, UNESCO signed a Memorandum of Understanding (MOU) with the NTI to establish the Preventive Education Unit. This MOU covers funding for the preparation of NTI staff and other Nigerians distance education experts in the use of education as a mechanism to change behaviour. The project was launched with the establishment of a unit and the development of curriculum guide and training manual for distance teachers working at NTI. Thus, NTI became the first academic institution in the African sub-region (Botswana, Namibia, Zambia, Zimbabwe and South Africa) to use ODL in the promotion of preventive education to educate people about the transmission and prevention of HIV/ AIDS. NTI, via the development of such ODL materials, is therefore proactively contributing to slowing the spread of HIV infection leading to AIDS. It is anticipated that these valuable teaching resources will be adopted and shared with other educators and experts working in the African sub-region.

One such initiative is the Literacy Enhancement Assistance Programme, a collaborative project funded by USAID and the Nigerian Federal Ministry of Education. Focusing on the states of Kano, Nasarawa, and Lagos, this literacy enhancement programme seeks to improve the ability of Nigerian children to read and write, as well as to master basic arithmetic by the end of their primary schooling years. Employing an innovative combination of interactive radio instruction and teacher training, literacy and basic arithmetic skills are being taught at the grassroots level in the community and its classrooms. Since this programme's inception, primary students living in the three states targeted in the programme scope, have shown a dramatic improvement in the reading and arithmetic skills. Clearly, FM radio programmes are improving students' oral and written English skills. It is anticipated that by the end of the first project cycle, hundreds of Nigerian pupils will benefit through improved basic literacy and arithmetic skills, thereby arming themselves with the basic education necessary to kick-start and maintain developmental processes

at the grassroots level (e.g., learning about HIV/ AIDS prevention to name one life-sustaining benefit).

\section{Some Reflections}

Reflecting on where, when, and how distance education has influenced development in Nigeria and Africa brings us to some examples of collaboration and cooperation in distance education. Having analysed the nature, concept, and linkages between education and development and how developmental agencies have helped to establish and nurture distance institutions throughout Africa, it is instructive to examine the influence these educational initiatives have had on the 
development and growth of individuals, and how such growth has translated into opportunities that have reshaped and bettered individuals’ immediate lives and their communities.

Reflecting on the Nigerian situation reveals the high degree of influence distance education initiatives have had on personal, community, and overall national development. Nigeria can now boast of capable and competent teachers working in its education sector. Nigeria's distance learning institutions also continue to contribute immensely to the provision and improvement in the quantity, quality, and overall capacity of education managers and school administrators necessary to lead the nation's educational system. In addition, more than 300,000 primary school teachers enrolled in the NTI, have gone on to successfully earned their Teacher's Grade II Certificate. NTI has similarly registered serving teachers in its Nigeria Certificate in Education, and the Pivotal Teacher Training programmes, thereby improving the quality of those teachers already working in the field. Having since qualified, these teachers have not only contributed to the increase in school enrolments across Nigeria, they have also increased the quality of education and thus contributed to higher student retention rates (Ojokheta, 2000).

The power and growing use of information and communication technologies and the resulting trend towards globalisation have reduced the world into that of a small village (McLuhan and Powers, 1989). Distance education remains the primary mechanism for the information-driven age, a tool that is bridges the gap between developed and developing communities. It serves as an avenue for developing intellectuals at all levels of their educational journey and facilitates a pedagogy for enhancing learning of both learners and teachers. When used to supplement distance education programmes, information communication technology - the technical medium through which people send and receive messages, acquire knowledge, and learn about new things that add value and context to their lives - can play a positive role in contributing to more egalitarian growth of the global community. People now have access to many different forms and channels of communication including e-mail, e-learning, tele- and video-conferencing, virtual learning, and virtual libraries, to name just some of the more common applications.

A process of social transformation has begun to take place in Nigeria, and those less fortunate, if given adequate access and opportunity, can and do benefit from the establishment of tele-centres within less privileged communities. Today, a process of social transformation is taking place as more and more individuals are striving to be become a part of an emerging "learning society," a society that at the grassroots level - and arguably where it is most needed - has been brought about by the power of open learning initiatives. Thus, we are moving gradually from the exclusive, closed system mode of "privileged" access to education, towards a more inclusive educational model, which supports and is reflective of UNESCO's goal of Education For All for the 21st Century. Through various initiatives, such as those undertaken by UNESCO, COL, the British Council, the Literacy Enhancement Assistance Program, and others, the gap between education and the world of work that many developing countries have experienced in the past (and which was initially exacerbated by the integration of new technologies into almost every sphere of professional activity) is now being greatly narrowed. Distance education in Nigeria and throughout the continent of Africa is helping to democratise and spread knowledge even to those living in the most remote, marginalized, and isolated communities. Clearly, this has helped individuals to acquire basic literacy and arithmetic skills, and in some instances even obtain certification in higher education degrees, as well as a multitude of broad-brush education objectives targeting whole populations (e.g., governance skills, life skills, AIDS education aimed at preventing and reducing its spread, improved farming techniques, etc.). At the level of higher education, distance education in Nigeria has offered greater access to many people who would 
Aderinoye \& Ojokheta Open-Distance Education as a Mechanism for Sustainable Development:

Reflections on the Nigerian Experience

have been previously been denied access to educational opportunities based on where they live and work, poor economic circumstances, social status, etc.

Early graduates of Nigeria's and Africa's distance education systems helped pave the way for the much needed educational reforms, development of economic plans, and the establishment of political frameworks that characterize the transition that most African countries are undergoing today.

In economic terms, distance education has helped to produce a better skilled workforce, which in turn has led to the growth and development of both local and national economies. Typically, graduates of distance education programmes find it easier to participate in the economic mainstream. Even older individuals, who after their retirement have chosen to engage in academic upgrading, have gone on to become small business owners/ managers, an educational ripple-effect that has helped enhance the development and growth of both local and national economies.

\section{Brain Drain}

In terms of development, the worth of distance education must not only be measured simply from what a given individual can contribute towards community and national development. It must also be measured in terms of the changes or improvement such an individual enjoys as a result of the skills and knowledge they have learned and acquired. A dangerous reality, however, is that Africa is clearly facing a "brain drain syndrome," wherein academics travel abroad to continue their study. A research study conducted by the South African Institute of International Affairs, and published in the September 2003 issue of the Electronic Journal of Governance and Innovation, revealed that: "recruiting agencies abroad, on a South African Internet search engine, found 20,000 hits, while a global engine found 1,040,000 hits with thousands of agencies specifically targeting African Professionals to work abroad,"(e-Africa, http://www.wits.ac.za/saiia). This online journal article explored the implications of the brain drain syndrome on the continent: "At a time when Africa most needs its skilled professionals, the continent is experiencing a steady, de-habilitating brain drain caused by aggressive professional recruiting agencies, personal ambition, and the substantial wage gap between the developed and developing world." The good news is that an organisation known as "African Recruit," funded by the Commonwealth Business Council (CBC), has started Job Fairs to recruit Africans studying abroad for jobs back in Africa (Herbert, 2003). In this capacity, the CBC has acted as an employment agency searching for talents to reverse the Diaspora.

\section{Brain Drain turns to Brain Trust}

The initial problem created by mass movement of intellectuals of African descent to developed countries, is now turning into a blessing. African experts, many of whom have returned home, have started ploughing back their skills and knowledge gained abroad into the development of their native communities and countries. As such, Africa is now beginning to witness the beginning of a "Brain Trust" rather than "Brain Drain.” The cross fertilization created by this newly emerging Brain Trust, however, must be sustained through incentives and improved infrastructure designed to prevent frustration and regret of those intellectuals and highly trained individuals returning home. 
Aderinoye \& Ojokheta Open-Distance Education as a Mechanism for Sustainable Development:

Reflections on the Nigerian Experience

Some Nigerian distance education experts who have, at one time or the other, contributed to the development of other countries include: Jones Akinpelu who in 1996 returned to establish and develop the Centre for Continuing Education, University of Botswana. During his six years in Botswana, he developed courses that were strategically in-line with the needs of the people of Botswana, as he assisted in the training of middle level workforce needed for the development of Botswana's rural areas. In doing this, Akinpelu made a request for more capable hands from Africa's pool of intellectuals. In response to his call, Gbolagade Adekanmbi, who earned his $\mathrm{PhD}$ in distance education from the University of Ibadan in 1992, joined Akinpelu in the task of Botswana's nation building. Now a Professor Emeritus in the University of Ibadan, Akinpelu is back home to shape research in Nigeria with innovative ideas.

Michael Omolewa brought international acclaim to himself, the Department of Adult Education, University of Ibadan, and his country, Nigeria, when he won the UNESCO Chair on the application of ICTs to Adult and Non-Formal Education for his department in 1998. This Chair has helped the University of Ibadan's staff to achieve in goals of institutional and personal capacity building. The use of ICT has now led to the establishment of an International Network of Academic Partners that spans the globe.

In 2000, Michael Omolewa and Gbolagade Adekanmbi, along with the author, under the sponsorship of the UNESCO Office in Nigeria, collaborated with other African intellectuals, in a research study of distance education institutions in Africa (Omolewa, 2000). The outcome of this collaborative research study now serves as fertile resource material, for those venturing into the discipline of open and distance education in Africa.

Another distinguished Nigerian distance education expert is Olugbemiro Jegede who, in 2001, returned home to Nigeria to re-establish the National Open University, which as mentioned earlier, had been closed since 1984. Prior to this, Jegede lived in Hong Kong and Australia, and the wealth of experience he brought home from those two countries has advanced the course of the distance education system in Nigeria. The first admission exercise of the National Open University, for example, admitted more than 32,000 students. Through his work, Jegede has proved that open and distance learning is not only cost effective, it is also a most appropriate avenue for widening access to education, especially to those most marginalized and poorest populations in the world.

\section{Some Continental Experience}

Distance education in Africa and other continents has been instrumental in lowering illiteracy rate, and more importantly turning about "dropout rates" into "drop-in rates." For example, in the African countries where the INADES-Formation Project of Jesuits Organization has taken root (Siaciwena, 2000), many subsistence farmers, village women, community leaders, and adults have gained valuable education, expertise, and knowledge, which they have subsequently applied towards the transformation of their local communities. The INADES-Formation programme, launched in 1962, was modelled after the radio-based Canadian and Indian Radio Farm Forum and focused on Africa nations such as Kenya, Tanzania, Uganda, Rwanda, Burkina Faso, Chad, and Cote d'Ivoire (Omolewa, 2000). In scope, the INADES-Formation Programme covers the development of reading materials in agriculture, health, and community civic education for adult learners, and is combined with the use of facilitators who lead discussions and disseminate information via radio. Government policies in Kenya, Tanzania, and Mali have been broadcast to 
the grassroots through radio, thus producing a citizenry that is more informed about government programmes available to them.

The Sudan Open Learning Organisation (SOLO) undertook a comprehensive re-orientation of untrained teachers in the Republic of Sudan in 1998. In October 2001, a meeting with the Director of SOLO, representatives of the Sudanese Ministry of Education, and selected members of the community, described the contributions of the SOLO programme:

- SOLO has assisted the Sudanese government to improve the quality of education by improving the quality of teachers

- Fourteen Sudanese states increased their education sector's workforce by training 50,000 teachers, many of whom had not previously taught within a formal "four walled" classroom setting

- The Certificate in Education, issued by SOLO and approved by Sudan's Ministry of Labour and Ministry of Education, has enhanced the image of teachers

- In addition to their role in Sudan's school system, teachers are also paid to engage in programmes designed to respond to the educational needs of refugees and adult learners in vocational and life skills acquisition

These initiatives have contributed immensely to the education, social, and economic development of the Sudanese people - particularly those living in the war free states (UNESCO, 2001).

Human resource development has equally benefited from the first distance university in Africa. The University of South Africa (UNISA), established in 1873, has contributed to the emergence of many distance education institutions throughout Africa, and has assisted in developing the capacity of distance education experts across the continent.

In addition to the integration of HIV/ AIDS preventive education into the NTI programme discussed above, distance education has helped to reduce discrimination and stigmatisation faced by those living with HIV/ AIDS. The NTI programme strives to achieve this objective through the broadcast of public education programmes via radio, television, community theatres, posters, classrooms, etc. Such broad-brush programmes have empowered illiterate individuals as well as neo-literates (i.e., those who have engaged in such distance learning systems as the University Village Association), to acquire information and knowledge on how HIV/AIDS is transmitted and how it can be avoided. Details on essential care and support services for those living with HIV/ AIDS are also included in educational material developed for adult and youth (adolescent) learners currently attending the organisation's open school system.

\section{Conclusion}

This article has briefly touched upon the interplay and linkages between open and distance learning and its influence on development. Due to limitations of its focus and intent, this paper has not examined critical issues militating against the effective translation of policies to action. Clearly, there are many ongoing challenges of putting words and policies into action, particularly for ODL experts who are working to enhance and strengthen ODL research, capacity building, and the educational infrastructure, which are all essential ingredients for realization of the 
Aderinoye \& Ojokheta Open-Distance Education as a Mechanism for Sustainable Development: Reflections on the Nigerian Experience

Capability Approach Theory described above. Given such challenge, experts working in this area need to remain united in their efforts in the building of a sustainable educational infrastructure.

\section{References}

Aderinoye, R. A. (1992). Retention and Failure in Distance Education: The Nigeria Teachers Institute experience. Unpublished PhD Thesis. The Department of Adult Education, University of Ibadan.

Aderinoye, R. A. (1995). Teacher Training by Distance: The Nigerian Experience. In John Daniels (Ed.) Proceeding of the 1995 ICDE Conference. Birmingham, UK.

Aderinoye, R. A. (2001). Alternative To Teacher Training. In H. Perraton (Ed.) Cost Effectiveness in Teacher Training. Paris: UNESCO.

Akintayo, M. O. (1989). Investment in University Education and the Problems of Unsatisfied Demand. Journal of Andragogy and Development, 1(1) 88 - 95.

Ansere, N. (1982). The Inevitability of Distance Education in Africa. In J.S. Daniel, (Ed.) Learning at a Distance: A World perspective. Alberta, Canada: Athabasca University.

Bell, R., and Tight, M. (1999). Open Universities: A British Tradition? Society for Research into Higher Education. Birmingham, UK: Open University Press.

Calvert, B. (1986). Facilitating Transfer of Distance Courses. Paper presented at the 8th World Conference on Development and Social Opportunity, Delhi, India: Open University Press.

Common Wealth Of Learning (1994). A Compendium of Activities: Canada. Vancouver: Commonwealth of Learning.

Dreze, J., and Sen, A. (1995). India Economic Development and Social Opportunity. Delhi, India: Oxford University Press.

Herbert, R. (2003). Brain Drain vs Brain Trust in East Africa. The Electronic Journal of Governance and Innovation 1. September 6/ 8. Retrieved December 3, 2003 from: http://www.wits.ac.za/saiia

INADES Formation Network (n/d). Retrieved December 4, 2003 from: http://www.sdnp.undp.org/sdncmr/subweb/cminade4.htm

LEAP (2003). Literacy Enhancement Assistance Program: Mid-project assessment.

McLuhan, M., and Powers, B. (1989). The Global Village: Transformations in world life in the 21st century. Oxford University Press: New York. 
Ojokheta, K. O. (2000). Analysis of Selected Predictors for Motivating Distance Learners Towards Effective Learning in some Distance Teaching Institutions in Nigeria. Unpublished PhD Thesis. The Department of Adult Education, University of Ibadan.

Laoye D. (2000). A Study of the Impact of UNIVA Rural Literacy Programme on the People of Oyo State. Unpublished PhD Thesis. University of Ibadan.

Omolewa, M. (1982). Historical Antecedents of Distance Education in Nigeria, 1887-1960. Adult Education in Nigeria, 2(7) 7 - 26.

Omolewa, M. (2000). Directory of Distance Education Institutions in Africa. (Ed). Abuja: UNESCO.

Schultz, T. W. (1961). Investment in human Capital. American Economic Review, 51, 1 - 17.

Siaciwena, R. (2000). Case studies of non-formal education by the Distance and Open Learning, UK. University of Zambia: Commonwealth of Learning and Department of Foreign International Development.

Tait, A. (2003). Reflections on Student Support in Open and Distance Learning. United Nations website. Retrieved December 3, 2003 from: www.undp.org/info21/public/distance/pb$\underline{\text { dis2.html }}$

UNESCO (2002). Sudan Basic Education Sector Study. UNESCO: Paris

UNESCO (2003). Education in the context of HIV/AIDS. UNESCO: Abuja

United Nations Development Programme (1991). Development Report 1975. Retrieved December 4, 2003 from: http://www.undp.org/

UNESCO (2003). The University Twinning and Networking Scheme (n/d). Retrieved December 4, 2003 from: http://www.unesco.org/education/educprog/unitwin/

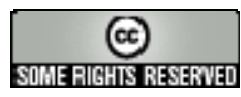


April - 2004

\title{
Broadband: A solution for rural e-Learning?
}

\author{
Robin Mason \\ The Open University, UK \\ Frank Rennie \\ University of the Highlands and Islands Millennium Institute \\ Lews Castle College, UK
}

\begin{abstract}
Rural and remote learners are disadvantaged even with online provision due to poor connections. Broadband offers a potential solution. This paper looks at the initial results of a project to install broadband services in the Western Isles of Scotland. It focuses on the educational potential of broadband and the design implications for online courses. It also considers more informal kinds of learning that broadband facilitates in rural areas.
\end{abstract}

Keywords: broadband; rural development; e-learning; online communication; e-learning course design

\section{Introduction}

Broadband technologies offer the potential to overcome many unique challenges and traditional limitations that characterize the rural economy, particularly those associated with distance and access. Citizens of rural and remote areas have similar needs to those of urban areas, but are disadvantaged in a number of ways. For example, low population density means a lower taxation base to support essential services; geographical remoteness means transportation difficulties; distance from markets can be a disincentive to new business growth; finally, remoteness usually means a lack of access to education, training and professional updating. Economic diversification is considered a key survival mechanism for many rural communities, and high-speed network access offers opportunities for tele-work, call-centre operations, and other distance-neutral applications and services.

This paper reports the initial findings of an ongoing broadband study conducted in the Western Isles of Scotland. It focuses specifically on the e-learning aspects of the study, but does so in the light of broader issues of rural sustainability, technology push, growth of connectivity and the changing nature of learning. In particular, three questions will be addressed:

1. What implications does broadband have for the design of e-learning?

2. What is the level of rural readiness for broadband and e-learning?

3. Do local learning centers have a continuing role with the introduction of broadband to the home? 
An important aspect of the study is to build on the outcomes of other rural installations of broadband technology and to highlight lessons from the early adopters internationally: the smart communities in Canada, the electronic villages in the USA, and the municipal networks of Finland.

The paper begins with an examination of a number of interdependent issues related to broadband and e-learning. It then summarizes relevant lessons from our desk research on broadband for rural and remote areas. We then turn to the presentation and analysis of data from the initial survey and focus on the questions and responses concerning e-learning, taken in the broadest sense. Finally the paper examines the ways in which e-learning providers could capitalise on the growing availability of broadband in the design of e-learning opportunities.

\section{Key Issues}

\section{e-Learning and Connectivity}

e-Learning is one of the most significant uses of broadband to be identified in numerous studies (e.g., Sage Research, 2002; Rural Secretariat Report, 2001). The best e-learning courses offer a wide range of benefits for distance learners:

- Flexibility in terms of both time and place of study

- Access to and guidance through Internet resources

- Engagement with a community of fellow learners and tutors

All of these benefits are equally available to both rural and urban students. This apparent equality is undermined, however, if some students who when logging on and accessing the course over low-speed, unreliable networks, browsing webpages, and accessing multimedia materials, take significantly longer and are subject to many technical hitches. Meanwhile, out-migration of young people has been highlighted as a major concern in many rural studies and recommendations from such research inevitably cite the need for providing further opportunities for rural youth.

Young people continue to leave rural communities to seek employment and higher education. New technologies offer potential for creation of new types of employment for young people, opportunities which can help to retain them in their communities, or attract others to locate there. Without the ability to be 'connected' to the global economy, young people will continue to leave rural places. While high-speed access will not guarantee that youth will stay, return, or on the other hand, move to rural communities, it does provide an additional tool and incentive to help attract and retain young people. It is a prerequisite for the young generation to be connected (Rural Secretariat, 2001, p. 5)

Studies also show that in a knowledge-based society, human capital is the main source of competitive advantage (Levis, 2002). Lifelong learning, both formal and informal, is the key to developing appropriate skills and maintaining employability. Increasingly the skills of knowledge workers lie in the domain of "learning how to e-learn," and clearly this requires good connectivity.

The fundamental reason driving the [e-learning] revolution is the need in a knowledge-based economy for vastly more learning opportunities, both formal and informal, than was previously 
required in an industrial society, and the need for a more systematic approach to the sharing of knowledge. Knowledge workers need to process enormous amounts of information and to tap into the knowledge of others and the collective knowledge of their organisations. They also need to acquire large amounts of knowledge and skills throughout their working lives. Classroom training is often an ineffective as well as expensive way of enabling adults to acquire knowledge, however (Levis, 2002, p. 12).

In theory, therefore, it would seem that broadband technology and the provision of e-learning promise a real solution to rural sustainability, both socially and economically.

\section{Technology Push}

Experience of new technology deployment over many years makes clear that it is the social structures and human processes that need to be re-engineered before the transformative potential of the new technology can be fully realized (Daniel, 2002). As changing human processes and evolving social structures are much harder to effect than installing technology, new initiatives typically tend to grind to a halt after the easy part has been accomplished. It is too simplistic, however, to blame "technology push" as the cause of many failures in the take-up of technologybased innovations. This is clear in the case of broadband where the classic dilemma pertains. The technology needs to be in place before people see how they might use it and before services are created to attract users, thus making the technology available is inevitably a technology-led operation.

Educational institutions are notoriously conservative organizations and though e-learning is currently the innovative face of most universities and colleges, designing online courses and events specifically for a broadband market seems to be too speculative a venture for such publicfunded bodies. So the implementation and take up of broadband technology tends to move in fits and starts.

Following roughly a decade of development and experimentation and a recent period of rapid growth, first-generation broadband services, using primarily cable modems and digital subscriber lines, are available in many markets. This progress, however, is offset by recent business failures and uncertainty about the pace of future investment - factors that in part reflect slow growth in subscriptions of broadband services (NRC, 2002, p. 1).

For rural subscribers in particular, broadband provides higher-performance options in connecting to familiar Internet and other online services. Its enhanced capacity and "always on" nature enables new networked activities, which are largely undeveloped. Evaluations of broadband projects (Lynch, 2000; Sage Research, 2002) generally recognise that true exploitation of highspeed connectivity is still in its infancy.

\section{Broadband and Wider Social Changes}

Broadband technology is only one element in a spectrum of inter-related social changes. The explosive growth in connectivity and the changing nature of the content and processes of learning are intimately tied into the demand for broadband.

Mobile phones, online communities, and Web-based developments like blogging, e-games, and eBay, are just a few components of 21st century life in the "connected economy." The scientific 
and economic underpinnings of pervasive computing have been building for decades, and the social side effects are only beginning to erupt. The virtual, social, and physical worlds are colliding, merging, and coordinating (Rheingold, 2002, xviii).

New technologies create new social environments (Baudrillard, 1993), which alter the nature of social interaction and community. We have moved from the Age of Information to the Age of Connectivity. Broadband - until it is superseded by the next technology - has a role to play in this kaleidoscope of social change.

Changes in education, reflecting these wider social changes, are also beginning to appear. Both the content of what is learned as well as the processes of learning are undergoing a transformation. For example:

Learning-to-e-learn skills are necessary for employability in many fields

The ability to find and analyze information and to identify relevant and reliable material amongst large amounts of data, are more important than learning content

Informal learning - from peers, the workplace, and life events - is taking on greater importance, especially where formal courses are not flexible enough, tailored enough, or modular enough for busy employees

Lifelong learners will inevitably be fitting their learning in and around many other demands on their time. A few course providers (usually from the commercial sector) are beginning to offer learning opportunities that are quickly adaptable to different markets, that can be re-sized, and customized or updated, and that can be produced or perhaps assembled in response to changing demands. Most e-learning programmes emphasise a student-centered pedagogy, in keeping with the passing of responsibility for the general 'health' of one's learning onto the learner or employee. So, for example, online activities develop skills in communication, working in teams, finding and evaluating information resources, storing, accessing and handling large amounts of data, working with new technologies, updating and refining existing skills and knowledge. Finally, the field of professional updating is less about acquiring qualifications and more about learning opportunities. In some employment areas, the beginnings of a convergence between working and learning are evident (Levis, 2002). This has profound implications for educational institutions, and e-learning providers need to lead the way in working through the implications of all these changes in their design and presentation of learning.

\section{Case Study}

\section{Project Background}

This project is an initiative of Lews Castle College, UHI, and the Institute of Educational Technology at The Open University. The study is being funded by the Western Isles Enterprise Company, Comhairle nan Eilean Siar, The Western Isles, Skye and Lochalsh LEADER+, and the UHI Millennium Institute. The study focuses on the potential adoption of wireless broadband in the Western Isles of Scotland, and provides a community perspective with local facilitation and training.

The purpose of this project is to provide a clear understanding of the aspirations and potential demand for broadband connectivity among Western Isles communities and businesses. To provide a baseline analysis for subsequent monitoring of the developing community networks, the 
work focuses on three particular communities. Comparison will also be made with international examples of best practice in community network operations in remote and rural areas, particularly in North America and the Nordic countries. Using identified examples of best practice, the project team will seek to provide specific outcomes for education, social, and business engagement with community networks, which in turn will serve as a model for knowledge transfer to broadband installations in other relevant geographical areas.

The delivery of services to the remote and rural areas of Scotland has already utilised both low and high technology solutions to address the difficulties of a low population density, difficult topography, and economies of scale for certain specialised services. Low-tech solutions include local and regional partnerships to share accommodation, equipment, and staff. In some localities this has resulted in a more integrated structure of the planning process for rural development, and the adoption of innovative approaches to service provision through contract agreements, greater community involvement, and closer community-agency planning. High-tech solutions include the establishment of computer-based networks for the delivery of further and higher education to remote sites, use of telemedicine techniques, and the application of Internet-based business transaction facilities for the marketing, sale, and purchasing of commodities which are generally unavailable in most rural locations.

Scotland has had an early engagement with the use of information and communication technology (ICT) in helping to provide services in rural areas, through such initiatives as the Community Teleservice Centre project of the Highlands and Islands Enterprise, and more recently with the spread of Local Learning Centers through the Scottish University for Industry (SUfI) and the UHI Millennium Institute. Early Teleservice Centers in rural areas were based upon the model of the Swedish Telecottage network, and several of these initiatives still function as rural business centers and provide local training and/or development facilitation. There have also been some recent experiments with telemedicine and e-learning in the form of delivery of health and educational services to localities distant from the specialist provider.

The imminent arrival of broadband wireless connections to the Western Isles offers a unique opportunity to utilise online community techniques to encourage greater social and economic development in and between relatively remote and disadvantaged rural communities. The combination of local community involvement and more effective use of technology offer a powerful combination for transforming the range and the quality of services provided within many rural areas.

\section{Broadband Implementation}

Broadband refers to a new generation of high-speed transmission services aimed at residential and small business users. It is a generic term used in relation to a number of technologies for delivering fast data communications services. There is no agreed threshold, however, that marks the boundary between broadband and narrowband. A recent National Research Center study claims that "various groups have struggled to develop appropriate definitions of broadband, and these definitions have changed over time" (NRC, 2002, p. 3).

Communications capacity or speed is only one of the characteristics that define broadband. Another way of distinguishing broadband - at least from dial-up access - is "always-on" connectivity. There are also other parameters such as bandwidth symmetry between upstream and downstream capacity, latency or delay in how long it takes to deliver a packet across the network, and addressability. All these aspects have implications for the types of services that can be 
appropriately deployed over broadband. Video-on-demand and other streaming media applications rely on the availability of downstream bandwidth, while information appliances require always-on service though the bandwidth requirement is low. The total broadband use in a home may be made up of multiple applications being used simultaneously by different family members. This is relevant to e-learning applications, which are unlikely to be the primary reason for initial broadband take-up, but nonetheless will piggyback on a range of other uses of broadband in the home.

The Western Isles “Connected Communities” project will deliver an innovative high performance broadband wireless network access across the five main populated islands of Lewis and Harris, North Uist, Benbecula, South Uist, and Barra. The "Connected Communities" island network will utilise a combination of fibre and leading edge wireless broadband-based stations and multipoint in-community links. This will allow new networks to be demonstrated in community locations, and provide tele-workers and local companies with high-speed connections through wireless antennas. Initially schools, health centers, and council offices will receive a high-speed connection and through this same infrastructure, the rest of the community will gradually have access as the network develops.

\section{The Use of Existing Literature}

One aspect of this research has been to carry out a survey of findings from similar implementations to ascertain best practice and benefit from the mistakes of the earliest adopters. Three elements characterised our literature search for similar studies:

- The use of broadband connectivity

- An isolated rural context

- An e-learning focus

Apart from the UK itself, which also has a number of relevant implementations in rural parts of Wales, Yorkshire, Devon, and the East of England, the USA, Canada, Nordic countries, and Korea were the leading areas of rural broadband roll-out. The most extensively researched programmes were several Canadian and American studies, which provided valuable research reports and longitudinal evaluations of the use of broadband in rural areas (Kavanaugh, 1996a; Kavanaugh, 1999; Smart Communities, 2002; The National Broadband Task Force, 2002; The Rural Secretariat, 2001). The most notable finding from all of the studies was how similar the results, recommendations, and issues were across a wide range of implementations. These can be summarised as follows:

- Development of a community of broadband users requires more time, support, and investment than is usually anticipated - far more than the simple implementation of the technology

- The best community developments are led by the community - specifically those local early adopters and champions - and not by outside enthusiasts or technologists

- E-learning take-up is based on the greater speed, reliability, and "always-on" nature of broadband, rather than its capacity to deliver high-bandwidth material or real-time video applications

- E-learning is a growing market but e-shopping, communications and entertainment are the primary drivers of domestic broadband take-up 
- Informal learning, pursuing leisure interests, peer-to-peer learning in online communities, and accessing information (i.e., about health matters), are as big a component of the elearning market-space as formal, accredited online courses

- The development of online community enhances rather than reduces face-to-face community in rural settings

- Public access sites (e.g., tele-cottages and libraries) demonstrate a growing rather than declining demand in broadband-rich areas

Our Western Isles project has used these findings in a number of ways. Most importantly, we have enlisted the support of six existing local community facilitators to raise awareness of the broadband implementation, to work with existing communities to capitalise on the facilities, and to animate online discussions and other networked activities. Second, we have replicated many of the questions from broadband studies elsewhere in our initial survey, in order to benchmark our study against other rural implementations. Third, we have placed our initial emphasis on commercial and social uses of broadband and encouraged the creation of online community and informal learning opportunities. We are putting in a further research proposal to work with existing educational providers to develop formal courses specifically for the rural broadband market. Finally, we are working with existing staff at local learning and resource centres, collaboratively analysing the results of our survey and conducting interviews with current and potential users of their facilities.

\section{Findings}

\section{The Initial Survey}

In order to obtain baseline statistics on existing online activity with which to compare subsequent broadband uses, we conducted a survey prior to the implementation of the high-speed technology. We used (with permission) some of the questions from a similar survey originally conducted in Grand Rapids, USA, primarily because this implementation is well documented and a longstanding rural broadband study. (Arguably many of the Canadian implementations have more in common with the context of the Highlands and Islands of Scotland, but they are not as far advanced and so do not provide benchmarking data).

The questions aim to establish what kind of connectivity people currently enjoy and how they use the Internet. The survey goes on to ask what kind of uses people might make of connectivity if they had broadband access. Finally, it asks what areas of education and training would be of interest if an "always on" network were available.

\section{Profile of Questionnaire Respondents}

Of the 200 questionnaire respondents, 66 per cent were male and 33 per cent female. This is the same gender distribution as the Grand Rapids initial survey. Questionnaire respondents' age range was from 18 to 70, with the majority between age 30 and 50. Interestingly, over 85 per cent owned a mobile phone, and 90 per cent had a personal computer in their home. Fifty-seven per cent indicated that they had their own website, and 78 per cent considered themselves to be "very" or "fairly" competent users of the computer and the Internet. Forty-five per cent indicated that they had been using the Internet for 4-6 years. 
Clearly the respondents are not representative of the population as a whole. The questionnaire was available on an open website and received publicity through local meetings, newspaper articles, and personal contacts by local facilitators. There were also parallel promotions of the broadband implementation through "road show" presentations in several locations on the islands. Nevertheless, those who have taken the time to fill in the questionnaire reflect a subset of the total island population that is most computer literate, most "connected" and most interested in what broadband has to offer. Surveys carried out in Blacksburg, Virginia in 1996 and 1999 (another relevant rural broadband initiative of long standing) reflect a similar subset of the local population, in that 87 per cent of initial users of the technology were affiliated with the local college (Kavanaugh, 1999).

Respondents were asked whether they ever accessed the Internet from outside their home and workplace. Two categories were provided: public locations such as the library, school or local learning centre and other locations such as friends' homes or cyber-cafes. Figure 1 shows a relatively modest level of access from public locations, but clearly the majority of respondents have made some use of Internet access from machines other than their own. We intend to follow up the survey with personal interviews, and this is one of the questions we will investigate - for what reasons and under what circumstances do people use other locations to access the Internet.

Figure 1. Respondents’ Access to the Internet Outside their Home

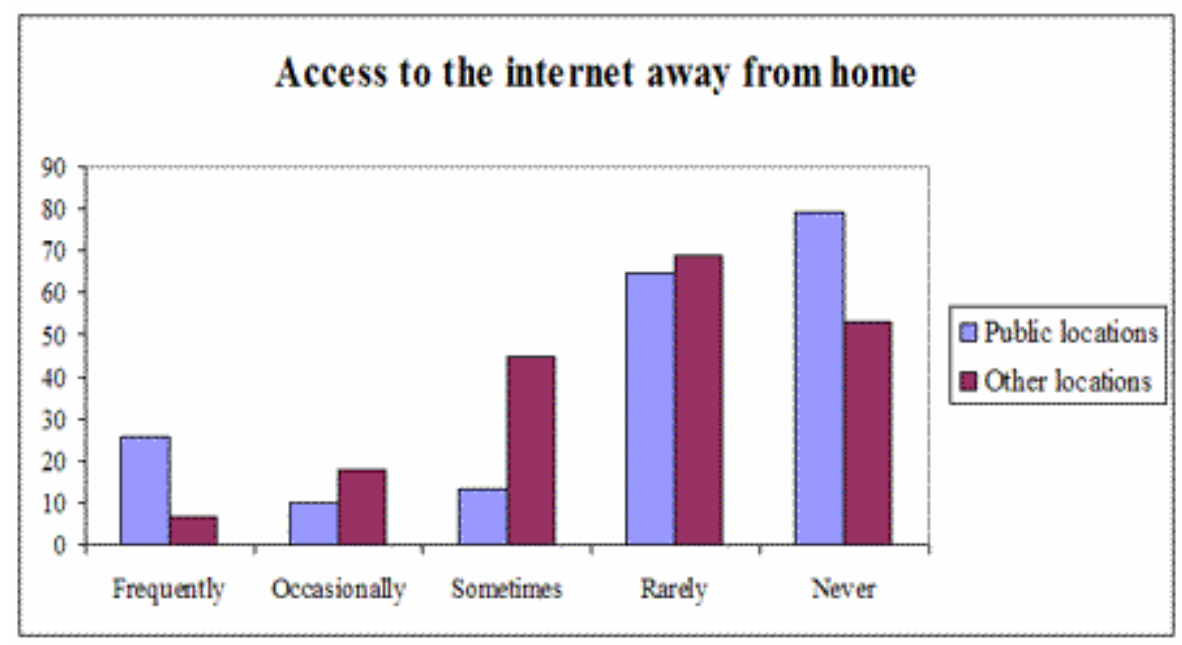

An open-ended question then asked respondents to describe what limitations they personally experience to greater use of the Internet. The overwhelming majority (80 per cent) cited slow speed as the main deterrent. Poor connections and the cost of connecting were listed by a further 15 per cent. The final 5 per cent cited lack of time.

A series of questions then asked respondents to say how their involvement with other people and with local issues had been affected by their use of the Internet. Sixty per cent said their connection to other people had increased considerably, and 55 per cent said their involvement with local organisations had increased. This finding confirms other studies that show that online connectivity complements face-to-face connectivity. 


\section{Current and Anticipated Uses of the Internet}

Using a number of questions from the Grand Rapids survey, we asked people to categorize their current use of the Internet for a range of formal and informal learning opportunities. We asked how frequently they used the Internet to find out about local news and events, and to obtain information from local public agencies. While these show relatively high uses, the more directly educational uses are significantly higher. Nearly 50 per cent said they frequently used the Internet to gain knowledge of various kinds. Three more specific kinds of educational uses were surveyed:

- Developing computer skills

- Obtaining educational materials

- Studying distance education courses

Respondents were then asked to speculate about how much they would use the same range of informative and educational activities when they had access to broadband. The figures below compare their current and anticipated use for the same activities.

While speculating about future uses is not entirely possible, the data nevertheless indicate something about expectations and possibilities. Figure 2 shows that respondents are clearly expecting to use broadband to access local information far more frequently than currently. As subsequent comparisons show (e.g., Figure 6), there is a greater growth in anticipated uses of broadband for local information and community networking thSan for specifically educational uses.

Figure 2. Respondents' Current and Anticipated Use of the Internet to Obtain News and Information

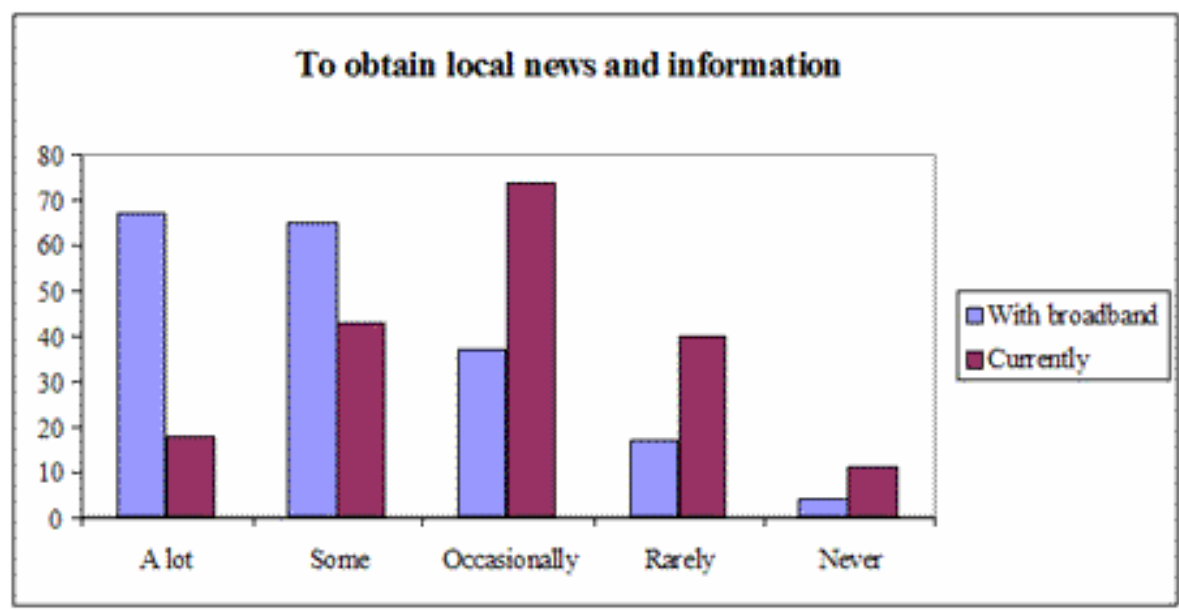

Figure 3 shows a similar rise in anticipated broadband use to access information from public agencies. In particular, we asked respondents to indicate whether they would use broadband to access information about local health provision. Three quarters of them said they would either frequently or sometimes. 
Figure 3. Respondents' Current and Anticipated Use of the Internet to Obtain Information from Public Agencies

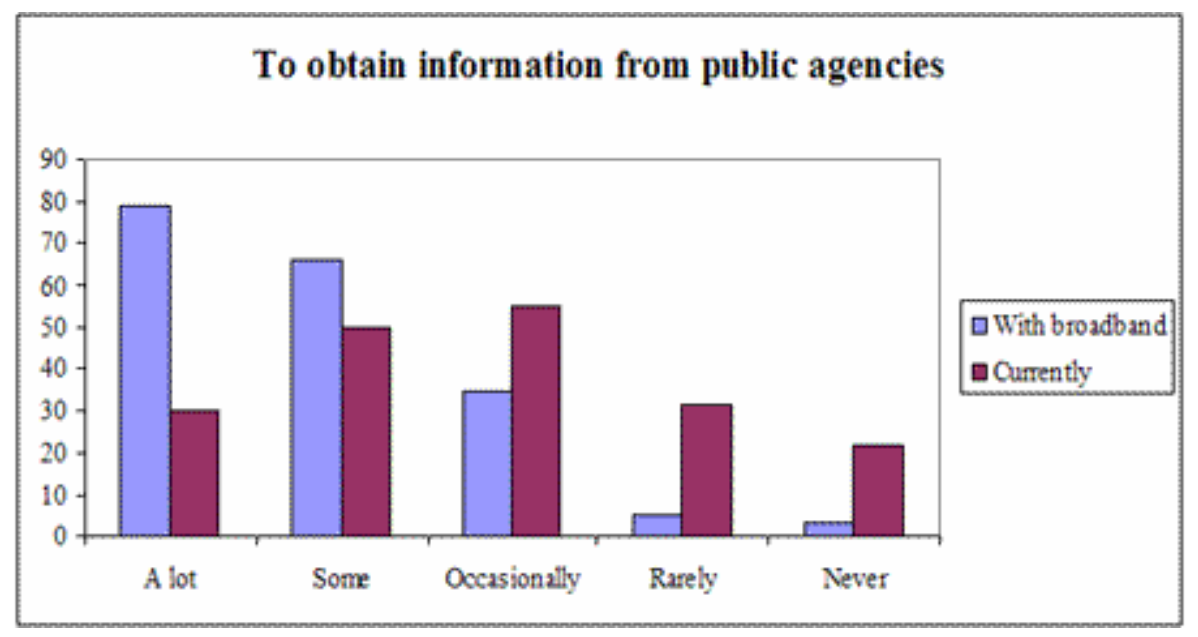

Using the Internet to develop computer skills is already a common activity among respondents, but this too is expected to rise with the availability of broadband as Figure 4 shows.

Figure 4. Respondents' Current and Anticipated Use of the Internet for Developing Computer Skills

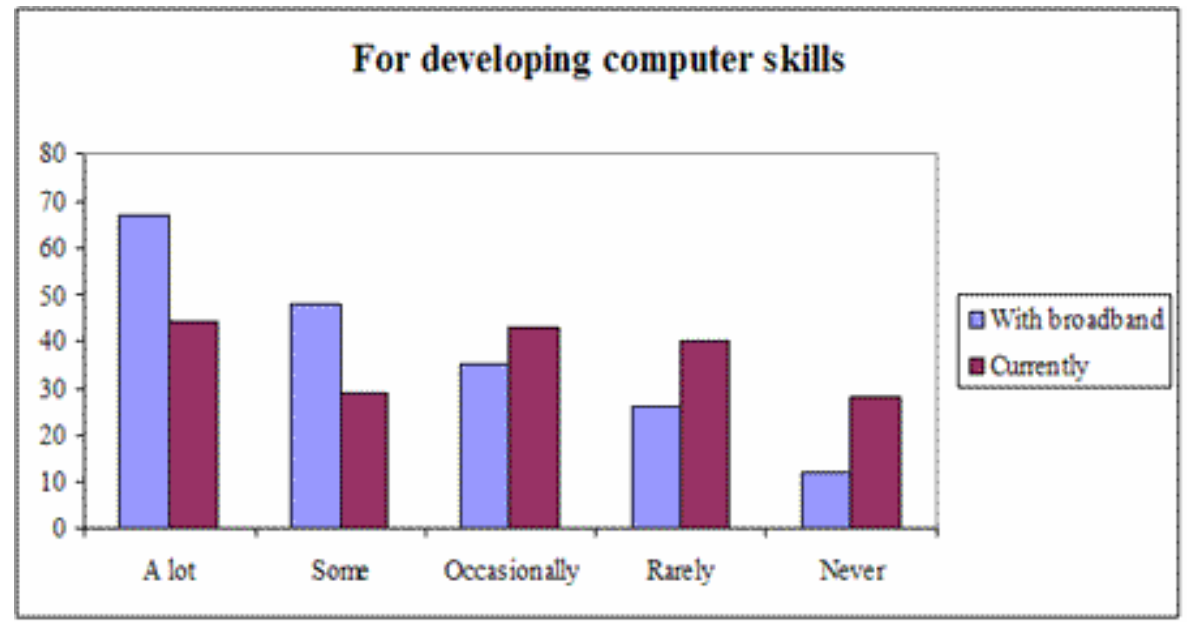

Figures 5 and 6 show that this group of information technology (IT) literate respondents already make relatively high use of the Internet for education, but these are also expected to rise with broadband. Note that both the current and the anticipated uses of the Internet are higher for "obtaining educational materials" than for formal distance education courses. 
Figure 5. Respondents' Current and Anticipated Use of the Internet to Obtain Educational Materials

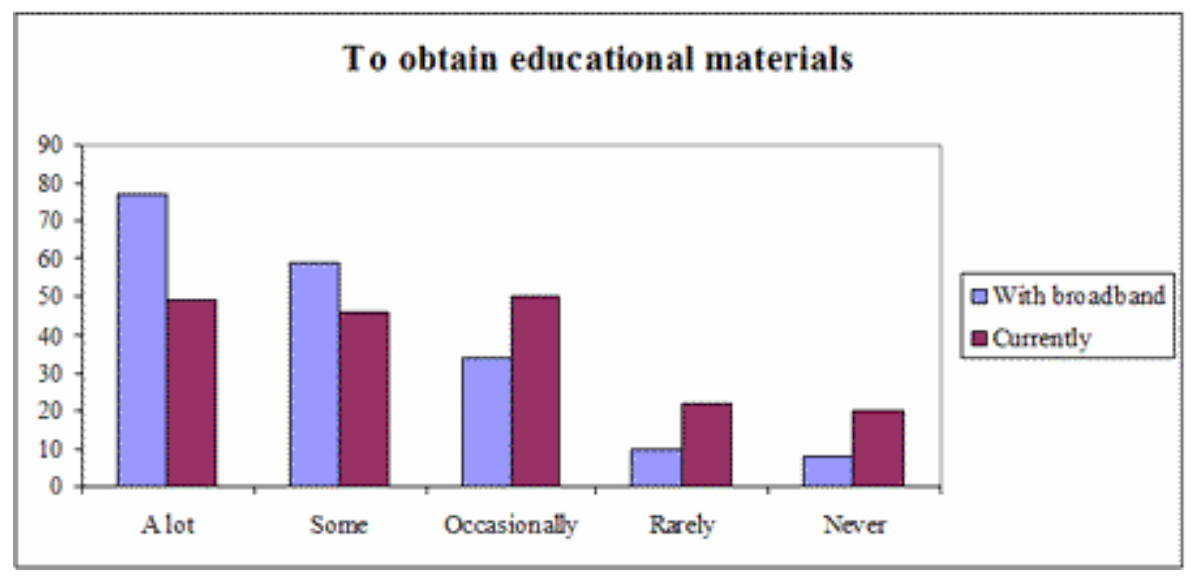

Respondents were also asked to describe their concerns about the introduction of broadband and hence their greater use of the Internet. Issues mentioned were:

- It can be addictive and time wasting

- Virus problems and security issues

- There are questionable websites, especially for young people

Figure 6. Respondents' Current and Anticipated Use of the Internet for Taking Distance Learning Courses

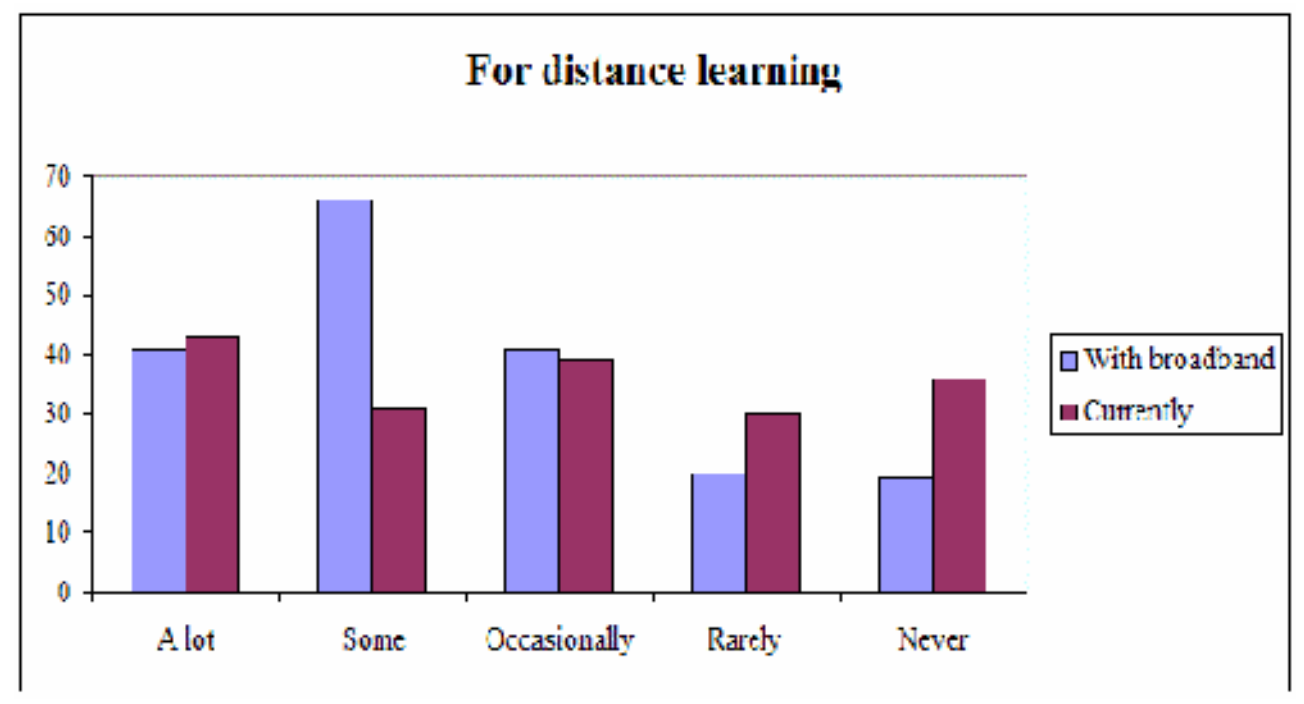

Nevertheless, many respondents said the Internet was largely beneficial and they only saw it positively. Perhaps the most indicative response was: "The Internet is a double edged sword. Buying online is fantastic, but presents challenges to local retailers who need to compete to survive. In the long run, it will have a negative as well as a positive effect on the local economy.” 


\section{Training Requested}

Training in basic Web-design was requested by half of the respondents with only slightly fewer requesting training in using Web-based educational materials. Nearly 40 per cent asked for training in databases and PowerPoint, and 30 per cent in spreadsheet applications. In an openended question about other kinds of training which would be of interest, the most often mentioned requests were for various kinds of advanced training, for example, in Web-design, producing educational Web material, marketing online, and multimedia applications using video and audio. Given the acknowledged IT competence of these respondents, the level of interest in training represents a clear market opportunity for the local college and other training providers to upon which to capitalise.

When asked what services they would like to see provided locally, a wide range of interesting, relevant, and innovative suggestions were made. Figure 7 shows only the most common.

Figure 7. Respondents’ Requests for Desirable Online Local Services

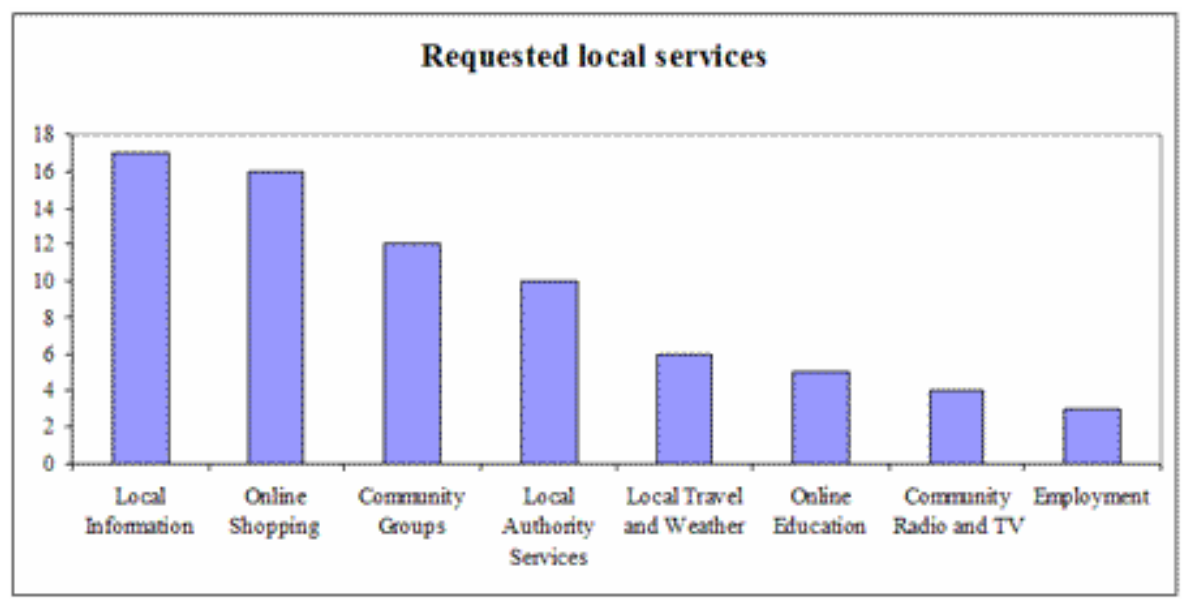

These open-ended responses confirm earlier data about interest in local opportunities for a wide range of activities ranging from shopping to socializing, from community development to information services. Again, it is notable how much stronger the demand is for local information than for formal educational opportunities.

The final open-ended question asked respondents to comment on the opportunities they perceive with the introduction of broadband. Most responses focused on the employment possibilities that could come to the islands:

"Increasing small cottage industry expansion in remote areas - crucial. Better connection with the rest of the world. Tourist opportunities, economic opportunities, educational opportunities.”

"Allow people to work from home and encourage businesses to set up locally."

"A council that is more aware of local problems; international companies working from the islands; better links to the rest of the world; a feeling of being less isolated etc. The only limitation is the imagination of those that use it." 
"Marketing a more positive image of the Western Isles to the world; potential for Gaelic development."

Two comments were more acerbic:

"If broadband is to be introduced to the Western Isles, it should not be on a piecemeal basis, but made available to all areas equally and if phased, should start in the most remote area from Stornoway - i.e., Barra and Vatersay and work northwards from there. 'Pilot projects, which start in one area and never spread beyond, are potentially counterproductive if they serve only to reinforce a perception that some communities are more favored than others. Assuming equal access to the same level of connectivity, then the opportunities are enormous not just in education (for widening and deepening the curricular spread), but also in the business and voluntary sectors. It could really bring the island communities together."

"If it's a tool to facilitate action locally, it is great. If not, then it is just another reason (like TV) for people to stay in their houses behind a VDU [video display unit] rather than getting out in the community and meeting people."

\section{Analysis}

The data present us with a picture of the current and future activities of a small, unrepresentative subset of the population of the Western Isles. Nevertheless, these are no doubt the very people who will be the first adopters of broadband, and the early champions, providers, and users of local information, services, and training.

The survey shows a strong demand for a whole range of local groups, committees and shops to develop an online presence. For this to happen, awareness raising, training, and support will be necessary. Studies in North America and Finland are adamant that nurturing efforts - in the form of training and on-going support - are absolutely essential if the whole initiative is to be successful.

Existing local centres have an obvious role to play in the short to medium term. Raising awareness, using local facilitators, will be the first requirement. Introductory training is probably best handled face-to-face in local centres, while advanced training may be best offered totally online. Evidence from broadband implementations in other countries indicates that local learning centres, even in the medium term, continue to act as vital centers where people come to access a range of resources (e.g., subscription-only material), obtain help and advice, socialise, and try out software before purchasing.

\section{Informal Opportunities for Learning}

The survey also indicates that informal learning will be a large component of the overall use of broadband. The Internet provides two kinds of informal learning opportunities:

Online communities offering advice, socializing, support, and networking

Portals or gateways to information, resources, and articles 
This study shows how important both of these are at a local level, but they need support, maintenance, and promotion. The Blacksburg evaluators noted:

What we DO know is that if computer networking is a medium that can help increase community participation, it will not do this by itself. We, as citizens and community leaders must create the 'structure' and the 'space' - a virtual commons - within which discussion can flourish. We must cultivate group participation by moderating discussion, updating content, archiving conference discussions, organizing information into dynamic, usable, and readily accessible, material full of feedback options (Kavanaugh, 1996b, p. 4).

The community net in Upper Karelia, Finland, attributes its success to the free support and training it provided:

The key implementer was local, the project leaders were local, and the laytrainers had themselves been local unemployed persons; they were highly sensitive to the starting level and needs of the local people. . . Anyone could use the Net and its equipment cost-free at the 32 kiosks that were made available in public spaces, such as libraries, youth centers, homes of unemployed persons, local banks and shops. Training and support was free and easily accessible (Oksa and Turunen, 2000, p. 4).

The Western Isles implementation needs to consider ways of providing support for on-going maintenance of local online networks and information portals. There are also many opportunities for local education providers to offer a broad range of IT training, from the most basic to the most advanced.

\section{Implications of Broadband for Formal e-Learning}

At the simplest level, by providing a faster and more reliable connection to existing provision, broadband will equalise rural and remote learners' access to educational materials and courses. In order to create more attractive and compelling learning environments, course designers could and should therefore be re-thinking the nature of their e-learning courses with the benefits of broadband in mind. From our experience as online course developers, we suggest five such areas for consideration.

\section{Online Activities}

The information and communication aspects of the Internet provide rich opportunities for models of courses that are activity-based and experiential. Activities can be individual or collaborative, and arguably a mix of the two is ideal, as one of the difficulties that even broadband cannot solve is the time constraints many adult learners experience when trying to juggle lifelong learning with professional and family commitments.

Individual activities can make use of the vast resources of the Web to investigate course issues, find and analyse relevant material, prepare reports for a class repository, and comment on fellow students' work. Broadband makes extensive online time affordable and it is less disruptive of family life (i.e., access over dial-up services ties up the one phone line into the household, which can have negative effects). 
Collaborative activities provide the advantages of peer-to-peer learning and a sense of community for isolated learners. Small group activities can involve joint investigations and presentations, and larger teams can produce websites, take part in simulations and role-playing, debates, and structured discussions.

Re-thinking lectures as online activities, provides students with more opportunities to develop self-directed learning skills and resources. Resourced-based learning offers choice and student initiative in making the course their own. Activities can be based around problems (Jonassesn, 2002) or around online seminars and dialogue (Harasim, 2002).

To some extent these activities are already embedded in online courses (Mason, 2000), but broadband access would make them feasible for more learners. Course designers could develop whole courses around the notion of pervasive "always-on" connectivity.

\section{Real-Time Events}

Distance learning and now e-learning has a strong asynchronous bias, mainly because most learners are fitting their studies around other full time commitments. Face-to-face meetings reduce the flexibility of the course, though they would add valuable immediacy, motivation, and presence to the experience of learning. Various forms of real-time connections are possible with broadband that can provide many of these advantages without the flexibility drawbacks typical of face-to-face meetings.

Tutorials and small group meetings can be held over software such as Netmeeting ${ }^{\circledR}$ which provides video, audio and shared screen facilities. Groove ${ }^{\circledR}$ messaging offers near-instant communication as well as shared files, and other software provides buddy systems that allow students to be in close contact with their peers. Activities could be based around these facilities whereby students engage in peer commenting, team projects, and self-help groups.

Webcasting ${ }^{\circledR}$, for example using guest lectures, offers immediacy and the opportunity to engage in discussion with experts and special advisers. The fact the lecture can be stored and accessed after the event provides flexibility as well as immediacy.

Most of these real-time activities are difficult, costly, or actually impossible over dial-up lines. Broadband offers course designers the opportunity to design courses using the optimal mix of synchronous and asynchronous modalities, without concern about disadvantaging remote users.

\section{Hyper-Interactivity}

A whole range of software for simulations, problem-solving and interactive animations used in campus-based learning environments can be implemented for distance learners where broadband is available. Examples include cognitive tools for analysing ideas, dynamic modeling tools for creating representations of mental models, visualization tools for helping to "see" phenomena in different ways, or conversational tools for enabling learners to build collaborative knowledge bases.

The problem or project space must also provide students with the opportunity to manipulate or massage the problem in order to make it more meaningful. Students cannot assume any ownership of the problem unless they know that they can effect the problem situation in some 
meaningful way, so manipulating the phenomena and seeing the results of those manipulations are important (Jonassen, 2002, p. 85 - 86).

Even accessing large databases of articles and interacting with them to find and download appropriate information is made more feasible with broadband than over dial-up lines.

\section{Multimedia}

While true multimedia teaching material is extremely costly to design and produce, there are many ways in which course providers can make use of video and audio clips to add interest and variety to online courses. Used judiciously, both audio and video can provide the kind of immediacy that many distance learners find missing in purely text-based learning material. For example, video and audio clips could be used as annotations to hear or see an expert in the field, to record an interview, to see a process, or to hear the instructor talk through a problem, painting, or procedure. Even pictures, cartoons, drawings, and graphical material add variety to text material, but nonetheless introduce complications in accessing online material for people reliant on dial-up connections. While broadband supports more multimedia than most e-learning course providers can afford to produce, there are many ways in which they could introduce elements of multimedia, which have the desired pedagogical effect without unacceptable cost.

\section{Assessment}

It has been argued (Boud, 2000) that traditional assessment fails to provide opportunities for students to learn the very thing they most need to know: how to assess their own learning. One aim of higher education must surely be to prepare students for an increasingly unpredictable future. There is a need for programmes in which students reach not just immediate course-related objectives, but much wider learning and self-development goals. Existing assessment practices frequently dis-empower learners and put the control and the judgement of learning in the hands of assessors and tutors.

The Web and broadband access to it permit a whole range of online assessments that could begin to address the aim of developing lifelong learners armed with the skills to assess their own learning, give and receive feedback, and make realistic judgements about the quality and value of information. Examples could involve:

Assignments from previous years being made available in a digital repository, which then becomes part of the course resources to be drawn upon by subsequent students

Current assignment being made accessible to students after the submission deadline - with or without grades, and with or without the feedback from the instructor. Students would then be able to benefit from writing assignments for their peers and not just for the instructor

Assigning students the task of commenting on previous students' work

Students are assigned the task of producing websites as assignments, either individually or collaboratively. These can include multimedia elements such as photos and audio clips

\section{e-Learning Providers and Informal Learning}

These five ways of making use of broadband in e-learning are relatively inexpensive but would add richness to the formal online course environment. However, it is evident in this study of the current and anticipated uses of the internet in the Western Isles, as well as in numerous other 
research studies (Levis, 2002), that informal learning opportunities may be more important than formal course provision over broadband networks.

Online course providers might do well to consider the implications of informal learning online and design creative solutions for the broadband market. These might include:

- Short and even shorter learning opportunities

- Online events based around topical issues

- Repositories of professional up-dating material

- Online alumni networks for peer-to-peer exchanges

- E-learning is at the forefront of a revolution in education. Broadband will hasten and support the changes that are already taking place.

\section{Rural e-Learning in Developing Countries}

Though it is beyond the scope of this study, it is nevertheless interesting to consider how applicable broadband is for rural e-learning in developing countries. It is notable that all of the examples drawn upon in this study are from developed countries, whereas the need for educational opportunities in rural areas of developing countries is often even greater. There are two aspects that must be taken into consideration: technology infrastructure and pedagogical readiness.

A recent report about wireless Internet connectivity for developing nations (Press, 2003) indicates that there is some (perhaps over) optimism about the way in which developing nations can cross the digital divide and leapfrog ahead of developed nations using wireless technology. Press is himself doubtful about the reality of such assertions and asks: "Might it be time for some large networking projects rather than demonstrations projects, e-readiness studies, publication of bestpractices databases, etc?” (Press, 2003, p. 8).

Turning to the issues of use, take up, and educational readiness, a number of observations can be made based on the findings in the Western Isles study:

- After funding for the initial infrastructure subsides or is finished, readiness of the population to take up the advantages of broadband is a crucial factor in its sustainability

- Educational providers need to be alert to the training opportunities for both formal and informal learning

- Telecentres offer an interim solution between classroom-based learning and home-based e-learning

- E-learning needs to build on a wide variety of other uses of broadband, such as entertainment, entrepreneurial activities, community networking, and access to public services

These requirements are less likely to be available in developing countries. However, the motivation and determination of many learners in rural, disadvantaged areas often overcome what would be considered insurmountable hurdles even in a developed country. A report (Diamond, 2003) on the take up of Massachusetts Institute to Technology (MIT) open courseware is evidence of this phenomenon. Diamond documents students and institutions using MIT courses in Nepal, Vietnam, Pakistan, and the Mauritius. 


\section{Conclusions}

This paper has examined the learning implications of a larger study of broadband implementation in the Western Isles of Scotland. It has done so in light of similar studies conducted elsewhere and has tried to build on their results. e-Learning has been considered in the broadest possible way to include a range of informal learning opportunities ranging from information portals to community networking, as well as the obvious formal education and training courses.

Although our survey attracted responses from the most IT literate people residing on these Scottish Islands, it is clear that there is at least a small nucleus of people that is ready for broadband and are aware of its educational, economic, and social potential to sustain this remote community. The local centers, which already act as community learning venues as well as the facilitators who run them, have a continuing role to play, though adequate funding needs to underpin their use in the broadband initiative. In order to prevent broadband being viewed as another technology-led project, a range of services must be developed in parallel with the technology implementation. e-Learning opportunities, both formal and informal, are a key part of this "solution" for the Western Isles.

\section{References}

Baudrillard, J. (1993). Symbolic Exchange and Death. Sage Publications: London

Boud, D. (2000). Developing Student Autonomy in Learning (2nd Edition). Kogan Page: London

Daniel, J. (2002). Preface to Distance Education and Distributed Learning. In C. Vrasidas and G. Glass (Eds.) Current Perspectives on Applied Information Technologies: Online professional development for teachers. Greenwich, CT.: Information Age Publishing.

Diamond, D. (2003). MIT Everyware. Wired 11(9). Retrieved September 27, 2003 from: http://www.wired.com/wired/archive/11.09/mit_pr.html

Harasim, L. (2002). What Makes Online Learning Communities Successful? The role of collaborative learning in social and intellectual development. In: Distance Education and Distributed Learning. In C. Vrasidas and G. Glass, (Eds.) Current Perspectives on Applied Information Technologies: Online professional development for teachers. Greenwich, CT: Information Age Publishing.

Jonassen, D. (2002). Learning to Solve Problems Online: Distance education and distributed learning In: Distance Education and Distributed Learning. In C. Vrasidas and G. Glass, (Eds.) Current Perspectives on Applied Information Technologies: Online professional development for teachers. Greenwich, CT: Information Age Publishing.

Kavanaugh, A. (1996a). Highlights of User Surveys 1994-1996. Retrieved December 12, 2003 from: http://www.bev.net/project/research

Kavanaugh, A. (1996b). The Use of the Internet for Civic Engagement: A view from Blacksburg, Virginia. Luncheon Address to the Virginia Municipal League. Retrieved December 20, 2002 from: http://www.bev.net/project/research 
Kavanaugh, A. (1999). Education via Wireless Internet. Roundtable on Tele-Education. UNISPACE III. Retrieved December 20, 2002 from: http://www.bev.net

Levis, K. (2002). The Business of (e)Learning. A revolution in training and education markets. Screendigest: London.

Lynch, C. (2000). Why Broadband Really Matters: Applications and architectural challenges, Educause Quarterly, 4.

Mason, R. (2000). IET's Masters in Open and Distance Education. What have we learned? Retrieved December 20, 2002 from: http://iet.open.ac.uk/pp/r.d.mason/downloads/maeval.pdf

Oksa, J., and Turunen, J. (2000). Local Community Net. Evaluation study of the Learning Upper Karelia Project. Retrieved September 12, 2002 from: http://www.joensuu.fi/ktl/projsoc/infosoc/upperka2.htm

Press, L. (2003). Wireless Internet Connectivity for Developing Nations, First Monday, 8(9). Retrieved January 23, 2004 from: http://firstmonday.org/issues/issue8_9/press/index.html

Rheingold, H. (2002). Smart Mobs. The Next Social Revolution. Cambridge, MA.: Perseus Publishing.

National Research Council (2002). Broadband. Bringing Home the Bits. Washington, DC.:National Academy Press.

Sage Research (2002). Customers at the Gate: Mounting Demand for Broadband-enabled Services. Natick, MA. Retrieved January 23, 2004 from: http://www.sageresearch.com

The New National Dream: Networking the Nation for Broadband Access (2002). Report of the National Broadband Task Force. Retrieved June 12, 2003 from: http://broadband.gc.ca/Broadband-document/table content e.asp

The Rural Secretariat, Agriculture and Agri-Food Canada (2001). Rural and Remote Broadband Access. Background report to the National Broadband Task Force. Retrieved May 12, 2002 from: http://broadband.gc.ca/english/resources/ruralsec_report.html
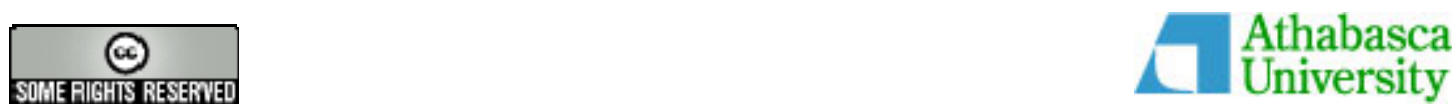
April - 2004

\title{
Distance Learning for Teacher Training in Brazil
}

\author{
Alvana Maria Bof \\ Brazilian Ministry of Education
}

\begin{abstract}
Proformação is a distance teacher certification course aimed at providing training to 27,000 uncertified teachers in 15 Brazilian states. This innovative program organizes human and technical resources for delivering distance education in a cost-effective manner. Different from other institutional systems - which typically employ their own dedicated content, design, and instructional resource personnel, and accompanied by a large pool of administrative staff Proformação leverages pre-existing learning resources such as content experts, technology specialists, instruction, and student support systems from several institutions. Proformação goal is to create a viable teacher certification course to upgrade thousands of non-certified teachers working in the field. Proformação is coordinated by an administrative unit of the Brazilian Ministry of Education. To support the program, an information system was implemented to continuously and consistently monitor the program's activities and results. Results of an external evaluation have been positive; Proformação is regarded by some as an innovative model for delivering decentralized training opportunities to large student numbers. Therefore, the findings in this article may prove interesting to those charged with implementing distance learning initiatives in developing countries, in that the lessons learned in Brazil may help others interested in implementing similar distance training programs.
\end{abstract}

Keywords: distance teacher training; distance education; in-service teacher training; distance education in developing countries

\section{Introduction}

Distance learning is a viable avenue for developing countries to provide education opportunities to their population. In contrast to developed countries, however, which typically can afford comprehensive distance learning systems (e.g., full service open and distance universities) developing countries usually lack the resources and funding for such costly endeavors. This means developing countries must often seek innovative lower cost strategies for the delivery of distance education programming.

This article describes a viable distance learning in-service training program developed to upgrade 27,000 teachers working throughout Brazil. The program described has proven to be a successful model for the delivery of education at a distance. While exhibiting all the important features of distance teaching institutions around the world, this model does so without the establishment of a traditional bricks-and-mortar institution. Instead, this model, which is coordinated by a management unit in the Brazilian Ministry of Education, is comprised of a collaborative, decentralized system that leverages human and technical resources from several institutions. 
Providing an innovative and cost-effective way of delivering training, Proformação is regarded by Moore (2001) as “a distance learning program for the 21 Century.” In sum, Proformação may be of particular interest to those seeking to implement distance education other developing countries.

This article describes the design and implementation structure of Proformação. It also reports the results of an external evaluation. The article concludes by summarizing the lessons learned during the implementation process.

\section{The Program}

Proformação is a distance teacher certification course aimed at upgrading those individuals teaching the first four primary school grades in the North, Northeast, and Midwest regions of Brazil. It employs a distance education model that combines self-study, school-based practice, local-based biweekly meetings for tutors and teacher-trainees, and a supportive communication network to provide assistance and support to tutors and teacher-trainees operating through Training Agencies, located in each Brazilian State.

\section{Objectives}

The main objectives of the Proformação are to:

- Certify un-certified teachers teaching literacy classes and the first four years of primary school

- Increase the knowledge base, abilities, and professional qualifications of those individuals already working as teachers

- Improve of primary grade-level student learning and performance in Brazil's State and Municipal public schools

- Elevate the importance teaching, by promoting the image of "professionalization" of the teaching discipline

- Improvement in the quality of learning in Brazil

\section{Course Design}

The program's aim is to deliver 3,200 hours of training, divided into four modules (semesters), each comprising 800 hours of individual and group activities. These modules encompass:

- A face-to-face session held at local Training Agencies, during which teacher-trainees are introduced to each module's content and activities. This session is typically conducted during teachers' vacation period

- Individual activities outlined in a study guides, along with workbook exercises on course content, and journal entries kept by teacher-trainees to record their observations, progress, problems, and experiences in the classroom 
- Tutor evaluation of the teaching practice in the teacher-trainees' own schools following the course studies

- Tutorial meetings conducted every other Saturday. These tutorial meetings focus on guiding and monitoring the teacher-trainees' work in progress, and include support materials such as videos related to each of the Study Guide units, and a forum for discussion and dialog to clarify any problems or questions the teacher-trainees may have

- Bimonthly tests on all content areas

- Activities to prepare for the bimonthly tests - i.e., activities organized by the Training Agencies for teacher-trainees prior to test-taking

The program also includes school projects and a foreign language, as well as a permanent learning support system. In total, this program includes:

- Tutorials: learning support provided by a local tutor, who in turn are guided by the Training Agencies

- Communication services: communication services among tutors, Training Agencies, State Management Teams and the National Coordination Unit. This includes free educational assistance provided by the Training Agencies via toll-free telephone, that allows teacher-trainees to contact area content tutors to clarify any doubts they may have, or obtain additional information

\section{Curriculum and Trainee Evaluation}

Proformação's curriculum is based on The National Curriculum Parameters (NCP), and is organized in six thematic areas: 1) Codes and Language; 2) Mathematics and Logic; 3) Science and Environment; 4) Identity, Society and Culture; 5) Educational Foundations; and 6) Theory and Praxis of Education. Curriculum objectives and content take into account the general guidelines of Brazil's secondary education system, as well as the specific requirements for teacher certification. The curricula's nucleus is comprised of an interdisciplinary core, including a field research project were teacher-trainees must examine aspects of their local experience. This research project may address specific themes of local interest such as regional culture, environmental issues, local history, etc.

Evaluation of teacher-trainees takes place continuously and is based on an analysis of several evaluation instruments: workbook assignments, bi-monthly tests on the six thematic areas, class plans, observation of actual classroom practices, written reports (i.e., journal), and field research projects.

To be approved, the teacher-trainee must achieve an overall performance level equal to, or greater than, 60 percent; and not less than 50 percent on any specific individual evaluation instrument or any of the six thematic areas. 


\section{Materials}

Course and instructional materials were developed by a nationally-based team of subject matter specialists and instructional designers. Learning materials include:

- 32 study guides in the subjects that comprise the self-study part of the course

- 32 videos per module, for each of unit

- 32 workbooks with assignments

Proformação also offers printed material containing all the necessary information about the course, including orientation on how to use the methodology, implementation strategies, Proformação's operational structure, responsibilities of individual partners, and the roles and functions of tutors and the Training Agencies. These materials include: a general guide, operational guide, tutor guide, tutor support texts, tutor training video, Training Agency support text, etc.

\section{Implementation Structure}

Proformação’s organizational structure operates at three levels:

Federal level: Brazil's Federal Government is responsible for defining the technical and pedagogical design, developing and producing instructional materials, defining the implementation strategy, coordinating the implementation process, providing training to participants and technical support to states, and monitoring and evaluating processes and results. There is a national unit at the Brazilian Ministry of Education.

State level. Brazil's individual states are responsible for establishing a state management coordination (SMC) team, based in the State Secretariat of Education in charge of managing the program at the state level. This team selects and designates staff, and provides the infrastructure for Proformação’s Training Agencies.

Municipal level. Municipalities are responsible for the payment of tutors' wages, providing transport for tutors for visits to teacher-trainees' schools, and transport, meals, and accommodation for both teacher-trainees and tutors during the face-to-face sessions of Proformação.

Contrary to what typically occurs where there is a formal physical institution responsible for providing training, Proformação has created a virtual structure, comprising several actors and local institutions responsible for specific activities involved in the Program's implementation. This organizational structure was established by a partnership between Brazil's Federal, State, and Municipal governments, who signed a formal agreement outlining each level of governments' area of control.

The support system comprises: locally-based tutors that support the teacher-trainees; Training Agencies; the State Management Unit; technical assistants that support and monitor the Training Agencies; and the National Coordination Unit required to support, monitor, and evaluate the various state teams. Figure 2 shows this structure: 
The Training Agency is comprised of a team of six specialist teachers, one from each of the curriculum content areas, who are in turn responsible for selecting, training, and monitoring the work of the tutors. These six specialist teachers are also responsible for planning and implementing face-to-face in-service training activities, and organizing and managing the learning support system (including answering a toll free telephone number) for both tutors and teacher-trainees. As well as being the pedagogical center of the program, the Training Agency also acts as a micro management unit where teacher-trainees' academic data is collected, collated, analyzed, and evaluated. A communication system was installed (i.e., email; interactive television programs; and teleconferencing) for the Training Agencies, State Management Units, and the National Coordination Unit, to monitor teacher-trainee performance and manage the administrative aspects Proformação.

Figure 1. Proformação Organizational Structure

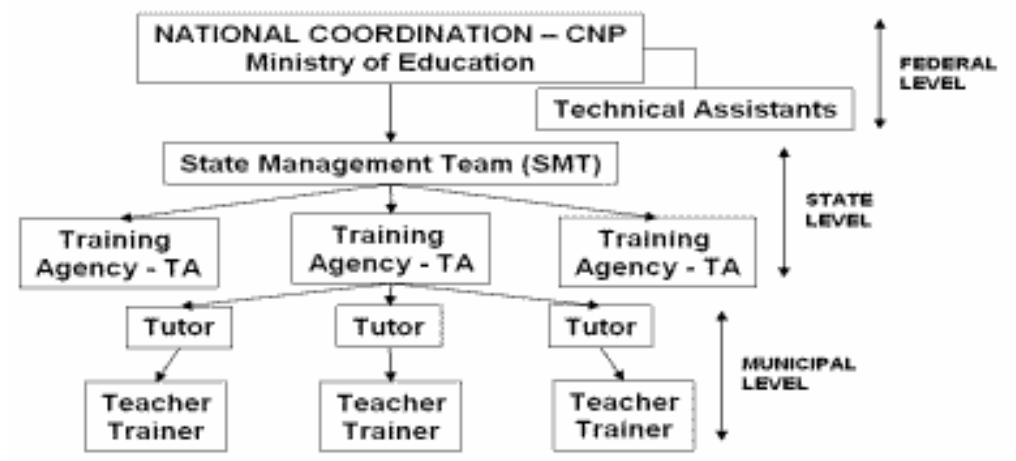

Tutors are selected among a pool of fully certified public school teachers. Those selected as tutors, receive training from their respective local Training Agencies, which serves as the "hub or base" from which they conduct biweekly meetings with local teacher-trainees, provide program orientation and training support, travel to visit the teacher-trainees' local school to guide and evaluate their pedagogical practice, and evaluate the their performance based on workbook assignments and journal entries. Each tutor typically supervises approximately 12 teachertrainees.

\section{Monitoring and Evaluation System}

Proformação installed a computer information system to collect and analyze data to track and assess teacher-trainee performance, and monitor the Program's processes, progress, and activities. Data collection at the Training Agency level allows the Training Agency team and the managers at state and national levels to track and evaluate Proformação's ongoing performance. Information is gathered in to evaluate teacher-trainees' performance by content area, region, or Training Agency, which in turn gives all participants involved the targeted level of information they need to resolve and/ or address problems as they arise.

Tutors and Training Agency staff continuously monitor teacher-trainees' performance at the local level. Tutors track and evaluate the teacher-trainees' work, enabling them to provide continuous feedback, and offer remedial help when and were needed, typically by offering additional exercises, explanations, etc. The Training Agencies also monitors teacher-trainee performance 
and addresses any difficulties, usually during monthly meetings with held with tutors. During these meetings, the group reviews the teacher-trainees' performance data (based on the six different thematic areas) using evaluative instruments designed to identify and assess difficulties. From these meetings, customized strategies are developed to improve the teacher-trainees' performance on a local and/or individual basis.

Program activities and student performance also monitored at the state and national levels. The National Coordination Unit employs technical assistants who work in each participating state. Their role is to visit the Training Agencies, to monitor their performance, observe biweekly meetings, conduct examinations and face-to-face sessions, etc. These professionals work with the State Management Team and submit standardized monthly reports to the National Coordination Unit. From these reports, the National Coordination Unit can take action to address any problems that arise at the state level.

Each semester, the National Coordination Unit also conducts systematic data review on all program implementation aspects by conducting face-to-face sessions with teacher-trainees, tutors, and teachers. Data results are discussed between the State Management Teams and their cadre of technical assessors, in order to identify problems and define strategies to resolve them.

The National Coordination Unit has also a support unit that establishes regular communication with the State Management Teams and the Training Agencies. Such communication and support take place via phone, email, an electronic bulletin, teleconferencing, as well as a printed bulletin, to convey news, information, and experiences from the Training Agencies and their tutors and teacher-trainees.

Proformação also holds midterm evaluation meetings and continuing education sessions for the staff of the Training, State, and National agencies. These meetings include presentations of performance data, information on new procedures, and follow-up discussions on these and other relevant topics. Recently, an interactive tele-conferencing system was implemented, allowing those working in the field at the Teaching Agencies, to work directly with the National Coordination Unit to define strategies. The tele-conference meetings are evaluated by all participants, the results of which help the National Coordination Unit improve the organization and content of future tele-conference meetings.

\section{Cost}

Proformação's cost per teacher-trainee is $\$ 1,100$ for the two-year course. The Ministry of Education covers 36 percent of the total cost. The remaining 64 percent of cost are shared among the State and Municipal governments.

\section{Results and External Evaluation}

Since the program's inception, a team of external evaluators from various Brazilian universities and institutions ${ }^{1}$ has been contracted to collect and analyze data. Their task is to identify issues concerning program implementation, and determine program results based on teacher-trainee performance, classroom practice, and the impact the program has had on the schools and in developing local communities. These findings inform any needed adjustments to the program. 
External evaluation comprises three main kinds of studies: (1) statistical analyses of trainee performance; (2) surveys of all participants; and (3) six case studies in different regions. The main findings are summarized below (Placco, 2002; André, 2002; Gatti, 2002).

\section{Teacher-Trainee Performance}

Performance data in Figure 1 shows that 85.7 percent of teacher trainees achieved certification/ promotion, 3 percent were retained; and 11.5 percent dropped out (Gatti, 2001). In contrast with the high dropout rates typically experienced in distance learning programs, these results are positive. In addition, when looking at performance in each of the content areas, results show that the majority of teacher-trainees perform well above of the minimum required for promotion.

Figure 2a. Teacher-Trainee Performance

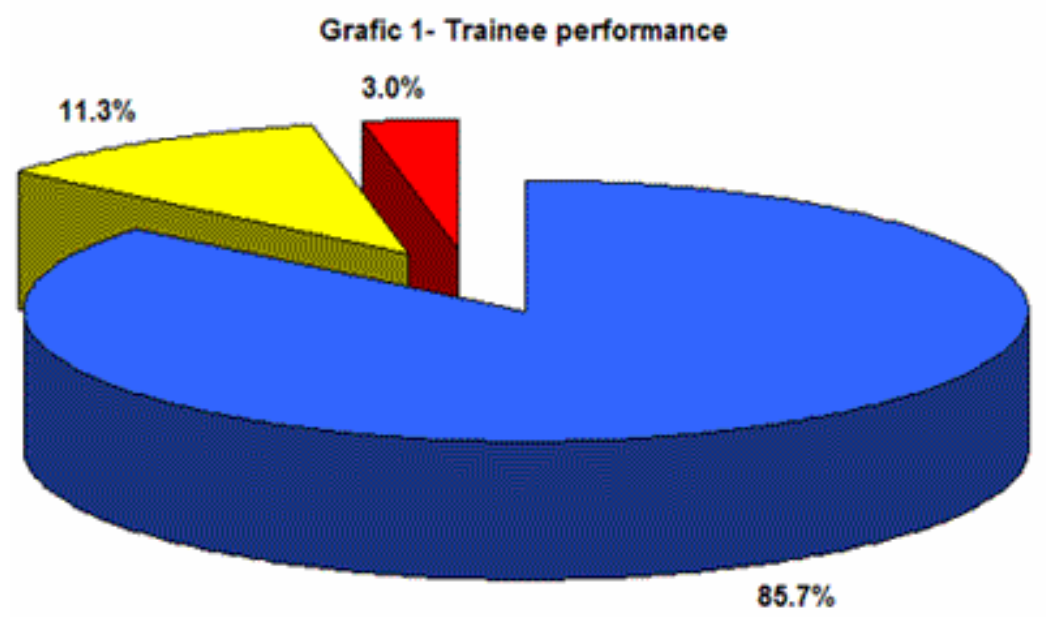

aPromotion aDropouts a Retention

Figure 2b. Teacher-Trainee Performance 


\begin{tabular}{|c|c|c|c|c|c|c|c|c|c|c|}
\hline \multirow[b]{2}{*}{ Grupo } & \multirow[b]{2}{*}{ Estados } & \multirow[b]{2}{*}{$\begin{array}{l}\text { Agêneias } \\
\text { Foermadoras }\end{array}$} & \multirow[b]{2}{*}{$\begin{array}{c}\text { Municipios } \\
\text { Adesidos }\end{array}$} & \multirow[b]{2}{*}{ ATP } & \multirow[b]{2}{*}{ PF } & \multirow[b]{2}{*}{ TR } & \multicolumn{4}{|c|}{ Cursistas } \\
\hline & & & & & & & Inseritos & $\begin{array}{c}\text { Promotio } \\
\text { n }\end{array}$ & Dropouts & Retention \\
\hline \multirow{2}{*}{ Plote } & MT & 11 & 118 & 1 & 66 & 117 & 1,170 & 1.120 & & 0 \\
\hline & MS & 2 & 28 & 1 & 12 & 33 & 203 & 203 & & 0 \\
\hline \multicolumn{2}{|c|}{ SUBTOTAL } & 13 & 146 & 2 & 78 & 150 & 1,373 & 1,323 & 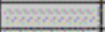 & 0 \\
\hline \multirow{8}{*}{ Ginpol } & $A C$ & 8 & 23 & 2 & 78 & 153 & 1,845 & 1.634 & 174 & 37 \\
\hline & $C E$ & 30 & 74 & 2 & 180 & 332 & 3.575 & 3.013 & 419 & 143 \\
\hline & $\mathrm{GO}$ & 16 & 156 & 2 & 102 & 219 & 2,244 & 1.853 & 346 & 45 \\
\hline & $\mathrm{PB}$ & 17 & 102 & 1 & 108 & 149 & 1.537 & 1,358 & 148 & 31 \\
\hline & PE & 21 & 106 & 2 & 126 & 186 & 1.844 & 1.712 & 95 & 37 \\
\hline & PI & 19 & 76 & 2 & 120 & 240 & 2.414 & 2.179 & 163 & 72 \\
\hline & $\mathrm{RO}$ & 9 & 34 & 1 & 60 & 122 & 1.297 & 1.109 & 136 & 52 \\
\hline & $\overline{\mathrm{SE}}$ & 8 & 52 & 1 & 54 & 146 & 1,522 & 1,398 & 94 & 30 \\
\hline \multicolumn{2}{|c|}{ SUBTOTAL. } & 128 & 623. & 13 & 828 & 1,547 & 16,278 & 14.256 & 1,575 & 447 \\
\hline \multirow{5}{*}{ Gropoll } & $A L$ & 5 & 35 & 1 & 36 & 60 & 678 & 615 & 49 & 14 \\
\hline & $\overline{A M}$ & 6 & 25 & 2 & 42 & 131 & 1.274 & 1.003 & 195 & 76 \\
\hline & $\mathrm{BA}$ & 30 & 174 & 2 & 186 & 422 & 4,435 & 3.627 & 631 & 177 \\
\hline & $\overline{\mathrm{MA}}$ & 12 & 50 & 1 & 78 & 207 & 2.431 & 1,935 & 423 & 73 \\
\hline & TO & 15 & 54 & 1 & 90 & 79 & 903 & 660 & 216 & 27 \\
\hline \multicolumn{2}{|c|}{ SUBTOTAL } & 68 & 338 & 7 & 432 & 899 & 9,721 & 7,840 & 1,514 & 367 \\
\hline \multirow[t]{2}{*}{ TOTAL } & & 209 & 1.107 & 22 & 1,338 & 2,596 & 27,372 & 23,419 & 3,088 & 815 \\
\hline & & & & & & & & $85.6 \%$ & $11.3 \%$ & 3.09 \\
\hline
\end{tabular}

This includes dropouts, teachers who were dismissed, and those who have died.

\section{Changes in Classroom Practice}

Results of a final survey conducted with about 2000 participants, showed that 99.4 percent of teacher-trainees felt that their teaching practices had improved after they joined Proformação. Ninety-seven percent of tutors and 99 percent of teacher-trainees also agreed this to be true. Changes in class planning, teaching methods, classroom management, and in teacher-trainees' attitudes towards their students, were also positively registered.

Nine-night percent of trainees agreed that their ability to plan classes has improved because of the program, and 98.8 percent believe that their classes are now more interesting for their students. Ninety-seven percent of teacher-trainees' surveyed reported that all students are capable of learning; 98.5 percent are allowing their students to participate more in class; and 83 percent reported that they are more sensitive and responsive to students' individual characteristics, differences, and needs.

These results are consistent with the results of case studies of this program, which revealed significant changes in the teacher-trainees' teaching practice in the classroom. Positive changes include: use of refined teaching strategies, methodology, and resources; use of games, reasoning activities, and concrete activities use to teach students; more emphasis placed on student participation; consideration of differing levels of student development; using student's previous knowledge in the educational setting; and overall positive changes in teacher-trainee's attitudes towards their students. "Besides creating a cozy learning environment, with several stimuli to learning, they develop diversified activities, promote student participation and keep the classroom with environment with mutual respect and trust” (André, 2002, pg. 19).

A field note entry by one researcher illustrates well the teacher-trainees' work in the classroom:

It is worthwhile to emphasize a math class observed on 06/11. According to the teacher, it was based on Proformação study guides. The class, divided into three groups of four students each (one was absent today), was to follow this plan: starting from some calculations showed by the teacher, each group should write 
math quizzes that would be exchanged among the groups. Each group would solve the quizzes from another group. The teacher asked them to think about everyday situations (Diário de Campo de Teolândia, BA; André, 2002, p.19).

Most teacher-trainees talked positively about the changes they adopted in planning and classroom practice:

Before, I used to make a daily class plan back to front: first I would deliver the class, then I would register it. . . Only when I came to Proformação, I learned how to make and use a class plan. I became more independent, more autonomous, more confident (Teacher Trainee, Teolândia, BA; André, 2002, p.12).

Proformação is very rich and helps a lot teachers in the classroom . . . Before, the teacher used to come to the classroom and dictate content, only dictate content, content without explanation. Nowadays, the teacher comes to the classroom, explains everything he is going to do, and goes about developing the class activities. It became easier for students to understand and learn the content (PC, Cacimba Velha, CE; André, 2002, p.12).

Results of classroom observation also points out Proformação's effects on classroom environment and class management strategies. These results indicate that the organization of the classroom to create an exciting learning environment is something all teacher-trainees are concerned about. Classrooms are decorated with posters and students' work, and teacher-trainees are more active in promoting group work and other activities, strengthening integration and collective work among students. "Besides using learning motivation materials, valuing students work and the place they live, the trainees organize the (classroom) space in a variety of ways to address the students' needs, in multi-grade classes” (André, 2002, p.17).

Results of these and other interview s with teacher-trainees reinforce our findings: "In all interviews, one can note the teacher awareness about his/ her changes and the concern (desire) of trying to transfer to the classroom what they have learned participating in Proformação "(André, 2002, p.12)

It must be noted, however, that changes in content knowledge appear to be less apparent. In two classrooms, the tutor observed that the teacher-trainees had difficulties with written language and math content. "The explanation may be that those teachers were educated by practicing. Since they are isolated in rural areas, they have some practices that require more time to change. Two years is too little to accomplish some more dramatic changes, such as content knowledge. This fact make us to stress the importance of continuing to foster this network of supervision and support of trainee teachers” (Andre, 2002, p. 32).

\section{Teacher Professional Development and Self-Esteem}

Survey results show that after participation in the program, 98 percent of teacher trainees reported that they perceive they are more valued by their school and communities, and 99.3 percent agreed that they had grown considerably within their profession. Tutors and teacher-trainees also indicated that the program contributed to an increase in self-esteem, in that they feel more valued professionally, which in turn has elevated their overall participation in their schools and 
classrooms. As such, teacher-trainees indicated they felt more respected in their school and local community.

Additionally, the results of case studies show that Proformação has created situations that foster teacher trainees' professional identity. Proformação appears to have given more consistency in their chosen career as educators. To many, participating in the program represented the realization of their dream of being a teacher (André, 2002).

With Proformação, I fulfilled a dream. One thing I [a teacher without certification] wanted most was not to be called "leiga teacher" . . I will finish Proformação and want to pursue pedagogy [a higher education course on education theories and teaching/learning methodologies]....

These results indicate that principal objective of Proformação - to raise teachers' professional value - has been achieved. "We can say that Proformação has contributed to the conquering of citizenship by these educators, who are now publicly acknowledged as qualified to exercise the profession. Besides legitimizing their rights, this certification gives them the feeling of being part of a group (André, 2002).

My life was transformed after Proformação. I learned much more, I learned to be more expansive, more patient, kinder with the kids. My life has really been transformed. Now I am truly a teacher. I can say I am truly a teacher after [completing] Proformação. (PC, Rio Branco, AC; André, 2002, p.13).

\section{Participation in the School and Community}

After completing the program, 99 percent of teacher trainees surveyed agreed that they had increased their participation in their schools. Analysis of case studies results showed that teacher trainees changed their attitude toward school meetings. They are more confident in participating and expressing their opinion about the school pedagogic plan and other school related activities. "Many of them began to feel they had rights after Proformação. Nowadays the trainees feel they have the right to express their opinions, to be on an equal footing as others in planning meetings or in a public activity” (Diario de Campo de Quixadá, CE: André, 2002, p. 13).

Nine-six percent of teacher trainees surveyed agreed in that it is easier to participate in their communities. High levels of participation were evident in the teacher-trainees' research projects, which addressed local issues, such as family violence; environmental problems; medical herbs found in their region, local culture, etc. These research projects involved not only the teachertrainees, but also their students, schools, and local communities. They also reported organizing cultural or scientific events with the participation of the local community and, in some cases, with local authorities.

\section{Program Operational Structure}

The majority of participants agreed that Proformação is a distance learning system that works well (98.3 percent of teachers trainees; 97 percent of tutors; and 100 percent of local managers). The fact that most tutors (95 percent), training teachers (100 percent), and local managers (100 percent) indicated that Proformação's monitoring system was "good," may indicate the main factor that helps explain the high-level of performance of teacher-trainees, many of which work 
in such disadvantaged situations (e.g., having few years of formal education). The majority of teacher-trainees (95.4 percent) reported they are "well guided to work with program's contents, and feel free to ask questions during the activities" (92 percent).

Although simple and apparently adequate in most cases, Proformação's infrastructure does vary among states. Survey results show that the place and conditions where face-to-face activities are conducted, are considered adequate (88.8 percent); as well as the location and conditions where biweekly meetings are held (87.6 percent). When asked these questions, participants in the State of Acre reported the lowest agreement rates: 81.6 percent and 80.7 percent, respectively; whereas the State of Permambuco reported the highest agreement rates: 94.6 percent and 93.1 percent.

These results indicate that more than 95 percent of participants surveyed in all States agreed that the teacher-trainees performed well. Eighty-four percent of teacher trainees surveyed reported that pedagogical support offered by telephone by the Training Agency is working well. This finding, however, was not evenly spread in that some States appeared to have more difficulties in this respect than others. For example, in Acre 7.6 percent and in Pernambuco 14 percent of teacher trainees did not agree that these services were functioning well.

In terms of tutor performance, the results of the evaluation were generally positive. The great majority of trainees (95 percent), in all States, agreed that their tutors fulfilled their specific roles in terms of following up and supervising their pedagogical practice, conducting biweekly meetings, clarifying doubts, providing guidance during individual studies, and encouraging teacher-trainees to study and apply new learning to their classroom practice.

Because the tutors' role is extremely important in Proformação pedagogical model, these results are extremely important. Indeed, when it is considered that teacher-trainees teach different grade levels, and yet the majority have not even completed basic education themselves, the role of the tutor in Proformação becomes truly central to the program's overall success. The presence and ongoing coaching and mentoring of individual tutors can and do influence teacher-trainees' motivation in the classroom in study, adoption and use of appropriate pedagogical methods (Placco, 2002, p.31).

\section{Partnership among Federal, State, and Municipal Governments}

Data gathered to analyze the partnerships with municipalities revealed that this is one area of apparent weakness, which deserves closer attention. Eighty-one percent of trainees agreed that they have received support from their municipality. However, when questioned on if they received support at the State level, the rates of agreement varied widely. The States of Acre and Goiás, reported the lowest agreement rates: 59.7 percent and 75.9 percent, respectively. In Ceará and Pernambuco, the highest agreement rates were reported: 87.4 percent and 92.3 percent, respectively.

When asked about the face-to-face sessions, the teacher-trainees' surveyed revealed weak points: lack of transportation (23 percent), and inadequate food (14.9 percent).

Of those surveyed, 89 percent of tutors reported that their salary was paid by their local municipality. Nevertheless, 44 percent of those same tutors surveyed indicated they did not have funding for transportation necessary to travel to the teacher-trainees' schools. Because these rates 
Bof Distance Learning for Teacher Training in Brazil

varied widely from State to States, such findings suggest uneven support for the program at the Municipal level.

One factor that explains, disparate levels of support, is that municipal elections were held at the end of 2000. These elections resulted in many changes taking place at the Municipal level. As such, the National Coordination Unit, as well as the State Management Team, and technical assessor developed a common strategy to offset the consequent threat of program discontinuity caused by changes in Municipal governments.

When comparing the fist and second rounds of data collection over the life of the program, however, findings revealed an improvement in the support of Municipalities. Tutors' salaries were usually paid on time, and needless duplication of work was eliminated (e.g., from municipal secretariats of education and from Proformação). Such improvements are likely due to the way Proformação works: on one hand, efforts are being made to integrate the administrative activities of Municipal, State, and Federal governments; on the other hand, implementation agents, such as the National Coordination Unit and Training Agencies, have also made tremendous efforts to resolve problems during program implementation. In sum, the effort and personal commitment of all parties involved to talk, share information, and coordinate activities, have been important ingredients in the program's success (André, 2002).

\section{Program Quality}

Proformação is viewed as a high quality teacher training-program by most participants: teachertrainees (99 percent), tutors (98 percent) and local managers (100 percent). Those surveyed viewed the program as not being overly theoretical and contributing to increased quality of classroom teaching. It was considered by 88.8 percent of training-teachers and tutors surveyed, as equal to traditional (face-to-face) teacher-training programs. Only 4.3 percent disagreed with this view, and seven percent offered null responses. Ninety-eight percent of respondents agreed that teacher-trainees received quality certification training through Proformação.

\section{Lessons Learned}

The novelty, size, and decentralized operational structure of Proformação imposed some challenges on the implementation team. When difficulties arose, corrective actions had to be taken. As such, several important lessons were learned, all of which should be taken into consideration when undertaking similar programs. Some of these "lessons learned" are presented below:

Having a detailed implementation plan in advance is crucial to a successful implementation. Moreover, all participants must have adequate training from the outset, allowing them to participate satisfactorily in the program. No implementation can be successful without providing clear information to all program participants about what they are supposed to do and how they can do it. After evaluating the results of the pilot study, the need for careful preparation and training of State Management Teams, technical assessors, Training Agency teams, and the tutors, was evident. Thus, a training program was established and specific implementation support guides were developed to guarantee that information could be readily available to all implementation agents. As reported by participants later, having well-defined training and materials was essential to successful implementation. Additionally, ongoing support was available to all participants, so that problems could be resolved as needed, at any time. 
Having enough time to conduct both planning and training can prevent subsequent difficulties during implementation. Proformação, however, was implemented in an extremely tight timeframe. The experience gained, however, reveals that it takes time to plan all the details of an implementation strategy, and it takes time to prepare those who are charged with implementing it. In sum, these aspects must be considered fully, to avoid difficulties during the implementation process.

Having instruction materials ready prior to implementation is strongly recommended. Revision of Proformação instructional materials, for instance, was carried out during the implementation process. This situation resulted in serious delays, especially during the beginning-phase of the program. The suggested solution is to develop a contingency plan, wherein teacher-trainees are engaged in face-face sessions with their tutors, until the arrival of (revised) print-based materials arrive. This experience showed that in distance learning courses, it is crucial to guarantee that materials are ready prior to beginning the course. However, if there is any doubt about whether material will be available on time, the contingency plan described above is strongly recommended.

The establishment of an effective partnership among institutions and governments is likewise recommended. It is essential, however, to have a well-defined legal arrangement to ensure each partner knows their respective areas of responsibility and parameters for fulfillment of such legal responsibilities. Moreover, it is most advisable to avoid, if possible, electoral periods and changes in local governments. A main problem in the implementation of Proformação, for example, arose when some newly elected municipal governments did not abide by the agreement signed by the previous government. To deal with this problem, the Local Management Team and technical assessors visited several municipalities to explain their position. Unfortunately, in some cases, the National Coordination Unit had no choice but to engage Brazil's legal system to enforce the agreement. Our experience was that undesired situation took place after the municipal elections were held, or in the middle of program implementation. In sum, several changes occurred in several municipal administrations, which in turn created problems for the continuity of the program. In all cases, having a legal instrument to support the agreement was essential, allowing even for judicial actions.

An integrated information system is crucial for the management, monitoring, and evaluation of a program such as Proformação, but like other elements of the program, it also takes time and effort to make it functional to support the program's specific information and communication needs. Proformação developed an information system to collect management data and monitor varying levels of program results and activities. Our experience was that it took more time to implement a functional system at the local level than we had originally anticipated, particularly if participants are not computer literate. Training strategies must therefore be well thought-out in advance to help individual Training Agencies resolve computer literacy problems as they arise.

It is possible to organize an effective decentralized distance learning system. Proformação represents a different way of organizing a system to deliver education at a distance. By establishing a highly structured system, engaging local partners by investing in their training and continuous motivation, and having a good support and monitoring system, it shows that it is possible to provide good training opportunities to those who live isolated or in rural areas.

Monitoring and evaluation mechanisms at all levels are fundamental for quality control. The Proformação experience shows that the success of the program is largely due to the existence of 
monitoring and evaluation mechanisms and instruments that allowed implementation agents to identify problems and propose solutions in a flexible and fluid manner.

Efficient communication channels are also important to program Implementation. In distance learning programs such as Proformação, with so many partners and participants involved, the establishment of an efficient communication system is essential to success. Such as system is not only needed to send and receive relevant information, it also provides the mechanism through which all involved can be proactively motivated - especially those who need to feel they are not alone in the process.

\section{References}

André, M. (2002). Relatório de Avaliação Externa do Proformação: Estudo de Casos. Brasília: SEED - MEC.

Gatti, B. (2002). Relatório de Avaliação Externa do Proformação: Pesquisa de Opinião. Brasília: SEED - MEC.

Guia Geral do Proformação (2000). Brasília: MEC.FUNDESCOLA.

Manual de Operacionalização do Proformação (2000). Brasília: MEC.FUNDESCOLA.

Moore, M (2001). Brazil's Proformação. 20th World Conference on Open Learning and Distance Education, Düsseldorf, Germany.

Placco, V. (2002). Relatório de Avaliação Externa do Proformação: EntrevisTraining Agencies. Brasília: SEED - MEC.

Relatório (2000). Proformação. SEED - Ministério da Educação.

\section{Endnotes}

1. External Evaluation team: Prof. Dra. Bernardete Gatti (Carlos Chagas Foundation/Catholic University (PUC) -SP); Prof. Dra. Vera Placco (Catholic University (PUC) -SP), and Prof. Dra. Marly André (University of São Paulo/ Catholic University (PUC) -SP).

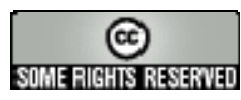


April - 2004

\title{
Tutoring Large Numbers: An unmet challenge
}

\author{
Helen Lentell and Jennifer O’Rourke \\ Commonwealth of Learning
}

Open and distance learning (ODL) is increasingly being regarded as a viable policy option for developing countries with limited educational resources for buildings, books and trained teachers, seeking to increase accessibility for large numbers of learners in education and training opportunities. Advocates of ODL as an appropriate solution to development issues tend to emphasise the hardware and software (curricula, materials and media of instruction and delivery, and especially ICTs) rather than the learning support needed (See, for example, World Bank, 2002).

In one sense this should not be surprising. As Lentell has noted, tutoring has never been at the forefront of mainstream writing on distance education, at least not until fairly recently (Lentell, 2003). However, whilst tutoring might not be central to the writing about ODL in the north, the practice is somewhat different. Tutoring tends to be the less visible element of ODL, but it is no less essential than good materials and effective administration. Distance education cannot exist without tutors who provide feedback and guidance to students. This point is well demonstrated by, for example, the array of institutional handbooks on tutoring produced by distance education universities. In practice, established distance education providers typically invest considerably in tutoring and other forms of learner support (Rumble, 1997). Moreover, and certainly among learner support professionals, there is an implicit "preferred" model. This model assumes a relatively low student-to-tutor ratio, with the tutor offering proactive individual guidance and feedback. Such a model, however, is not easily transferable to a situation where the reasons for adopting distance education are limited numbers of teachers and limited access to educational provision.

This situation suggests the need to research viable alternative learner support models developed to provide ongoing support and feedback to large groups of learners in proportion to limited numbers of tutors. This research is needed because:

1. Policy planners tend to be silent on tutoring and learner support where there are few teachers and limited resources

2. Models of tutoring and learner support based on low student-to-tutor ratios are not easily transferable to situations where there are limited educational resources

There are many unanswered questions about how best to achieve effective ODL provision when there are large numbers of learners in proportion to quite small numbers of qualified and trained tutors and/or educational counselors. Without a sustained examination of how to provide quality learner support in these situations, these ODL programmes risk high attrition rates and lost opportunities both for learners and their societies. 
This paper presents a research agenda, rather than research findings on learner-support in situations where tutor-student ratios are high. We argue that there is a need to rethink some underlying assumptions about tutoring that are implicit in many established models of ODL that assume relatively small tutor-to-student ratios. Because it is unrealistic to assume that there will be small student-to-tutor ratios in many contexts, especially in the developing world, we suggest the need to research viable alternative learner support models that will provide ongoing support and feedback to large groups of learners. If ODL cannot meet the needs of large cohorts of learners, then it is in danger of becoming yet another exported Western approach that consumes large amounts of resource at the initiation stage, yet fails to be sustainable in the long-run.

\section{Background}

Most models of open and distance learning that have evolved over the past three decades have assumed consistent and personal interaction between learners and a tutor. This interaction provides motivation, guidance, feedback, assessment, and support for learners. But the frequency and level of interaction assumed by this model is feasible only if there is a manageable group of learners assigned to each tutor. Definitions of "manageable" vary among providers, but the guiding principle is usually stated in terms of response times: for example, that tutors should be able to provide feedback to learners within 10 days to two weeks of receiving their assignment. Online tuition has changed expectations for a response to two or three days.

The concept of personalised tutoring evolved out of two parallel approaches that the UK Open University adopted and adapted for open and distance learning. One is based on the Oxbridge concept of the tutorial in which a tutor with subject expertise meets with a small number of students and comments on each individual learner's work (Mills, 1999). The other is the concept of a counsellor, who "would not necessarily have expert knowledge of every specific element of the course, but would be concerned with the educational process in which the student was engaged” (Sewart, n.d.). In other words, while the tutor was mostly focused on the learner's grasp of the subject, the counsellor was most concerned about developing the learner's skills in learning. Currently, tutors handle both roles in many open and distance learning programmes. However, the concept of a counsellor who is not a subject expert offers potential models and methods for supporting large numbers of distance learners. We will return to this idea later in the article.

More recent developments in e-learning assume a greater level of interaction among learners, and more frequent and timely interaction between learners and a tutor than in print-based courses. Because this type of learning requires much more input from tutors than previous forms of distance education, reports on e-learning experience often indicate a ratio of no more 20 to 30 learners per tutor (Conrad, 2002; Mason, 1999; Goodfellow, 1999). E-learning has been typically used in graduate programmes or in specialised fields which benefit from collaborative learning. The tutor's role includes moderating online discussions, facilitating group learning, problem solving, and guidance. However, there have not yet been practical proposals concerning "scaling up" e-learning so that it can manage even current learner-tutor ratios handled by conventional distance learning, much less the usually large learner numbers facing open and distance learning providers in many parts of Africa and Asia.

In the past few decades, proponents of distance education have made great efforts to counteract the lingering image of correspondence schools that enrolled huge numbers, but provided minimal or no support and offered successful outcomes to even fewer. In contrast, distance educators emphasised the "continuity of concern" (Sewart, n.d.) offered by personalised attention from 
individual tutors. The UKOU's model of distance education stressed the value of local tutorials and personal contact with a tutor, even as numbers expanded dramatically. The UKOU's own research, however, indicates that only a proportion of learners actually take up the offer of individualised help (Mason, 2003). Many learner support systems are predicated on the assumption that not everyone will use them, which means that support staff would be overwhelmed if all enrolled learners actually took advantage of all the tutorial and support services on offer. Seasoned distance educators suggest that rather than offering one-size-fits-all support, providing customised levels of support for different learners in different contexts may be more effective and efficient (Mason, 2003; Mills, 2003).

Following the success of the OU model, many other ODL providers that evolved have maintained the central importance of individualised tutoring. Research has provided evidence of the effectiveness of this approach (Gibbs and Simpson, 2002). Having made great strides in developing successful approaches to ODL predicated upon the strengths of personalised support, it is understandable that distance educators may be reluctant to reconsider one of the basic tenets of their practice.

The issue, however, is not whether or not there should be personalised tutoring in ODL, but what can be learned from the success of personalised tutoring that might inform us of the processes that may be transferable to other situations. How can the effective elements of personalised tutoring be brought into situations where there are large numbers of learners? Can we rethink new models of ODL learning support that address these situations of large numbers and limited resources without introducing a "deficit perspective" - i.e., that these alternatives are second best. What are the strengths of these approaches with large student numbers that can be used to create alternative models of supportive learning situations?

Rather than start from the judgmental position that there should not be large numbers of learners per tutor in ODL systems, we will expand the discussion to consider how to address the reality of large numbers. A distance methodology has to accommodate large numbers if it is to be of any practical value in most educational and training contexts in Africa, Asia, and the Caribbean. Moreover, providing support to large numbers of learners is not just a fact of life in large, single mode distance education institutions, but on many programmes offered by traditional face-to-face institutions and non-governmental organizations: for example, programmes for pupils in secondary schools, training teachers, and healthcare workers.

When the following scenarios were presented at the Cambridge Conference in 2003, we invited colleagues from Africa, Europe, and North America to consider how to meet learners' needs appropriately. All but one of these scenarios were drawn from ODL situations with large numbers of learners; the non-ODL example was about the possibility of ODL methodology enabling teachers to manage large classes in conventional settings. Some scenarios were drawn from technology-rich contexts and some in situations where resources are limited. A summary of each scenario is provided below; readers can click on the title to read the whole scenario and consider the questions posed.

1. Tutoring large numbers of students older than 16 years of age who were preparing for advanced school leaving exams in a conventional tertiary college in the Caribbean. See Appendix $\underline{1 .}$

2. Strengthening tutor support at a local study centre that serves students enrolled at a new open university in Africa. See Appendix 2. 
3. Developing tutor support systems for a Care in the Community programme offered to learners living on widely dispersed small islands in the South Pacific. See Appendix 3.

4. Scaling-up tutorial support for a worldwide environmental education programme for professionals. See Appendix 4.

5. Adopting a more effective tutorial strategy for learners in an unpaced programme leading to a law degree. See appendix 5.

6. Developing a more efficient tutorial approach for participants preparing for accountancy accreditation. See Appendix 6.

7. Planning appropriate support and assessment for infection control training for medical staff. See Appendix 7.

8. Strengthening support for a work-based skills training programme in the leather industry. See Appendix 8.

Although participants found the issues challenging, they recognized the scenarios as remarkably similar to the real issues they face daily as distance educators. Their proposed strategies included:

- Decentralising learner support so that it is as localised as possible; making use of local resources such as experienced teachers or healthcare professionals, who could be mentors or resource people for learners

- Helping learner groups to become self-sustaining, by providing resource materials and guides for group study

- Developing self-assessment tools for groups of learners

- $\quad$ Supporting discussions (online or face-to-face) that build communities of practice

- Enabling collaboration among professionals

Participants also agreed that learner support is essential for most learners, and it can be fostered in different ways:

- $\quad$ Supporting self-directed learner groups

- Supporting local people who can provide mentoring

- linking learning and the workplace so that learners can apply their learning in practice, with the guidance of more experienced staff

\section{Supporting Social Learning}

One of the prevailing perspectives on learning in many Western educational institutions is that learning is regarded as a personal acquisition achieved through individual effort, to obtain personal qualifications and recognition. Individualised tutoring is consistent with this perspective. This dominant model in education is not necessarily representative of the many cultures within western societies, and it is not necessarily appropriate for non-western societies either. North 
American aboriginal learners, for example, typically value a more collective approach (Spronk, 1995). Facey (2001) comments:

Although generalisations are necessarily limited, there is a wealth of evidence in anthropology to show that peoples whose societies forefront kinship relationships do have a more group - than individual - oriented identity ... This means in practice that the student weighs his or her community's needs - for example, needing certain categories of native workers such as nurses, foresters or social workers - alongside his or her personal interests in taking certain programs or training. Similarly, personal educational priorities appear to be always subjugated to family priorities, matters such as illness or a funeral taking precedence over attending class, meeting an assignment deadline, and so forth.

There may be room to develop alternative models for providing learner support that recognise and build on the strength of the learners' social context, particularly in contexts where learning is regarded as a social activity, achieved through collaboration, which benefits society as much as it benefits the individual. If social models of learner support were developed as valid in their own right, rather than as low-cost or high-volume alternatives to the individual support model, open and distance learning practice could become much more responsive to the needs of learners in a broad range of situations. Rather than serving as a pro-tem answer to a critical shortage of educated people, to be replaced with better alternatives when the crisis abates, ODL could become the best option for responsive education.

Here are two examples of support that may address the needs of larger groups of learners, but there are many more possibilities:

\section{Self-Directed Study Groups}

Chadibe (2002) describes how participation in self-directed study groups enables South African learners to make better use of distance courses and tutorials:

. . . study groups are set up, usually by learners themselves, in conjunction with tutorials, so that tutorials enable study groups and also keep them on track. . . The reasons respondents gave for participating in a study group are themselves examples of the development of 'learner autonomy' among them: “. . . a study group gives one more insight and enables you to participate. What you have discussed in a group once, you will never forget. If you agree to come to the group knowing something about the chapter you agreed to prepare for that meeting you are forced to do so. It is usually unacceptable if you keep coming up with apologies caused by lack of prior preparations. It benefits us, as we know that each one of us has to prepare before hand. It also encourages us to study hard. We build confidence in each other; even introverts become extroverts because each one is given a chance to say something. Each one chooses the chapter she wishes to prepare for the next study group meeting; especially a chapter she wants to understand better (Chadibe, 2002, www.col.org).

Chadibe points out that, given the value of these groups, there should be more support provided for them, especially from local and regional study centres. She also recommends that providers with limited resources should concentrate on providing tutorial support for first-year learners. 
... there is a need for the learning centre to advise the new learners thoroughly so that they can begin their studies by taking the courses that usually have tutorials their first year and then proceed to the less popular courses in their second year of studying. This would be in keeping with the principle of incremental 'enskilling' the learner in the first year with, for example, study skills, development of reading and writing skills, and participation in collaborative or peer group studying. This would empower the learners to develop into critical and independent learners (Chadibe, 2002, www.col.org).

Bertram's research on self-directed study groups examines how learning takes place within them, and observes that learners "are adopting a communal approach to learning" by sharing responsibility for reading and explaining the course materials. Groups with limited university experience had difficulties in going beyond surface learning approaches and in developing individual learning skills, although the groups provided a great deal of motivation and continuity. Provisions to develop generic academic skills in writing, developing a thesis, and so on, could complement the affective support offered by self-directed study groups (Bertram, 2003).

\section{Reviving the Concept of Learner-Counsellors}

Reviving the concept of the counsellor might also help to address the needs of large numbers of learners. As Beevers, the UKOU's first Director of Studies observed: “Adult education experience suggests that at least 50 per cent of a given student's needs are not strictly related to the subject at hand. That is not to say that his needs are solely psychological and unconnected with the content of study; the help s/he needs is of an educational kind, even of an academic kind, but not strictly subject-based" (as quoted in Sewart, n.d.). Sewart expands on this idea: "The counsellor . . . would be concerned with the educational process in which the student was engaged. Conceived of in this fashion, the counsellor was much more likely be available on a local basis" (Sewart, n.d.). Some recent ODL programmes build in a role for a mentor, especially in workplace and professional programs (Leach, 1999). There is potential to expand and define other roles for local support people who can help learners build confidence, enhance their learning skills, and maintain a commitment to their studies. As Beevers and Sewart point out, this kind of support does not necessarily require subject-matter expertise, so it should be possible to make it available on a local or community basis (Seward, n.d.).

\section{Managing Expanded Learner Support}

Implementing effective learning support is also a management challenge. One large distance education provider, China Central Radio and TV University (CCRTVU), which has served millions of learners since 1979, is now moving into a multi-tier system for strengthening provision of learner support ( $\mathrm{Li}$ Yawan and $\mathrm{Li}$ Linshu, 2003). In addition to its existing cooperative arrangements with provincial universities, branch schools, and local teaching centres, CCRTVU is in the process of establishing a national public support system platform, providing online access to learning resources, individual experts, and support for study groups. It is expected that within three years, 1000 study centers will be established that can be used for learner support by any distance education providers. This initiative is a response to an identified need for strengthened support for distance learners. 


\section{Conclusion}

In writing this article, the authors have tried to take into account the real context for ODL in many parts of Africa, Asia, and the Caribbean, but it is inevitably framed by our underpinning assumptions about tutoring in ODL. We hope that educators who serve large numbers of learners will enter into the discussion and share their insights and perspectives in IRRODL.

At this stage, we have more questions than answers. However, we think it is worth posing questions about our oftentimes 'unexamined' assumptions, even those cherished beliefs on the role of tutors in learner support. Asking such questions is an important step, given that there has been a reluctance to ask: "How can we tutor large numbers?" This reluctance is rooted in a dominant viewpoint that distance education must have tutors to provide personal attention to relatively small groups of learners. We know there are many ways of learning and many ways of supporting learning in both conventional and distance settings. Perhaps it is time to ask ourselves: Is the precept about individualized tutor support for small numbers yet another example of a Western world approach dictating 'the right way' to do something, despite its impracticality for the majority world? We suggest it is time to start researching other models and methods of providing learner support in situations of large student numbers. We believe that ignoring this issue will lead to the failure of ODL to deliver on its promise: increasing accessibility for large numbers of learners to education and training opportunities.

\section{References}

Bertram, C. (2003). Exploring informal student study groups. In A. Tait and R. Mills (Eds.) Rethinking Learner Support in Distance Education: Change and Continuity in an International Context. London: Routledge.

Centre for Advanced Learning Technologies (n.d.). Centre for Advance Learning Technologies website. Retrieved November 23, 2003 from: http://csalt.lancs.ac.uk/jisc/advice.htm

Chadibe, I. A. (2002). Case Study Examining The Extent To Which Urban And Semi-Rural Learning Centres Are Used As Support Systems For Distance Education Learners. UNISA, Pretoria. Retrieved November 23,2003 from: www.col.org

Conrad, D. (2002). Deep in the hearts of learners: Insights into the nature of online community, Journal of Distance Education, 17(1). Retrieved November 23, 2003 from: http://cade.athabascau.ca/vol17.1/conrad.html

Corry, N., and Lelliot, T. (2003). Supporting the Masses? Learner Perceptions Of A South African ODL Programme. In A. Tait and R. Mills (Eds.) Rethinking Learner Support in Distance Education: Change and continuity in an international context. London: Routledge.

Facey, E. (2001). First Nations and Education by Internet: The Path Forward or Back? Journal of Distance Education, 16(1). Retrieved November 23, 2003 from: http://cade.athabascau.ca/vol16.1/facey.html

Gibbs, G., and Simpson, C. (2002). How Assessment Influences Student Learning: A conceptual overview. SSRG, 42/2002, Student Support Research Group, Centre for Higher 
Education Practice, Open University UK. Retrieved November 23, 2003 from: http://cehep.open.ac.uk/cehep/ssrg/projects/index.htm

Gibbs, G. (2002). Evaluating the impact of formative assessment on student learning behaviour. Paper presented at European Association for Learning and Instruction Assessment Conference, Newcastle, August.

Goodfellow, R. (1999). Expert, Assessor, Co-Learner: conflicting roles and expanding workload for the online teacher. CAL99. Retrieved November 23, 2003 from: http://wwwiet.open.ac.uk/pp/ r.goodfellow/CAL99/cal99.html

Higgison, C. A., and Harris, R. A. (2002). Online Tutoring. The OTIS Experience: a JISC guide for online tutors. New York: TechLearn. Retrieved November 2003 from: www.techlearn.ac.uk/NewDocs/Higgison\%20D3.doc

Leach, J. (1999). Learning in Practice: Support for Professional Development. In A. Tait and R. Mills, (Eds.) Supporting the Learning in Open and Distance Learning. New York: Routledge.

Lentell, H. (2003). The Importance of the Tutor. In A. Tait and R. Mills, (Eds.) Open and Distance Learning in Rethinking Learner Support in Distance Education: Change and continuity in an international context. Routledge: London.

Li, Yawan, and Li, Linshu (2003). Construct Learning Support System for Distance Education in China. Paper presented at 10th Cambridge International Conference on Open and Distance Learning. September. Madingley Hall, Cambridge, UK.

Mason, R. (1999). IET's Masters in Open and Distance Education: What have we learned? Retrieved November 23, 2003 from: http://iet.open.ac.uk/pp/r.d.mason/MAEval.PDF

Mason, R., and Weller, M. (2000). Factors Affecting Students' Satisfaction on a Web course. Australian Journal of Educational Technology, 16(2). Retrieved November 23, 2003 from: http://www.ascilite.org.au/ajet/ajet16/mason.html

Mason, R. (2003). Online learning and supporting students: new possibilities. In A. Tait and R. Mills (Eds.) Rethinking Learner Support in Distance Education: Change and Continuity in an International Context. London: Routledge.

Mills, R. (1999). Diversity, convergence, and the evolution of student support in higher education in the UK. In A. Tait and R. Mills (Eds.) The Convergence of Distance and Conventional Education: Patterns of Flexibility for the Individual Learner. New York: Routledge.

Nonyongo, E. (2003). Changing Entrenched Learner Support Systems. In A. Tait and R. Mills (Eds.) Rethinking Learner Support in Distance Education, Change and Continuity in an International Context. London: Routledge.

Rumble, G. (1997). The Costs and Economics of Open and Distance Education. London: Kogan Page. 
SAIDE, (1998) Supporting Distance Learners: A Tutor's Guide. Capetown, SA: Francolin.

Sewart, D. (n.d). Continuity of Concern for Students in a System of Learning at a Distance. Mimeo Document. Open University UK.

Spronk, B. (1995). Appropriate Learning Technologies: Aboriginal learners, needs, and practices. In J. Roberts and E. Keough. Why the Information Highway: Lessons from Open and Distance Learning. Toronto: Trifolium.

Student Support Research Group (2002). Student Vulnerability and Retention Project: Interim Evaluation Report. Retrieved November 23, 2003 from: http://cehep.open.ac.uk/cehep/ ssrg/projects/index.htm

Student Support Research Group (2003). The financial case for a comprehensive proactive regionally based student support system. SSRG 802003. Retrieved November 23, 2003 from: http://cehep.open.ac.uk/cehep/ssrg/projects/index.htm

Tait, A. (1996). Conversation and Community. In R. Mills and A. Tait (Eds.) Supporting the Learner in Open and Distance Learning. London: Pitman Publishing.

Tait, A. (2000). Planning Student Support for Open and Distance Learning , Open Learning, 15(3) $287-299$.

World Bank (2002). Enhancing Learning Opportunities in Africa: Distance education and information and communication technologies for learning. Retrieved November 23, 2003 from: http://www-wds.worldbank.org/ servlet/WDSContentServer/WDSP/IB/2002/05 /14/000094946 02043004023268/Rendered/PDF/multi0page.pdf

\section{WORKSHOPS: Tutoring in large numbers in ODL}

\section{Appendix 1}

\section{Scenario 1: Community College in the Caribbean}

You are a lecturer in a community college in "Juan" in the Caribbean. Your college is the only public provider on Juan of advanced study that enables students to obtain the qualifications for university entrance. The Caribbean Governments' have set a target to increase the numbers of appropriately qualified applicants for university and ODL has been seen as a strategy that can significantly help achieve this target.

Your college has in the last three years stopped teaching UK syllabuses and has adopted the Caribbean Examinations Council (CXC) Advance Proficiency Examinations. This was a major challenge for staff at the college and in truth has not been universally popular. CXC has developed ODL (paper based) self study materials in a number of subjects as a pilot. Your college is also a pilot college, and your subject is one of the pilot subjects. This means at least for the forthcoming academic year all students will receive these CXC materials free. Whilst your 
college has some adult education classes, the typical student studying full time is in the 16 to 18 year range.

You do not know much about ODL, but you are very keen to help your students. A typical class of yours starts out at the beginning of the academic year with over 100 students on the register. Although you hate this - you have to admit that you are pleased that drop-out is large, because you cannot support these large numbers and because there is a wide ability range. The college has classrooms, which with a tight squeeze can accommodate these large numbers - but not all learners will have a seat. There is little in the way of reliable audio-visual equipment in the college and even for that you have to book it so far in advance that it is frequently more trouble than it is worth. All classrooms are equipped with a blackboard and chalks. There is a college library - but it is very under equipped, but it does provide some extra study support areas, and your Principal and her Senior Management team have promised to allocate classroom space for self-study with the introduction of ODL. Although, when you did your teacher training you were introduced to other teaching methods the realities you face has pushed you into a transmission mode of teaching - i.e., you lecture. You know that frequently you are not a very stimulating lecturer and you are very troubled by the poor performance of your students in the public examinations. At the moment your classes are organized around a class contact time of 20 hours per class, and you have five hours of preparation time. These hours will not change with the introduction of ODL. But you have been given complete autonomy about how you organize your teaching within the 20 hours of class contact.

TASK: You have a month before the academic year starts. And you are planning your teaching. What are you going to do?

\section{Questions to consider:}

1. What are the most significant challenges in providing responsive tutoring support to your learners?

2. What resources are available to help you fulfil your role as a tutor, and how can you make the best use of these resources?

3. What tutoring strategies (including classroom management strategies) can you use that will enable learners to benefit from peer support and group learning?

4. How can you provide personalized feedback to each learner?

5. What assessment strategies would you use during the course, and what strategies would you recommend for end-of-course assessment of learners?

6. How will each of the tutoring and assessment strategies you have identified help learners to develop study skills and their knowledge of the subject. 


\section{Appendix 2}

\section{Scenario 2: Study Centre in West Africa}

You are a tutor for your subject at the study centre in the province of "Hope," for the Open University of Misson (OUM), a country in West Africa.

OUM is a new institution based in the capital and still developing its systems. Currently the University is organized around its study centres. There is one study centre in each provincial capital, where course materials are distributed, assignments handed in and so forth. Study materials arrive at the study centres in a big truck, which brings them from the capital where OUM head office and print shop is. Sometimes there are not sufficient copies of course materials for all the learners - but last year (your first year with the university and the first year of operation of the university) students managed by sharing and copying. But there was always uncertainty that the materials would arrive in time. The materials are produced on a batch system, approximately printing a quarter of the course at a time. This is because the university does not have sufficient capacity or warehousing to produce course materials in advance, and last year much of the material was not ready. This has meant that sometimes the materials are not available when needed by students. You are not confident that this year it will be sorted as the university still has problems with warehousing and distribution.

There are five tutors including you covering your subject at your study centre; and based on last year you can expect there to be approximately 325 students following your subject at Hope Study Centre this year. Your fellow tutors, like you, are part time, and are largely involved in OUM for the money for they cannot earn sufficient from their full time post. Like you, your fellow tutors are high school teachers, and one works in the local university. However, you suspect they, like you, have thoroughly enjoyed their first year despite all the difficulties because the learners are positive and the study centre has become quite a social venue.

Although students are nominally attached to a tutor so that each tutor has a student group, numbers are always uncertain and you have never been sure which students are actually "active" on your list given to you at the beginning of the year. Moreover when you hold study centre sessions you are sure that some of the students present are not on your list. You are running tutorial sessions at the same study centre at the same time as your fellow tutors on the same course. Apart from running two tutorial sessions a month you are contracted to mark and give feedback on the assignments of your students. Last year, you had 65 learners, which meant you were marking as many 650 assignments over the 10-month course, and you expect similar numbers this year. You are finding this a major challenge - but you are paid on a piece rate system so there is some incentive to tutor large numbers.

The study centre is open all day and all evening seven days a week, and serves some 4,500 students in the region. (2000 registered in year one of operation and 2500 registered for the second year.) The study centre has four tutorial rooms and a room with six Internet connected PCs. There is a study centre organizer who is responsible for the building and has some administrative duties: room booking, etc. There is also a part time clerical officer. The electricity supply is uncertain, but this year OUM supplied the study centre with its own generator so this will improve the situation. At the moment OUM has five faculties - Arts; Education and Social Science; Maths and Computing; Science and Technology; and Business Studies. One day a week is a faculty day and last year your faculty started to put on once monthly day schools at the weekend at study centres across the country. These were very popular because, as there is only 
one study centre in each province, students have to travel a long way to get to the study centre. So for those students not living in the provincial capital, evening classes are not really viable.

After the first year of operation the university decided to appoint lead tutors for each subject taught at each study centre. You have been asked to take on the lead tutor role for your subject area at your study centre. The idea of this role is to allow some local and subject autonomy in organizing the teaching and to create a process for communication between tutors and the university administration. So your new role is essentially how to make the tutorial subject support for learners on your subject better in year two, in cooperation with your fellow subject tutors at your study centre.

\section{Appendix 3}

\section{Scenario 3: College of the Islands}

You are the tutor organizer at the College of the Islands. You appoint tutors, timetable tutorial sessions and organize the widely dispersed group of part time tutors employed by the College of the Islands. You are responsible for induction and staff development. College of the Islands is the tertiary college servicing the 15 small island states of the Pacific. There are five indigenous languages, although all teaching at your college is done in English. The College of the Islands has three college campuses, one in each of the three larger islands, but although this three campus operation is a political necessity it often means things are less efficient because communication systems between the islands are not well developed and off necessity there is a lot of duplication of effort. The student population of the College of the Islands is very diverse and geographically isolated. Some island communities can only be accessed by light aircraft. The college has offered a limited number of sub degree courses following syllabuses from overseas examination bodies for many years and has built up a solid reputation based on mixing methods and technologies print, and in particular radio. Although tutorials are available at each of the college's campuses on a twice-monthly basis attendance is poor, even from the students who live on that island. One recent innovation was the introduction of a mobile tutor team with the objective of visiting each of the smaller islands twice a year. This had some success. You know that the critical issue is learner support and without deepening this, the college will fail most of the communities it has been set up to serve.

A new innovation for this forthcoming academic year is a course on "Care in the Community". It is a diploma level course developed and accredited by the Oceana University in Australia. This course acts as the common foundation year of a degree course in the caring professions (e.g., health and social services) and is a professional course for those currently working in the field but without appropriate qualifications. This is a very significant development for the college - and everyone is looking to see how it will work out. Each module or course is designed around a core text and a wrap around study guide to the text. These materials are fairly competently done but do not take account of the culture or circumstances of the islands because they were not written for these communities. Nor in the production of these materials has there been any recognition of the learner support needed for successful ODL study. The projected student numbers suggest that in the first year the college may enrol between 40 - 50 learners, but the potential for future years is much greater. This ratio of 1:50 is within the accepted tutor student ratio operating in the college. Students will be from all the island states and even if they are from the same island they may not live in easy proximity to each other. You have been able to identify three potential tutors; all are 
working professionally in the field, and each one lives on one of the three main islands. This has pleased you because you had been worried about finding suitably qualified tutors. The College has also been given funds from an international development agency to assist in the first year of introducing this course. What are you going to do?

\section{Appendix 4}

\section{Scenario 4: GREEN}

GREEN is an international organisation that provides learning opportunities for people whose work involves advocacy for environmental issues. The people that GREEN serves are in responsible positions; in government, in corporations, in media, or in non-government agencies, and are located throughout the world. Many of them are in countries with limited resources and technologies, and typically have multiple responsibilities to work, family and their communities. They all begin their connection with GREEN when they take part in an initial learning programme that includes intensive face to face meetings and a great deal of collaborative work. As a result, each cohort of GREEN graduates tends to continue their connections with their colleagues and with GREEN staff.

Some of GREEN's training is offered as self-study modules, either in print or on CD ROMs. However, people using these modules have consistently said that they would like to have a more in-depth learning experience and receive feedback on their work that goes beyond the suggested answers provided in the modules. GREEN provided tutoring for one pilot course, but found that it was not cost-effective, because of the amount of tutoring time required to provide detailed feedback to learners.

Now GREEN is ready to test another approach; enrolling large numbers (about 60 to 80 people) in a paced 20-week course that will combine the use of the CD ROM, a moderated computer conference, and tutorial support. All participants will have their own copy of the CD and Internet access, although in some cases their Internet access is intermittent. GREEN staff will manage enrolment of learners and distribution of materials, and will do some screening to ensure prospective participants have the appropriate background and adequate computer access. The course design requires every participant to work on a project throughout the course and to submit it for a mid-course review and for a final assessment.

You have been selected as the sole tutor for this course. Your responsibilities will be to provide support for participants so that they can each prepare a project that is appropriate for their own needs and for their context; to enable participants to support and learn from each other; and to ensure that each participants' project receives detailed and helpful feedback. You have tutored or facilitated e-learning situations before, but have always dealt with relatively small numbers of people who are from similar contexts and share similar values. You know that the strategies you've used for smaller numbers and more homogeneous groups won't necessarily be effective for a large, diverse group. 


\section{Appendix 5}

\section{Scenario 5: Seaforth College}

You are a tutor at Seaforth College in the UK on a foundation law course. Seaforth is a small charitable trust that was set up after the Second World War to provide education and training opportunities for de mobbed troops who were unable to study full time. Seaforth College pioneered part-time distance education utilizing correspondence methods. There are no-face-to face meetings for students, and on its core courses there is no student - student interaction, all interaction is between the tutor and the student conducted at a distance. Moreover the college is committed to openness by which it means students are free to register, and study at their own time and pace. They do not study in a "lock-step" fashion. Seaforth College's uniqueness stems from it being a "not for profit" provider of tutorial services. That is it provides a tutorial service for the courses/syllabuses of other providers. The college in some instances creates the student study materials that underpin the syllabuses of these providers. The Government does not fund Seaforth College; its only income is from the fees its students' pay. The college's significant reputation has been earned from its high standards of learner materials for British secondary school examinations - both the general and advanced syllabuses. The college is now providing very successfully study materials and tutor services for a range of occupational and professional qualifications, and is pioneering work based learning. The college is also positioning itself to move into a completely electronic environment with its own managed learning environment.

You are a tutor on what used to be a very significant area of the College's provision - namely support for the London University External Programme. You know that the college continues to provide a service here even though it just about covers its costs. Learners pay a registration fee that entitles them to an initial contact with you (phone, fax, or email) the purpose of which is to design a tailor - made study programme, and five assignment forms. An assignment form accompanies a students' submitted assignment. The assignment was set by you at the initial contact session or after the previous assignment was handed in. Students are essentially having one-to-one tutorial sessions at a distance with you after the submission of a piece of work. The only pacing that is provided is the London external examinations that are held once a year and students have to decide if they are going to enter the exams that year some months before. London University does not provide any study materials, but it does provide a syllabus and an extensive reading list.

You have for a number of years questioned why you continue with this tutoring, as it is certainly not financially worthwhile. But over the years you have had very rewarding relationships with your students, who are largely overseas, and for all of them this is the only way of getting higher education. Some of your past students have risen to high office in their countries, and a number have won University of London awards for the best student in the year - including on campus students.

At anyone time you have approximately 18-20 students attached to you, but they are all at different stages in their studies. If a student does not submit any work for two years, the college deems them to be dormant and they are removed from your list. You have known students become active again after "rests" of eight years. There is a high drop our rate on these programmes - learners stop submitting assignments even though they may have purchased assignment forms. The successful learners are very committed, and self motivated. You often think of them as auto-didacts. 
Task: The College has given you authority to reorganize your tutorial provision. What will you do to ensure that your time is used more effectively and tutorial provision is improved?

\section{Questions to consider:}

1. What are the challenges you face?

2. What resources are available to you?

3. What strategies could you use to achieve economies of scale in this customerised tutoring situation?

\section{Appendix 6}

\section{Scenario 6: Accounting}

You are a general accountant in a medium-sized city in the United Kingdom, and for some years, you have been tutoring people who are preparing for their certification exams. You are contracted by a local college to provide this tutoring service for people who have successfully completed and passed all their accountancy courses, but must pass two comprehensive exams, (a general one and one in their field of specialisation) in order to receive their professional certification. The college does not offer any face-to-face classes to those preparing for these exams; instead, it contracts with local accountants to provide individual tutoring. In your community, you are the only accountant taking on this work, but there are two or three other accountants in nearby cities who are also tutors. As well, since the exams are offered nationally, there are tutors across the country, most of them contracted by local colleges.

Opportunities to sit these exams are offered by the professional accountancy organisation twice a year, and candidates usually begin their preparation, either on their own or with tutorial help, about four months in advance of the exam date. You usually tutor about 20 candidates at a time, and help them prepare both for the general exam and for any one of five specialised exams. It is interesting work, but it means that you have to customise your tutoring for each person, because everyone has quite different levels of preparedness, and each person is also studying for a specialisation. Because the exams test learners' problem-solving abilities, most of your tutoring involves commenting on learners' assignments, which are based on previous exam questions and case studies. You do all your tutoring by email.

As you are nearing retirement, you would like to be able to increase the number of people you tutor to about 50 at a time, so that you can use this activity to supplement your income. (The college pays you a base rate according the number of students you have, plus a set fee for each assignment you mark.) You have developed some resource materials to help your learners; the college has copies of previous exams, and the professional accountancy organisation provides a handbook for candidates explaining the general principles of the qualifying exams. You are wondering how you can make your tutoring more efficient so that you can manage to work with up to 50 candidates at a time. What would you recommend? 


\section{Appendix 7}

\section{Scenario 7: SARS}

You are an instructor in a university school of medicine in Eastern Canada and your area of specialisation is infection control. You are a qualified nurse with a graduate degree and advanced training in microbiology and in infection control. Although medical students and nurses are usually very conscientious learners about your subject, you are sometimes frustrated that doctors do not always practice effective infection control. This is partly the result of an attitude that doctors are too busy and too crucial to the system to pay attention to all these detailed rules and procedures. However, the recent SARS outbreak worldwide has prompted the Ministry of Health to require new, more rigorous infection control precautions, and all hospital staff must complete training in these precautions within the next six months, so they are prepared for the next SARS outbreak.

Your university has prepared a distance course to provide this training, and you will be one of two tutors responsible for a group of 400 doctors at two teaching hospitals affiliated with your university. Even though participants are local, their busy schedules make it impossible to attend face-to-face classes. The course is designed to be as flexible as possible. It requires about 20 hours of study time over the two-month course duration. A CD provides the essential information, but as a tutor, you are responsible for ensuring that everyone has mastered it. As well, you know that your role involves changing attitudes among doctors so that they all take infection control seriously and follow the new protocol. The course material provides adequate data and good rationales to support the change in behaviour, and also encourages participants to form learning groups and engage in computer-mediated discussions so that they can raise questions and issues. You would like to use these discussions to draw out any objections or concerns about the new procedures so that these can be addressed, and participants will be more likely to apply these procedures in their practice. As well, you have to work out how to ensure that participants have in fact acquired the skills, knowledge and commitment to use the new procedures.

\section{Appendix 8}

\section{Scenario 8: Leather Industry in India}

The Government of India has identified the need to upgrade skills in tannery workers to propel the Indian Leather industry into the 21st Century. The formal education system was unable to meet this need because: the target group were in the work force, the numbers to be trained were very large (1.4 million), the areas to be trained were not covered by formal systems, learners were distributed geographically through various tanneries in the country, each tannery had needs specific to local requirements, educational background of learners varied drastically from graduate to illiterate and tanneries find it difficult to spare workers for training.

A national open university has developed a 20-week course, which is competency based, is work based and uses open learning and distance education methodologies. Strong partnerships have been established between the experts at the university and experts in the leather industry to develop and implement the programme. In order to cater for the varied educational backgrounds of learners - including range of languages - the entire course was produced in both print and on audiotape. Learners are assessed during the 20 week course on their practical competencies in a number of areas covered by the programme. 
The delivery system provides learner support through work based demonstration and training at the worker's tannery; and supplementary support, general guidance and assistance at study centers located in the tannery or in partnering institutions located in the community.

The course was introduced in March 1999, and all the feedback suggests that workers are showing strong motivation to undertake and pursue the training. The course has been praised internationally and nationally for providing a model of how flexible delivery methods can meet training needs and for showing the importance of a strong culture of partnerships involving government, training institutions and enterprises.

You are a worker trainer on the Tannery Training Programme. You work in a large leather factory and have been given remittance of eight hours for your duties of supporting 30 learners on the programme, half of which are for direct class contact. The other half of your time is for assessment, record keeping (recording marks), and individual or small group work where possible. The work-based training is on the job training and is very much in the hands of the managers of the different areas. Your training input is designed to supplement the work-based training. Although enabling employees to participate in the programme is company policy, in reality the ability of a worker to participate is determined by their foremen - are they supportive of the programme and an individual learner or not. So sometimes individual learner attendance is erratic. The room provided for the study center is very basic with little or no equipment but you do have sufficient copies of the learner materials for each learner. You also have a very mixed group with respect to educational abilities. The materials take "one-size" fits all approach, which is taxing given the wide range of abilities reflected in your group. In the early years of the course student motivation was indeed high but you have found that this is declining because promised wage increases and promotion for graduates of the programme that applied in the first years of the programme, no longer seem to be materializing. You are concerned about this. You are one of seven worker trainers in the factory. You do not meet other trainers because you each use the study center on different days. Although you are committed to the ideas behind the programme you are becoming a bit de motivated too. How can you restore your own motivation and that of your learners?

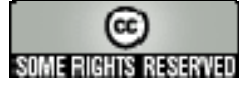


April - 2004

\title{
Interim Report: A case study of Internet-based distance education program development in Vietnam
}

\author{
Ramona R. Materi \\ Ingenia Consulting \\ Patrick J. Fahy \\ Athabasca University - Canada’s Open University
}

\section{Introduction}

This is a report of the role of Distance education (DE) in enhancing education and training in developing countries. As countries compete in an ever more challenging international marketplace, they recognize the need to continually train and upgrade their citizenry. As national leaders struggle to cope with increasing populations and decreasing budgets, DE can be an additional and often essential tool in accomplishing this goal.

This paper is a case study of the efforts of one college in Vietnam, Fisheries College Number 4, to develop a plan to introduce a small distance education offering to its regular courses. Its purpose was to better serve farmers in remote regions. The first author, Ramona Materi, through her company, Ingenia Consulting, carried out the work on behalf of the International Development Research Centre (IDRC), a public corporation created by the Parliament of Canada to help researchers and communities in the developing world to find solutions to their social, economic, and environmental problems. Materi's assignment was to work with College officials to develop the DE plan and funding proposal.

The paper begins with a brief description of the role of information and communications technology (ICT) in education and development, particularly in South East Asia. It then provides an overview of Vietnam and its current activities in DE. The next section offers a detailed examination of the challenges the College faced in developing a plan for DE on the Internet. The paper concludes with Materi's personal observations and commentary on lessons learned.

\section{ICT'S Role in Education and Development}

The debate on the role of education and development is complex as the appropriate role of DE, and more specifically the use of DE technologies, in advancing economic and social well being. Commenting on distance education, Chung (1990) notes:

Given the limited human and financial resources available to third world countries, distance education becomes an invaluable tool for development. Through distance education, one teacher can reach an audience of millions rather than only a handful. The cost of distance education can 
be a fraction of that of traditional formal education, thus enabling limited resources to reach a larger population (p. 64).

Casas-Armengol and Stojanovich (1990) argue that the "rational and well-planned use of new and advanced technologies" in distance education can enable developing countries to break out of offering degrees for social prestige and instead allow "true knowledge development” (p. 133).

Other writers, however, wonder if advanced multimedia technologies are practical for poor countries. As Penalever (1990) comments:

The application of modern technologies will entail an increase in the costs to be borne by the students, which, in turn, will affect their access. It is possible that third world countries will not be able to make use of the "technologically advanced" new modalities of distance teaching, which are being developed at present in industrialized countries (p. 28).

These concerns, though, have been no barrier to the use of interactive DE technology in Asia, as academic conferences throughout the years demonstrate. In 1990, the Universitas Terbuka in Indonesia hosted the "Interactive Communication in Distance Education" conference, at which scholars from DE institutions throughout the region discussed ways to increase two-way interaction between instructors and students. In 2001, another Indonesian conference with the same theme appeared, "Facing Global Competition: Open learning and Information technology: Problems and Promises" (2002), where scholars looked at quality issues in online learning and teaching, and other related topics.

Nonetheless, access to Internet technology varies widely in the region. The Asian Development Bank has prepared a series of reports looking at infrastructure problems and related matters. Countries, like Singapore and Malaysia, have solid structures in place, and others like Thailand and the Philippines are moving towards better connectivity, while others like Vietnam, Laos, and Cambodia require major investments to upgrade their technological networks. The majority of these countries, however, recognize the importance of the Internet and the urgency of investing in essential telecommunications infrastructure (Murray, 2003). Thus, distance educators working in the region must plan to deal with a wide range of capabilities when designing programs.

\section{Background of Vietnam}

Vietnam is considered one of the poorest and most underdeveloped countries in the world. As the CIA Fact Book (2002) notes: "Vietnam is a poor, densely populated country that has had to recover from the ravages of war, the loss of financial support from the old Soviet Bloc, and the rigidities of a centrally planned economy." The country was at war from 1945 to 1975, after which it faced an economic embargo until 1990. From 1993-1997, growth averaged 9 percent per year, but it has slowed in recent years because of the recession in the global economy and in South East (SE) Asia. With a population of 78 million, almost 80 percent of the workforce is involved in agriculture and lives in rural areas. In 2000, Gross Domestic Product (GDP) per capita was estimated at US \$300 per year.

With respect to education, Vietnam faces several urgent needs. With more than 75 percent of its population under the age of 30, it has numerous new students entering the primary and secondary schooling systems. It also has massive numbers of people to train in new technologies and practical skills to achieve economic development. Less than 25 percent of the total workforce is skilled labour. According to Thai Thanh Son (2001), an analyst working for the United Nations Development Program in Vietnam: 
Retraining, upgrading and standardizing working staff in all sectors of the national economy is [urgently required]. Approximately 80 percent of the country's workforce was originally trained along different lines. Consequently, they are not adequately prepared for today's economy and they need additional training.

As an example, the Vietnamese government has created Export Processing Zones, to encourage socio-economic development in rural areas. In one zone in Quang Ngai province, an oil refinery complex will need 4,000 engineers and 12,000 skilled workers by 2005. With the current state of education and training, however, the complex will do well to have 5 to 10 percent of that required workforce. Similarly, for lack of qualified Vietnamese personnel, British Petroleum, a multinational working with the Vietnamese government to develop offshore oil, must import engineers and oil field specialists from Thailand. The shortage of skilled workers is endemic across industries outside of the agricultural sector (McTavish, 2003).

\section{Distance Education in Vietnam}

Vietnam has been involved in distance education since the 1950s. Faced with swelling numbers of students and needs, the government is beginning to invest more in the sector. In particular, it believes that DE can be effective in promoting human resources training (Son, 2001).

In the mid-1950s, many colleges and universities established units and departments for correspondence training. In the 1980s and 1990s, the government established more formal DE institutions, including the Vietnam Institute of Open Learning (1988), and the Open Learning Institutes of Hanoi and Ho Chi Minh (1990). In 1993, the government established the Hanoi State Open University and the Semi-Public Open University in Ho Chi Minh City. These institutions manage and organize open learning and distance education throughout Vietnam.

In 1998-1999, approximately 800,000 learners participated in some sort of open learning or distance education offering. These included 40,000 undergraduate in-service learners, 10,000 students of in-service secondary vocational education, 100,000 continuing education students, 400,000 foreign language students, and 250,000 people upgrading literacy. Thousands of others participated in seminars and workshops (Global Distance Learning Network, 2001).

Much of the DE offered in Vietnam is print-based. Ha Noi Open University (HOU), for example, has regional learning centres throughout the country. Students receive their materials by mail or pick them up from the centres. HOU also produces audio and video materials for select courses and has videoconference facilities, funded by the World Bank. It has a simple website, and sends

emails to the regional centres for basic administrative matters. HOU's offerings mirror those of most other Vietnamese institutions.

The use of Internet for DE is relatively rare due to such constraints as:

- Lack of Equipment/ Infrastructure: In 2001, fewer than 100,000 people in Vietnam had private access to the Internet. For instance, only 10 percent of the students in the Faculty of Information Technology at the Hanoi State Open University had their own computer. Most use public-access computers in cyber cafes, which are ubiquitous; even small towns are likely to have access. Still, this access also has problems. Vietnam's Internet backbone has only one major line between Ha Noi and Ho Chi Minh, and military traffic has priority. For the average user access can be grindingly slow and unreliable. 
- Expense: In a country where average annual income is about US \$300, in 2003 a new desktop computer started at US \$800. Costs for Internet and telephone services are equally prohibitive when compared to average income. Relative to an on-campus student, a learner using the Internet for an hour a day would end up paying four to five times as much in fees.

- Language/ Culture: Language barriers are also present. Users require a certain proficiency in English to log onto websites, participate in chat rooms, and gain access to the information resources of the Net. The Vietnamese government also restricts access to certain sites.

- Instructional Design Capacity: There are few capable DE instructional designers in Vietnam, and fewer still experienced designers of materials for the Internet. Through its Mekong Delta Facility, the World Bank is engaged in a year long project to enhance the print-based design skills of a select group of instructional designers. In 2004, this group will turn to CD-ROM technology. State-owned companies have these capabilities as well, but even they acknowledge the need for further skills training and upgrading (Nelson, 2003; Nguyen, 2003).

Despite these constraints, Internet usage in Vietnam is growing. Infrastructure problems are being remedied with Asian Development Bank funding, Vietnam plans to install fibre optic networks in the Northern provinces by 2005. The "pipeline" between Ho Chi Minh and Saigon should be double-tracked by the end of 2003 (Chang, 2003). As for language, many young people study English, and it is common in large city cyber cafes to see them chatting for hours online, alternating between Vietnamese, French, and English language forums.

As these problems are resolved, the likelihood of Internet usage for DE is enhanced. Already, Vietnam and Japan have signed an agreement on e-Learning, whereby the Hanoi Institute of Technology, Vietnam's 's premier information technology (IT) facility, is working with Japan's Kyoto University to explore the use of e-learning for IT courses. Such initiatives are likely to continue to expand. The rest of this paper will describe how one college is moving forward to use the Internet as a DE teaching tool (Nguyen, 2003).

\section{The Challenges for Fisheries College Number 4 of Introducing the Internet}

\section{The Training Challenge}

Located outside of Ha Noi, Fisheries College Number 4 is responsible for providing college level and continuing education courses to students and workers in the northern provinces of Vietnam. Its courses range from business and accounting to aquaculture, information technology, and food processing technology.

The fisheries sector is important to Vietnam, employing millions of people, contributing four to five percent of GDP annually, and nine to 10 percent of Vietnam's total exports. The government would like to increase the number of fisheries technicians by 20 percent between 2000 and 2010 . The goal is to create jobs for two million people in aquaculture; at present, only 30 percent have been trained. In Vietnam, aquaculture is carried out at home in rural areas, with 45 percent of the workforce comprising women. Because the government sees aquaculture playing a major role in improving the role of women in rural and mountainous areas, the priority need is for worker training in rural areas (Wyne, 2002). 
In support of this goal, the College has developed a one-week, in-person short course in aquaculture targeting farmers. Instructors from Ha Noi help locally based staff deliver the course, traveling to learning centres in rural areas. They are away from the college for up to one month at a time. The College has a large area where it houses various species in aquaculture ponds, which are used to train farmers and regular students. As part of the government's rural development efforts, courses for farmers are offered free of charge. Class sizes range from 45-100 people, with the College offering the sessions two to three times per year.

This current training model places pressure on college staff, learners, and facilities; increasing the number of classes, learners, and teaching locations would only exacerbate the strain. Instructors must travel frequently in rural areas along roads crowded with carts, bicycles, and slow moving trucks, making for long, tiring, and dangerous journeys. Students also face difficult travel conditions and many must also be away from home and family responsibilities for extended periods.

To alleviate these problems, the College approached the Canadian International Development Research Centre (IDRC), seeking funding for the use of ICT to meet the needs of farmers. The first author was the consultant who carried out the development of a DE plan and funding proposal.

A basic needs assessment revealed the following issues related to the implementation of ICT in distance education:

- Teaching and Learning: The College had worked previously with Canadian donor agencies, including the Marine Institute, and the College of the North Atlantic in Newfoundland. As a result, it had a selection of audiovisual equipment and had produced 12 courses using systematic instructional design techniques. Once funding ceased, however, so did the use of these skills. Since 1997, when the design project ended, the College has designed no new courses using these techniques, nor has it revised any existing ones. Further, College instructors had minimal to non-existent experience with DE courses. None had ever developed materials for such courses, nor instructed in them. Some had basic computer and Internet skills, but only two IT instructors were acquainted with the technology.

Student skills were equally limited. Farmers ranged in age from 25 to 65, and their computer skills were almost non-existent. All, however, had excellent literacy skills; the United Nations Development Program estimates literacy rates in Vietnam at more than 90 percent.

- Technical Considerations: In Ha Noi, the College has a computer lab with relatively new computers. Only two computers, however, were connected to the Internet, and these were located in the director's and vice-director's offices. Connection speed was 11.5 Kbps, excruciatingly slow and unsuitable for DE activities.

The College has spent more than \$US 750,000 developing an extension training centre in Quang Ninh, a province about three hours from Ha Noi. In September of 2002, navigating the road required a four wheel drive vehicle after any rainfall. One building had a large room, which with air conditioning and rewiring upgrades, could accommodate a computer lab. Tests for connectivity at the College showed that speeds of 28.8Kbps were possible. The extension centre, however, had no computers. 
- Change Management: For more than 40 years, the College had specialized in face-toface training. No one had experience in budgeting for, planning, or administering DE programs, or seeing to student needs and related matters. If handled badly, introducing $\mathrm{DE}$ as well as the Internet could thus pose imposing organizational challenges.

- Cost and Budgets: Funds for education in Vietnam are limited. As such, the College would have to rely on outside, foreign donors to provide the financing necessary to train staff and purchase necessary equipment.

\section{The Proposed Solution}

The College decided to offer learners the option of taking the aquaculture course through DE. It sought to take advantage of current delivery trends in the developed world, which are to use the Internet and other ICT technologies to increase course quality and opportunities for interactivity. The College proposed a blended approach, whereby students would receive theoretical and supplemental information through DE, and the practical portion via face-to-face instruction in the field.

In pursuing this model, the College would be a leader and a pioneer; as mentioned previously, few post-secondary institutions in Vietnam are using the Internet for training purposes, and even then the scope of use is more limited than that which the College is proposing.

\section{Specific Objectives}

The overall objective of the project was to pilot the use of ICT tools in support of DE in rural areas of Vietnam. In addition, the project was designed to demonstrate the effectiveness of blended training as a development educational tool with rural adult learners. More specific objectives include:

1. Investigate whether the College can maintain quality learning by:

a. Developing, delivering and maintaining a combination of classroom and Internetbased learning

b. Exploring innovative strategies for using simple websites as a means to distribute scientific and technical information to rural audiences

2. Evaluate the effectiveness of various ICT tools as distance education tools for the Fisheries College by using servers and other tools that Vietnamese Internet service providers have developed specifically for the Vietnamese language, and for the slow connectivity typical of rural areas

3. Assess the effectiveness of the pilot project by collecting data on:

a. Instructor and learner satisfaction with the educational process and outcomes

b. Reliability of the ICT tools employed

c. Feasibility of expanding the model to other courses and potentially other colleges in Vietnam

The College would establish a DE teaching centre on its main campus, with computers connected to the Internet. College instructors would use this teaching centre to create DE materials for Internet delivery, respond to student inquiries, and conduct research to help them develop courses with the latest scientific and technical information. 
The College would set up a second DE centre at its Quang Ninh extension centre. For the pilot course, farmers would still attend classroom and field sessions. In addition, they would receive training in computer and Internet skills, and have access to supplementary materials that College instructors develop. This material would include information on aquaculture theory and techniques, as well as relevant information on Ministry of Fisheries programs.

The technologies the College plans to use include:

- Microsoft FrontPage for development of Web-based course information

- Adobe Acrobat for the development of PDF files for the course website

- Computers networked in a local area network, connected by a server to the Internet

\section{Proposed Process}

Described is an overview of the methodology for the project, developed by the College in conjunction with international advisors. Divided into three phases, the aim of the project is to address some potential pitfalls uncovered in the needs assessment.

\section{Phase 1: Preparation}

In this phase, lasting approximately eight months, the College will work with stakeholders, a local Internet Service Provider (ISP) NetNam, and foreign consultants to develop staff capacity in Internet technology and DE training. It will also set up the distance learning centres. Major activities will include:

- Stakeholder Meeting: To start the project, the College will hold a three day meeting with staff, farmers, Ministry of Fisheries officials, and other interested parties, to inform them of the project and to discuss and conduct detailed planning for project activities.

- Establishment of Internet-Connected DE Centres: The College will contract with NetNam to develop two Internet-connected DE centres, one in the College and one its Quang Ninh extension center.

- Staff Workshops/ Formal Training in ICT Technologies: NetNam will provide workshops on network administration, basic computer and Internet skills, and webpage construction skills to pertinent staff. Specifically, the College will contract with NetNam for:

1. A survey of the level of connectivity at each proposed site. NetNam will then provide advice on how to make arrangements to increase these speeds

2. Advice on equipment, help with arrangements to acquire it, and quality testing once purchased

3. Installation of equipment in the two DE centers

4. One two-day workshop for 20 teachers on basic computer and Internet skills

5. One two-day workshop for the same 20 teachers on basic Web-design skills

6. Ongoing telephone (and, as necessary, on site) technical support for the DE centres

- Staff Training in DE: An international consultant will provide a one-week workshop (delivered in a two-week timeframe to allow for translation time) to 20 College instructors on the development of teaching materials for the Internet. Using the existing 
course for farmers, the consultant will work with instructors to show them how to use materials from the Internet and paper sources, and use them to create an attractive and useful educational website that supports classroom teaching.

- Additional Training in Canada: Two College aquaculture instructors will receive advanced training in the latest ICT distance education techniques through on-site training in Canada. Training will take place at one or two selected institutions, over a period of two weeks.

- Development of Online Course Materials: College instructors will prepare appropriate Web-based materials for the course.

\section{Phase II - Implementation}

The process in the second phase, implementation, lasting approximately 14 months, will consist of:

- Course Delivery: The College will use Internet technology to deliver the course two to three times in each center, to classes of between 45 and 100 students. Farmers will have access to the labs over the entire week and will be able to review Web-based materials in shifts, as computers are available. For example, one group may attend a field session, while another group works in the computer lab.

- Course Revisions and Adjustment: After an initial round of courses, the College will revise course materials, with the help of an international advisor, who will visit for one week.

\section{Project Schedule}

Table 1 shows the two-year project schedule: 
Table 1. Implementation Schedule

\begin{tabular}{|l|c|}
\hline Major Milestones & Timing \\
\hline Project start & Month 1 \\
\hline Stakeholder meeting & Month 1 \\
\hline $\begin{array}{l}\text { NetNam survey and preparation of } \\
\text { computer network, DE centre staff } \\
\text { training }\end{array}$ & Month 1 to Month 8 \\
\hline $\begin{array}{l}\text { Web development, network } \\
\text { administration and other technical } \\
\text { skills workshops for College staff }\end{array}$ & Month 2 to Month 4 \\
\hline $\begin{array}{l}\text { In-country training workshop of } \\
\text { College staff in DE techniques }\end{array}$ & Month 3 or 4 \\
\hline $\begin{array}{l}\text { DE study tour to Canada for 6 } \\
\text { people }\end{array}$ & Month 5 \\
\hline DE materials complete & Month 8 \\
\hline First round of course delivery & Month 9 to Month 12 \\
\hline $\begin{array}{l}\text { Course revisions with assistance } \\
\text { from International consultant }\end{array}$ & Month 13 \\
\hline Second round of course delivery & Month15 to Month 17 \\
\hline Third round of course delivery & Month 21to Month 23 \\
\hline Stakeholder meeting & Month 24 \\
\hline Submission of final report to IDRC & \\
\hline
\end{tabular}

\section{Monitoring and Evaluation}

The College will undertake several activities to evaluate project quality. The areas it will assess include:

- Learner and Instructor Satisfaction: Internet supported courses will be new to students and instructors. The College will use questionnaires, focus groups, and interviews to gather data on their reactions, experiences and suggestions for improvement.

- Equipment/ Internet Reliability: Administrators of the DE centres will log equipment breakdowns, Internet service interruptions, electricity failures, and other technical difficulties that may affect the College's ability to deliver the course.

- Feasibility of Project Expansion: At the final stakeholder meeting, participants will discuss and evaluate the possibility of the College expanding online courses to its 
students, as well as the potential of offering courses to other students enrolled in other fisheries colleges in Vietnam and elsewhere.

Outputs from the project will include:

- Establishment of a DE centre at the Fisheries College Number 4 main campus, and at Quang Ninh.

- Development of Vietnamese language Web-based course materials for aquaculture training.

- Capacity building for College staff in network administration, Internet and Web design skills, and ICT-supported distance education.

- Capacity building for students in computer and Internet skills, and the latest techniques in aquaculture.

- $\quad$ Report assessing the viability of ICT supported DE in Vietnam's rural areas.

\section{Project Beneficiaries}

- Farmers: The computer and Internet skills farmers gain may help them in other ways in the future. As e-commerce in Vietnam develops, they will have access to market information to help them receive a better price for their product. Since aquaculture is more profitable than traditional rice farming, farmers may eventually be able to purchase their own computers to access valuable information on aquaculture from the College website.

- Instructors: By reducing the need to travel, instructors will have more time for teaching and other duties. They will also gain computer and Internet research skills, and enhance their teaching and instructional design skills for DE courses.

- NetNam: NetNam will use this project to further its research to adopt Internet tools and resources for Vietnamese conditions.

- Fisheries College Number 4: By increasing its capacity to meet learner needs, reduce costs in the long term, and pioneer innovative teaching methods, the College will gain prestige and increase capacity to assist other colleges and universities in Vietnam to enhance their DE skills.

- Ministry of Fisheries: The Ministry will have access to innovative and necessary training to promote its goals of poverty reduction and increased employment for the Vietnamese people in the fisheries sector.

\section{Current and Future Developments}

In December 2002, the IDRC accepted the College's proposal and contracted with the College of the North Atlantic, Newfoundland, Canada, to begin implementing the plan. As of April 2003, progress was on schedule, and the College was purchasing computers for its main campus and the provincial extension centre. While aware of the risks inherent in the project, the IDRC believes that the willingness and enthusiasm of the College administration and staff for the project will be enormously helpful in the likely event of difficulties (Lafond, 2003). 


\section{Conclusions and Recommendations}

In conclusion, the first author found the College Number 4 project to be interesting and satisfying on professional and personal levels. As a part-time Athabasca University student enrolled in the Master of Distance Education program, the author was gratified to put theory into practice. It was professionally gratifying to know that her efforts would benefit others in fundamental ways, since a well-designed program could contribute to basic economic development in poor provinces. Experiencing the warm and gracious hospitality of her Vietnamese hosts, she found it enjoyable to work once again in a cross-cultural environment.

Looking back, the key lessons learned from the project included:

- Preparation Pays: Prior to leaving for Vietnam, the first author consulted with academics (at Athabasca and elsewhere) for advice on the academic culture in Vietnam, as well as the key aspects to be considered in establishing a DE program. Business people and other consultants with experience in the region provided tips on business etiquette, cultural mores, and related topics. Recent travelers to Vietnam provided hints on the mundane to the exotic: where to stay, what to pay, and where to eat. As a result of the generosity of these people, the first author encountered few cultural surprises and was able to concentrate her efforts on the task at hand.

- Translation Counts: At first language problems were a concern for the first author, since the College translator tired quickly and encountered difficulties when the conversation moved beyond pleasantries. When a more experienced translator became involved, the project proceeded much more smoothly. In future projects, it would be preferable to bring one's own translator to initial meetings, until it was clear that the "house" translator was up to the demanding work of translating technical jargon and information, often for hours at a time.

- More Time, The Better: In any project, it becomes a refrain: "If only we had more time.” The two weeks the first author was in Vietnam were jam-packed, with work every day from early in the morning until late at night. Still, it would have been preferable for her to have had more time to interview college staff regarding their views on the project, and to meet with some farmers who would be taking courses. The information and perspectives they would have provided would have no doubt been beneficial to the proposal development. It would have also been good for the author to have had an opportunity to become more knowledgeable of other DE projects that may have been underway in the country.

As the project moves along, the first author will keep abreast of its doings, since the IDRC has suggested a midterm and final evaluation of the project. This will be an excellent opportunity for the author to evaluate the effectiveness of the project design and ascertain, once again, how well theory works in real life.

\section{References}

Asian Association of Open Universities. (1990). Interactive communication in Distance Education. Jakarta, Indonesia: Universitas Terbuka.

Central Intelligence Agency. (2002). The World Factbook 2002 - Vietnam. Retrieved April 8, 2003, from: www.odci.gov/cia/publications/factbook/geos/vm.html 
Casas-Armengol, M., and Stojanovich, L. (1990). Some Problems of Knowledge in Societies of Low Development: Different perspectives on conceptions and utilization of advanced technologies in distance education. In M. Croft, I. Mugridge, J. S. Daniel, and A. Hershfield (Eds.) Distance Education: Development and access (p. 130-133). Caracas: International Council for Distance Education.

Chang, P. (2003). Personal communication. (February 26).

Chung, F. (1990). Strategies for developing distance education. In M. Croft, I. Mugridge, J. S. Daniel, and A. Hershfield (Eds.) Distance Education: Development and access. (p. 6166). Caracas: International Council for Distance Education.

Global Distance Learning Network (2001). A Country Report on Open and Distance Learning in Vietnam. Retrieved April 7, 2003, from: http://gdenet.idln.or.id/country/ar_vietnam/CRVietnam.htm

Global Distance Learning Network (2002). Facing global competition: Open learning and technology: problems and promises. Retrieved April 7, 2003, from: http://gdenet.idln.or.id/symposium/program.asp

Chang, P. (2003). Personal communication. (February 26).

McTavish, I. (2003). Personal communication. (Feburary 21).

Murray, S. (2003). Personal communication. (February 25).

Nelson, M. (2003). Personal communication. (February 19).

Nguyen, D. (2003). Personal communication. (February 18).

Nguyen, N. (2003). Personal communication. (February 18).

Penalever, L. M. (1990). Distance Education: A strategy for development. In M. Croft, I. Mugridge, J. S. Daniel, and A. Hershfield (Eds.) Distance Education: Development and access (p. 21-30). Caracas: International Council for Distance Education.

Son, T. T. (2001). Distance education and its contribution to rural development. Retrieved on April 7, 2003, from: http://www.undp.org.vn/mlist/cngd/032002/post11.htm

Wyne, D. (2003). Personal communication. (September 4).

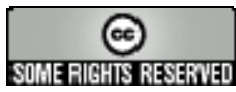


April - 2004

\section{Book Review - Reusing Online Resources: A sustainable approach to e-learning}

Editor: Littlejohn, A. (2003) Reusing Online Resources: A sustainable approach to e-learning. hardcover. £22.50. Kogan Page: London. ISBN: 0749439505

Review by: Sanjaya Mishra, PhD, Senior Lecturer in Distance Education, Staff Training and Research Institute of Distance Education, Indira Gandhi National Open University, New Delhi, India.

"Reuse" and "recycle" of existing teaching-learning resources have always been a common practice in the world of education. However, it had never been in the centre-stage of educational debate as it is in the recent past. The reasons for educational material reuse are: the need to provide greater access to quality education, shrinking financial resources, pressure to provide education in cost-effective ways, and the overall impact of the information and communication technology (ICT) in educational practices. In fact, with the advent of ICT it has become easier to store, retrieve, share, and reuse educational materials. Though for individual teachers, the practice of preparing learning materials (also called "learning objects") and their reuse have been simpler, the book under review covers a wide-range of complex issues in reuse of online resources for sustainable and cost-effective teaching from both institutional and global knowledge economy contexts.

Divided into four parts, the book covers eighteen chapters excluding the first one by the editor, Alison Littlejohn, which puts the book in perspective and identifies seven questions that are focus of discussion in the other chapters, all of which are written by eminent theoreticians and practitioners of the theory and practice of 'learning objects'. The questions are:

1. How can digital resources be used to support learning?

2. How can resources be reused within a range of educational models?

3. Why is standardization necessary?

4. Is there an optimum size for reusable resource?

5. Should resources retain contextual information?

6. How are educational institutions likely to change?

7. Is global sharing of resources a possibility? 
Book Review - Reusing Online Resources: A sustainable approach to e-learning

Chapters 2 - 19 of the book covers discussion that attempts to answer one or more of these questions. In Part 1, "Vision and theoretical perspectives," there are five chapters with an introduction by Mayes. In Chapter 2, Duncan introduces the concept of "granularization" of learning objects, but recognizes the difficulty to find an agreement on describing granularity and its levels. Rahek and Mason in Chapter 3 provide a definitive path for use of learning objects, while Campbell in Chapter 4 discusses the benefits in engaging with the learning object economy. In Chapter 5, Koper focuses on the problems with reuse of educational materials and provides an integrative framework for reuse. In Chapter 6, entitled "Models for open learning," describes the pedagogical approaches undertaken in the two innovative projects of MIT - The Open Knowledge Initiative (http://web.mit.edu/oki) and The Open Courseware Project (http://ocw.mit.edu).

Part 2, "Design perspectives," is comprised of four chapters with an introduction by Wiley. In Chapter 7, Laurillard and McAndrew propose the use of conversational framework in designing generic learning activities that could be reused. To illustrate the concept, the authors provide the example of SoURCE project (http://www.source.ac.uk).

Oliver and McLoughin in Chapter 8 present a range of reusable online designs that use effective pedagogy. Emphasizing the constructivist approach, the authors urge optimizing the use of the multimedia capabilities of the Web. "Designing for reuse and versioning" is the title of the next chapter by Thorpe, Kubiak, and Thorpe in which the authors describe course development methods that facilitate subsequent reuse and versioning. Based on their experience in the UKOU project "CoUrse Re-use and VErsioning” (http://iet.open.ac.uk/curve), the authors illustrate their ideas of reuse and versioning through the case studies. In Chapter 10, Jutta Treviranus and Judy Brewer focus on the important issue of designing accessible learning content for people with disability. It explores the architecture and authoring tools needed to create accessible learning objects, the use of standards, and institutional commitment needed for accessible electronic learning.

Part 3, "Resource perspectives," has five chapters with an introduction by Stiles. In Chapter 11, Duncan and Ekmekcioglu discuss the nature of digital learning resources, and the way they need to be stored and organized to retrieve and use at the time of need. In the next chapter, Olivier and Liber discuss why specifications and standards are important for reuse of resources. For any learning resource to be reused, it is essential that an agreed interoperable standard is adopted. Also, the use of metadata tags to locate the resource is emphasized in this chapter. In Chapter 13, Conole, Evans and Sims, discuss the reuse of digital images in teaching and learning. The authors identify the metadata information required to locate images. In the next chapter, Bull and Dalziel focus on the development and implementation of question banks as reusable learning objects. Within the implementation issues, the authors discuss copyrights, intellectual property, and digital rights management issues that are essential to be addressed in managing question banks.

Part 4, "Strategic perspectives," has four chapters with an introduction by Salmon. In Chapter 16, McNaught discusses the complex issues that influence sharing of learning objects in educational institutions. McNaught emphasizes that the change process in the institutions should be collegial, and only then sharing will be acceptable. In the next chapter, Littlejohn, Jung, and Broumley compare the issues of re-use in two different educational contexts - in a school in Korea, and in a college in the UK. This chapter highlighted that time of searching for learning objects as a critical factor in reuse; tutors need reward and encouragement for reuse of materials; and contextualized materials will only help teachers to reuse materials. In Chapter 18, Littlejohn describes an 
incremental approach to staff development in order to facilitate reuse of learning resources, while in the last chapter Harris and Higgison describe e-workshop as a reusable model for staff development. The authors recommend development of communities of practice as a model for cooperative staff development.

Having read the book from the editor's perspective outlined in Chapter 1, I would like to emphasize that this is a book to be seriously read, analysed, and reflected upon. This book has the potential to influence our educational practice. As such, the book received much attention through the special issue of the online journal - Journal of Interactive Media in Education (http://wwwjime.open.ac.uk/2003/1/), in which many experts around the world commented on the chapters, and generated discussion. With my academic background in Library and Information Science and current engagement in developing staff for distance education, I am, however, extremely excited with the concept of "learning objects." At the same time, I am also skeptical of a global knowledge repository to emerge in the near future. Though Littlejohn has been successful in giving us a compendium of wealth of information about the emerging areas of reusable learning objects, there are issues that need to be further discussed, standardized, and implemented in practice. For example, the definition of granularity is yet to have a standard meaning. The utopian idea of a global learning object repository is overwhelming. In reality, it is extremely difficult to have context-free learning objects, and, at the same time, convince educational institutions to share their learning object database with others without receiving economic benefit. Nevertheless, the "learning object strategy" would be beneficial to individual institutions, if planned, designed, and implemented properly. The book also provides examples of cooperative efforts in Learning Object repository development; there is thus scope beyond my personal skepticism of "Global Repository.” I would like to emphasize, however, that even if a global learning repository is feasible and emerges in the future, it is essential to have improved classification-based organization of learning objects that enables quick retrieval, quick compilation, and packaging to develop useful courses and programmes. Present classification practices are limited and search strategies depend on the free use of keywords in metadata tags. Therefore, controlled vocabulary for describing data about the learning objects is essential.

This book is a "must read" for every educational technologist looking to developing educational content, either for sharing or selling!
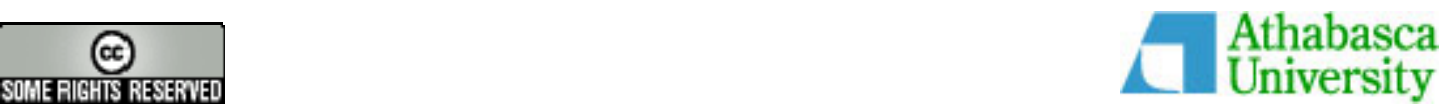
April - 2004

\section{Book Review - The Future of Learning: From eLearning to mLearning}

Editor: Keegan, D. (2002). The Future of Learning: From eLearning to mLearning. 172 pages, online. ZIFF Papiere 119, FernUniversitat - Hagen. ISSN: 1435 9340. Available at no cost online at: http://www.fernuni-hagen.d/ZIFF/mlearn.htm

Reviewed by: Murugan Krishnapillai, The University of the West Indies, Barbados

This e-book is a report of a study, which is supported by the European Union Leonardo da Vinci programme, about the potential of wireless technologies for teaching/learning at a distance. Despite its focus on the wireless e-learning scenario in Europe, this report does bring to the fore the pedagogic feasibility of using wireless technologies in distance teaching/learning contexts beyond Europe. Of the 10 chapters that form this report, the first three attempt to provide theoretical scaffolding to the discussion of mobile learning in Chapter 4. Chapters 5 to 8 contain a compendious account and a tenuous analysis of four wireless devices used for creating mobile learning contexts. Chapter 9 describes student perceptions of and experience with mobile learning. Building on the foregoing discussion, Chapter 10 urges Europe to take up the leadership role, because it forecasts the inevitability of adapting to mobile learning environments, consequent on the growth of wireless technologies and, indeed, a wireless future.

This 172-page report defines distance learning (“d-learning”) as essentially learning through print, e-learning as electronic learning in wired environments, and m-learning as wireless elearning. This report also claims "to provide an analytical and theoretical background to the field of education and training provision known as mobile learning...[a] provision of education and training courses on wireless devices...[and] sees the provision of education at a distance as a continuum and traces an evolution from d-learning (distance learning) to e-learning (electronic learning) to m-learning (mobile learning) ...” (p. 6).

Chapter 1 (p. 8 -17), 'The future of learning,' describes the close nexus between technologies and educational environments, and in that context outlines how industrial and electronic revolutions have paved the way for traditional distance education, the mainstays of which is the print medium and electronic learning (e-learning), respectively. This Chapter describes how the evolution of mobile technologies "will change the distance student from a citizen who chooses not to go to college, to a person who not only chooses not to go to college, but is moving at a distance from the college" (p. 11). The emerging challenge, as a consequence, is to build appropriate learning systems for "wireless computing and telephony" in the same way "as eLearning has provided for wired computing and telephony" (p. 16).

Chapter 2 (p. 18 - 30) entitled 'From d-Learning to e-Learning' describes distance education, and discusses its two forms and traces its history. The author uses the expression "d-Learning" to refer to both distance learning (p. 18) and teaching at a distance (p. 19). He then makes a 
distinction between individual-based and group-based distance education, seen respectively as the result of the Industrial and Electronic Revolutions. Finer distinctions between these two are also made: while "pre-prepared" (p. 23) and "without pre-prepared" (p. 25) materials are used for individual-based distance training, the group-based distance education is for both full-time and part-time students. Group-based distance learning is seen as linking "the teacher and the learners in several geographic locations by simultaneous audio, video, or satellite links, to a network of remote classrooms" (p. 20). The author points out that "Group-based d-Learning systems are referred to as 'distance learning' in the United States, while individual-based systems are referred to as 'distance education' in Europe" (p. 20). He further adds, "The distinctions between the American distance learning based largely on synchronous communication technologies and the European distance education based in the main on asynchronous technologies is important because it influences development in both e-Learning and m-Learning” (p. 26).

Chapter 3 (p. 31 - 43) 'From e-Learning to m-Learning' moves forward from where Chapter 2 left off, by discussing the status of e-learning. The author defines it as "the award of nationally and internationally recognised university degrees, college diplomas and training certificates to students who spend all or much of their study programme sitting in front of a computer” (p. 15). Referring to the TeleEducation directory (http://courses.telecampus.edu), a worthwhile reference, indeed, which contains a list of a number of online courses, the author remarks, "there is a growing acceptance of Web components of courses contributing to the award of a degree” (p. 36), though "The status of e-Learning is high in corporate training" (p. 36). He also points out, "the growing availability of commercially available Learning Management Systems (LMSs)” (p. 36) attests to this trend.

Chapter 4 (p. 43 - 84) 'm-Learning initiatives today,' presents 30 predominantly European initiatives (21 mobile learning trials, two portals, three conferences, one workshop, and three articles on the theoretical constructs of mobile learning) "to give the background and context to the sector and demonstrate the growing importance of m-Learning as a field of educational research and endeavour" (p. 43). Contrary to the author's claim that: "30 mobile learning initiatives today are presented and analysed" (p. 43), this Chapter is a collection of the descriptions of m-learning initiatives without any meaningful analysis. It presents three theoretical constructs of m-learning, one each from J. Sarida ('What are limits of academic teaching? - In search of the opportunities of mobile learning'), K. Nyiri ('Towards a philosophy of m-learning'), and G. Ring ('m-Learning case study with Nokia and INSCAD).

Chapter 5 (p. 85 - 86) 'm-Learning on the screen phone', the shortest chapter in the report, features the short life cycle of screen phones, because "It was never likely that students would purchase a device like the screen phone merely for the purpose of study" (p. 86). This reflects the author's earlier statement: "If there is a rule about the choice of technology for distance training, it is that technologies that are available to citizens may succeed" (p.11), and which is true. However, the author is quick to point out that, Ericsson's decision to suspend the production of screen phones "does not in any way weaken the field of mobile learning. ..” (p. 86).

Chapter 6 (p. 87 - 113) 'm-Learning on personal digital assistants (Compaq iPAQ)', seems to be a critical one, given the focus of the report and that it contains a description of Compaq iPAQ 3650 Pocket PC, and a discussion based on the lessons-learned article written by Fagerberg, et al. on the design of a learning environment and its delivery "carried out at NKI distance education during the year 2001 of the EU Leonardo Project” (p. 88). The chapter describes how a Webbased course was adapted and designed to suit the purpose, the options thought of for its delivery (as content made available on a commercial server for online access via mobile phone; download- 
on-demand as zipped HTML files, and as ready-to-use Microsoft Reader files), and the reasons for the choice of MS Reader with ClearType.

Chapter 7 (p. 114 - 119) 'm-Learning on the smart phone (Ericsson R 380)' contains a

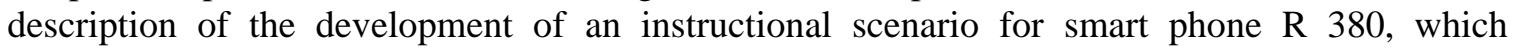
combines the roles of a mobile phone, personal digital assistant (PDA) and mobile Internet browser (WAP browser). The discussion of the pedagogical considerations to be addressed for the creation of learning environments suitable for smart phone is partly based on an article by Almeida ('The advantages and disadvantages of using WAP in developing an m-Learning course.')

Based on the article by Almeida referred to above, Chapter 8 (p. 120 - 125) 'm-Learning on the WAP phone (Ericsson R 520)' describes the development of courseware for R 520. As reported by the author, Almeida claims, "The main limitations of WAP today are related to the devices used and the mobile networks" (p. 122). For example, owing to narrow bandwidth for WAP network, large amounts of data, especially graphics and animations, are not recommended in mobile learning environments.

Chapter 9 (p. 126 - 166) 'Student use of m-Learning' describes "the experiences of mobile learning with real students in real learning situations" (p. 126). One such experience was an exercise in which 43 students (29 in Ireland and 14 in Norway) participated. Some of the criteria used to collect the feedback included student friendliness, didactic efficiency, technical feasibility, cost effectiveness, downloading and synchronising (to PDAs) speed, reading and studying/note taking ease on the PDA, interaction among tutors and students, etc.

In Chapter 10 (p. 166 - 169), 'Conclusion,' Keegan observes that mobile learning is firmly situated in the future of learning (p. 166) and advances two reasons to support mobile learning: the need for telecommunications industry to develop revenue-generating applications and the need to safeguard from the USA packaged learning environments, in which it leads. To complement the Ericsson and Nokia lead in wireless technologies, the author remarks that Europe must develop learning applications for wireless devices and take up the leadership role it enjoyed during the open education era. In any case, as Kristiansen remarks the challenge for the development of mobile learning "lies more within pedagogical and organisational aspects than with technological ones” (p. 55).

It is good to see that many titles listed under Bibliography (p. 170 -172) have electronic versions that are available online, which is indeed helpful to further satiate one's curiosity or interest in the field under discussion.

What seems to underlie the report is the anxiety, or perhaps the conviction that advancement of mobile learning will require a paradigm shift in learning. This interpretation merits debate. However, the point the report makes regarding the need for evolving a more robust instructional systems including design aspects, consequent to the inadequacy of present systems suitable for wired environments, is of critical importance. As much as the predominantly print-based traditional distance education provision is to be tailored to suit its electronic cousin, so is the need for trimming the online version available in wired environments to suit the wireless ones.

An account of the EU Leonardo da Vinci programme would have helped the readers place the report in the overall context. Except for a few sporadic references (of course, including a URL), 
the report does not contain information about that programme. It is also difficult to decipher why this report, in its presumably unedited and draft form, was posted on the Web. Had this been edited (content, language and copy), irritating errors in presentation including inconsistent descriptive statistics (p. 8, 11, 13), unabashed repetitions (p. 12, 15, 25, 34, etc.), language slips (spelling mistakes and wrong syntax, etc., pagination/layout, wrong placement of subheadings, etc.), would have been averted and could have made the reading interesting. The presentation is so woolly that it is difficult to say whether some of the statements made in the report belong to the author or others. Is there a lesson for those of us in the business of distance education, be it traditional or new technology-mediated/assisted? Despite content of remarkable quality, ineffective presentation can and will distract a reader, if the presentation is ineffective!

Furthermore, instead of contributing to clarity of the definition/ description of distance education (as did Keegan's now classic list of distance education characteristics), the presentation in this report is convoluted and confusing, to say the least. Linked to this definition fiasco is the issue the author raises as "an analyst," rather than a stakeholder who chooses "to champion distance learning or criticize campus universities” (p. 18): whether "institutional learning is essentially linked to these privileged places [schools and colleges] for institutional learning created by society” (p. 19). The point is learning (as we use it here) is indeed linked to institutions, whether the provision of education is place-bound or electronic. For example, in the context of the legal description of distance education, the author himself maintains "A student either contracts with a conventional school, college, or university to attend that institution, to join its community of students and to receive its certificate or diploma or degree. Whether this student receives the qualification by attending classes or lectures, working in the library, or the laboratory, or at a computer screen, or on the World Wide Web, depends on the legal requirements stipulated in the statutes of the institution” (p. 29).

In addition, going by the author's stance that "web-based education is best regarded as a subset of distance education" (p. 29), one may tend to believe that he considers m-learning along the same lines. But, he claims “. . . in spite of the arrival of eLearning, distance learning had established itself as a valid field of educational endeavour complementary to and side by side with conventional provision ....” (p. 30). This is as much contradictory as confusing. In addition, both distance learning and distance education are used synonymously as also learning, training, and education. But no reference is made in the report to this effect.

The report may be seen an account of the evolution of teaching/learning at a distance, from distance learning through electronic learning to mobile learning corresponding to the industrial, electronics and mobile revolutions. "Far from seeing conflict in the tensions ... the vision here is of the richness and choice that confronts the learner in the twenty-first century for both education and training ... .with the elimination of wiring and fixed installations for many applications, and the future blessing of voice input into machines.” (p.15). To this extent, the report clearly captures the possibilities of using wireless tools for providing education at a distance, but it chooses to ignore the issue of the digital divide. The author says, "At the time of writing we have only seen the beginning of the wireless information society" and "The World Wide Web and the Internet are not enough . . . wireless access independent of location and Internet services everywhere is the requirement. The air interface is replacing the wire interface.” (p. 11).

The overview of the report, which for reasons unknown, is given at the end of Chapter 1 , proclaims "This book seeks to present mobile learning within the context of distance learning (dLearning) and electronic learning (e-Learning)" (p. 17) which the author considers "the state of the art in distance learning at the time of writing" (p. 15). If this is so, how come mobile learning 
marks an evolutionary stage, a next stage in e-learning as presented in page 9: "The evolution in education and training at a distance can be characterised as a move form d-Learning (distance learning) to e-Learning (electronic learning) to m-Learning (mobile learning). These three stages of development. . ." It indeed is confusing. Based on the forecast about the access solely of mobile telephones, it has been pointed out: "There has never been a technology that has penetrated the world with the depth and rapidity of mobile telephony" (p.12) and suggested that the future lies in mobile learning. But what are the statistics available as regards screen phones, PDAs (Personal Digital Assistants), smart phones and WAP telephones, which the report deals with as mobile learning devices in Chapters 5 to 8? Are then mobile phones considered the primary device for mobile learning? If they are, then the argument about mobile learning will fall flat. All that one can then highlight is the possible support role of mobile phones for distance learning/teaching transactions.

The report would have been less distractive and cumbersome and, indeed, more forceful and revealing, had it focused only on the possibilities and promises the myriad wireless technologies hold for the conduct of teaching/learning transactions. I am at a loss to find why in the first instance the author laboured in vain to provide a theoretical scaffolding, when it is not available or not needed to the introduction of wireless (and therefore mobile, according to the author) technologies for distance teaching/learning. As Dichanz rightly observes, “ . . . e-learning seems to be used to convince users that some supernatural things happens with your brain when you place yourself in front of a computer screen. This miracle is unlikely to happen, as "learning in the real world is mainly hard work" and so learning "cannot be 'electronic"” and "learning cannot be mobile. Learners are probably more and more mobile, and they use mobile technology" (p. 90).

In a broad sense, this report demonstrates the influence corporate bodies can have on education in that companies involved in the business of mobile technologies fund research studies involving influential, and perhaps unsuspecting or willing, academics to promote their products under the guise of technology-enhanced learning. Sariola et al. wonder if the term 'm-Learning' 'is a commercial trick to market technology and educational services or if it is an emerging concept that educationalists should take seriously” (p. 91). As education gets increasingly commodified in the emerging trade in services regime of the World Trade Organization (WTO), it perhaps is little surprising that enterprises take upon themselves the task of research and its dissemination to further their interests, and as a consequence leave educational institutions, which hitherto assumed the role of generation, extension and dissemination of new knowledge, at the periphery. Government apathy towards higher education leaves it susceptible or vulnerable to the enterprising baits, lest it has to compete willy-nilly for scarce resources without any guarantee for success.

One may not fully agree with the mobile learning projection, but it is indeed a useful report to understand the growth of mobile technologies and their potential for learning. It is possible that the report will inspire readers/institutions to take up projects on similar lines, experiment with the PDA-based/ assisted learning environments and adjudge their use in various contexts. In any case, as the report is available online, every attempt must be made to access and read it in order to continue the discussion on distance education.

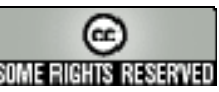


April - 2004

\section{Book Review - Reflections on Teaching and Learning in an Online Master Program: A case study}

Editors: Ulrich Bernath and Eugene Rubin (2003). Reflections on Teaching and Learning in an Online Master Program: A case study. 295 pages, softcover. Oldenburg: Bibliotheks-und Informationssystem der Carl von Ossietzky Universität Oldenburg. ISBN: 381420848 X

Reviewed by: Dianne Conrad, University of New Brunswick, Canada

In his review of a recent publication on leadership strategies in open and distance learning, Don Olcott commended the editors of that publication on their fine contribution, noting that there really is no substitute for experience in helping distance education's practitioners, leaders, and novices learning about open and distance education to acquaint themselves with the theory and practice that define the field. Bernath and Rubin's Reflections on Teaching and Learning in an Online Master Program gives us that rich study in experience as they examine online teaching and learning issues through the lens of the Master of Distance Education program (MDE), offered jointly by the University of Maryland University College and Carl von Ossietzky University of Oldenburg, Germany. This volume is the most recent publication in the Carl von Ossietzky University of Oldenburg's series from the Center for Research in Distance Education, Volume 6 of an intended 10.

The book contains 11 chapters divided into three parts. The first part outlines the basic structure of the program and details the organizational and managerial issues involved in the mounting and delivering of online programs. In the second part of the book, program faculty and visiting scholars draw upon their experiences to examine program issues from their respective positions. The third part gives voice to the program's students. To complete this volume, a series of indexes provide: a name index, an index of useful acronyms, and a highly detailed subject index.

Strategically, contributors' names, many of which are highly recognizable, are placed near the front of the book. As such, it falls upon the shoulders of these contributors to broad-brush the program and capture, theoretically and conceptually, the fundamental issues that inform the MDE case study. In their opening chapter, editors Bernath and Rubin outline the history of their joint program, tracing its political roots and development from its 1997 genesis in the experimental "Virtual Seminar for University Faculty and Administrators 'Professional Development in Distance Education"” program. We know from many recent studies in online education, that the details constituting a particular program's model of delivery are key to understanding that program's rationale, protocols, and resultant success. To this end, Bernath and Rubin describe the MDE by providing its early developmental history, course descriptions, lists of faculty, students' comments, and ample assessment information, including a detailed description of their assessment instruction and students' ratings. An appendix containing excerpts from their initial proposal will be of interest to those who may be contemplating putting forward similar proposals. 
Otto Peters' chapter on moderating a virtual seminar powerfully combines a career's worth of theory-based practice with his hands-on experience teaching in the MDE program. The case study format melds the immediacy of research's raw data with thoughtful interpretation: a bonanza of insight into the nuts-and-bolts of online teaching and learning. Peters' chapter is anchored by first-person narrative from the learners' perspective, the replication of email messages, and a section where he shares his personal techniques for communicating with seminar learners.

The writing here is forthright and practical, demonstrating an accessibility not always found in research papers. A full page lists the advantages of virtual seminars, as offered by the learners (who are identified by their real names!). This chapter's lengthy appendix also contains valuable information: copies of correspondence used to set up the seminar and copies of evaluation instruments. The format, unfortunately, remains clumsy and uncomfortable to read, as is the case throughout the volume.

Thomas Hülsmann's chapter (there are no chapter numbers!) addresses the intriguingly entitled concept of "texts that talk back" - a look at the potential for academic discourse in asynchronous fora. I personally found this chapter to be one of the most information-laden pieces of work I have ever encountered in our field. Thorough, detailed, anecdotal, research-based, Hülsmann plays ample quantitative data against references to Plato, Hegel, and McLuhan to create a deeply intelligent discussion on the nature of asynchronicity. Using the concepts of richness and noise, he captures the dichotomous nature of this medium wherein successful learners must "pursue their own learning agenda and, at times, link it to that of their peers" (p. 90). Section 4 of this chapter features an extremely detailed, graphic, and statistical 12-page "experiential" description of an MDE course. Too much information? Perhaps. I gave my students permission to "read by" it. A very eclectic and lengthy bibliography is followed by another statistically-intensive sevenpage appendix.

By comparison, Beaudoin's short chapter on "invisible" online learners was much more reminiscent of a journal publication. Explained by the author as representing only the results of a preliminary case study, Beaudoin nonetheless furthers our understanding of the nature of interaction and learning success through an articulate presentation of research-based findings.

The remainder of the second part of the volume addresses topics of support and costs. The title of Holmberg's short chapter suggests at first that it will discuss the issue of support, but it provides instead a brief overview of computer use in education. While slightly out of character with the intensive case-study orientations of other chapters, its conceptual discussion of the role of the computer in distance education is remains useful. Holmberg reminds us that the computer "does not represent the essence of distance education, which seems occasionally to be assumed. ..”

Those of us who have been responsible for constructing or delivering distance education programs appreciate the need for institutional support and infrastructure. In the chapter entitled, "Support Services for Online Faculty," the authors - administrators of, and teachers within, the MDE program - explore the key issues underlying the establishment of a supportive institutional culture. As befits a case study and as is typical of this volume, their discussion is detailed and information-rich. Its qualitative nature and structure renders this chapter more "reader-friendly" than some of the others in this volume. It is nicely referenced, drawing on a balance of internationally known sources and local documents. 
Hülsmann's second contribution to this work addresses the "dearth of cost data" that is made available on institutional projects such as this one. He does so in a very long 57-page chapter (It might be noted here that this chapter surpasses the combined length of the four student-authored chapters.) That said, Hülsmann's chapter contains, again, minutely detailed financial planning and analytical data as well as, surprisingly, methodological references that use Lincoln and Guba to explain the chapter's Geertz-like "thick description" and to differentiate between the concepts of generalizability and transferability. "Costs without camouflage" purports to strip away the cloak of secrecy that so often prevents the disclosure of distance education's true costs. To that end, Hülsmann's chapter includes answers to questions that "are asked again and again when it comes to online learning" and very detailed decompositions of related budgets and costs. The complexity of both building distance education programs and costing them, however, taxes the author's attempts to present a transferable understanding of his program's financial landscape. This is a difficult chapter that reminds us, once again, of the idiosyncratic existence of most innovative programming.

The concluding third section of Bernath and Rubin's monograph comprises four selections from participants in the MDE program. Collectively, the four chapters number only 49 pages: as short, topical, academically well-referenced papers they work well. While all offer insights on aspects of the MDE's mandate and implementation, only Fox's chapter presents a learner's personal account of his experience in the program. As such, it is a valuable commentary, raising questions where necessary, and providing insight into, among other things, areas of dissention among learners. Like the other chapters in this final section, Fox's work has been cross-referenced to other related topics discussed in the monograph.

If we can indeed learn from the experiences of others, then the MDE experience, well documented within this case study, is a valuable teaching tool. If you were to seek out this volume, however, and find it on the shelf, its poor first impression may well discourage you from looking past its exterior and discovering the value within its pages. Its appearance and style are decidedly un-bookish, resembling instead a legal journal from the outside and a technical report on the inside. The first page of each chapter is structured as a table of contents with an overwhelming amount of pagination detail. The chapters themselves have no numbers, making it difficult to refer to a particular piece, except as, for example, "the Peters chapter, on page 51." Valuable appendices to chapters are produced entirely in italics, and the labeling of figures and tables is often cramped and confusing. Charts and tables, laden with quantitative data, are squeezed in small fonts into busy pages. The awkward use of bullets, white space, indentations, quotation marks, and fonts often contributed to a sense of visual confusion for this reader.

In spite of that, this is a rich source of practical and applied knowledge that unflinchingly tackles the difficult and thorny questions that go hand-in-hand with innovation program implementation. Don't judge this book by its cover!
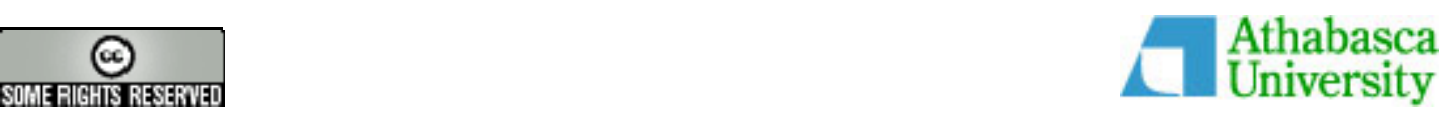
April - 2004

\title{
Technical Evaluation Report
}

\section{Best Practices in Online Conference Moderation}

\author{
Adrienne De Schutter, Patricia Fahrni, and Jim Rudolph \\ Master's of Distance Education Program \\ Athabasca University - Canada's Open University
}

\begin{abstract}
Facilitation by a moderator is crucial to a purposeful and productive conference. The moderator keeps the session focused, and ensures that all participants receive feedback regarding their contributions to the discussion. These functions are particularly important in the otherwise impersonal context of online discussion. The current report reviews recent literature regarding the moderator's roles regarding participant access and motivation, online socialization, information exchange and knowledge construction. A synchronous audio conference situation is assumed. Principles of online teaching and learning identified by Salmon (2002) are discussed, as well as the direct personal experiences of the report's co-authors.
\end{abstract}

\section{Access and Motivation}

Two contrasting approaches to conference moderation may be identified: 1) a facilitatory approach, which emphasizes the sharing of experiences between participants, so that they can build on each others' contributions without deviating too far from the intended topic of discussion; and 2) a more didactic, guided approach, which may be appropriate for the occasional steering and re-focusing of discussion. Different combinations of these two extreme approaches are appropriate in different teaching and learning situations contexts, and the moderator should be prepared to move effortlessly from one approach to the other as the moment demands.

The skills of online conference moderation are learned most effectively via a hands-on approach that encompasses the experience of being both a facilitator and a participant. Prior to the beginning of a conference session, participants should be encouraged to test their hardware and practice using the conferencing software. They should have access to information that explains how the software works (e.g., a troubleshooting guide, and a list of frequently asked questions). The moderator should provide an agenda including clear and relevant objectives, a description of what is expected of the participants, and an outline of recommended pre-readings. Green (1998) argues that provisions for ensuring that all participants are clear about the event's two-way expectations are central to a conference's design. Preparatory materials may be circulated by email or made available on, for example, a course website. The agenda for a conference session 
does not need to be elaborate or complex, but should operate with an "optimum amount of structure.”

\section{Online Socialization}

Green (1998) describes the social aspects of conference design as "creating a community." In considering the role of the moderator in an asynchronous text-based conference, Green acknowledges the particular problems that face a moderator in the attempt to foster interaction between participants. In face-to-face communication, visual and auditory cues are held to account for 70 percent of the information conveyed; and the moderator has the challenge of identifying alternative means of communication to compensate for the lack of these cues. Though they enjoy the advantages of aural cues, online audio conferences may also contain features that distort the manner in which they are transmitted and received. Even if ancillary webcam features are available, the visual cues provided may also be distorted by comparison with those conveyed in a normal face-to-face environment.

In this context, building a high degree of interactivity and participation is one of the moderator's most important facilitation skills (Hootstein, 2002). It is important for the moderator to create a learning environment that generates a sense of trust among the participants. Strategies such as personally welcoming everyone as they log in to the conference are important ("Hello, we hear you and are glad to have you with us"). Green (1998) suggests that beginning the conference by asking everyone to introduce themselves is a good way of promoting interaction. Such techniques put the participants at ease, and help to promote social interaction among them. They can be used to give the participants practice in interacting with the software interface; to inform them about their cohort; and to provide the moderator with information that can be used to engage them in conversations.

Hootstein (2002) indicates that effective facilitators use comments, questions, and probes to help learners connect around shared problems and experience in the use of the synchronous audio technology. For example, the tone of a response may be: "Thank you for posing that technical question. I'm sure many have been struggling with the same problem." Hootstein points out the many opportunities to model good behaviour that are provided by "verbal rewards;" and that moderators' wordings should be sensitively chosen. Thus, "Your speech is clear and concise" provides more constructive feedback than "Good job, I like the way you speak." What a facilitator says and how they say it both have a profound impact on the conference's outcome. Throughout the conferencing process, it is important to be mindful of 'netiquette,' which Greene defines as being respectful of other's opinions, beliefs and values; not dominating the discussion; and being supportive of others by encouraging and praising their contributions.

\section{Information Exchange}

Group size can be critical to the success of an online discussion, and to the effective exchange of information within it. Green (1998) suggests that the ideal number of participants in an asynchronous, educational, text-based conference is 10 to 15. It is the authors' experience that ideal group sizes in synchronous audio environments may be lower than this. It may be necessary for larger classes to be divided it into smaller groups in order to facilitate a meaningful discussion. 
Salmon (2002) recommends ensuring that participants are provided with practical ways of sharing information online, not only by linking with other media and processes in the course, but by sharing information about using the conference technology. The synchronous audio conference should be purposeful and play a role not met by other course processes. The text-chat boxes typically featured in online audio-conferencing software can be used to provide a means of sharing structured communication in parallel with the audio mode.

\section{Knowledge Construction}

Questioning techniques used by the moderator are critical to the function of 'knowledge construction.' Questions can be posed once a block of content has been provided for the purpose of focusing the discussion. The moderator should also provide brief summaries of relevant course content, paraphrases of participants' contributions, comparisons and contrasts between participants' views, and timely reiterations of earlier points. Green (2002) summarizes the moderator's responsibility to ask questions that are open-ended, thought-provoking, draw on personal experiences, and are suited to the learners' level. This approach stimulates interest by demonstrating the relevance of points and encouraging discussion of them. The moderator may call on a specific participant to speak, or may elicit responses from the group as a whole, though should be sensitive to the individual participants' personalities in, for example, providing warnings that such contributions will be invited. The features of synchronous audio technology should be carefully used in order to designate speaker order. This enhances the pace and purpose of the interactive event. In order to facilitate learning, the moderator needs to listen attentively and respond with positive and specific feedback.

It is also helpful for moderators to have access to information about the participants' hardware specifications, and to details of conference objectives, relevant text passages, definitions, illustrations, references, and hyperlinks. These can be "cut and pasted" into the conference text box at appropriate moments. In this case, learners may have to be advised to activate their text boxes. The moderator may also use features of the conferencing software during the session, to track student participation. Alternatively, s/he may simply use a checklist to record the frequency of contributions. As more software packages provide audio-archiving features, these may be employed for the purpose of more detailed records. The moderator may wish to follow up privately with non-participants via an email or telephone conversation.

In debriefing conference participants, the moderator can ask them to summarize the session's main issues and outcomes, thereby eliciting useful feedback about its content and process. It is usually appropriate for the moderator to close the session by providing his or her own summary of it, and clarify misconceptions and subsequent tasks.

\section{Conclusions}

Unlike asynchronous conferencing, the synchronous media afford little time for reflection and deliberation. Moderators of synchronous audio-conferences therefore face a daunting task. They must support both process and content, guide interaction through meaningful feedback and deft questioning strategies, and provide additional cues and information as needed. Moderating functions can be fulfilled collaboratively by teacher and learners, in the interests of effective information-sharing. Experience and practice is mandatory in the acquisition of moderating skills. 


\section{References}

Green, L. (1998). Playing Croquet with Flamingos: a guide to moderating online conferences. Human Resources Development Canada. Retrieved November 27, 2003 from: http://www.emoderators.com/moderators/flamingoe.pdf

Hootstein, E. (2002). Wearing Four Pairs of Shoes: the role of e-learning facilitators. Retrieved November 27, 2003 from: http://www.learningcircuits.org/2002/oct2002/elearn.html

Salmon, G. (2002). Five-step model of teaching and learning online. Retrieved November 27, 2003 from: http://www.centrinity.se/Conferences/Nerladdning/000231AE-80000001 /00A03C2A-001E85B5-00A03C32.7/Gilli\%20Salmon\%20Using\%20the\%20five.pdf

The next report in the series discusses potential educational uses of the 'Wiki'.

N.B. Owing to the speed with which Web addresses are changed, the online references cited in this report may be outdated. They can be checked at the Athabasca University software evaluation site: http://cde.athabascau.ca/softeval/. Italicised product names in this report are assumed to be registered trademarks.

JPB, Series Editor, Technical Evaluation Reports

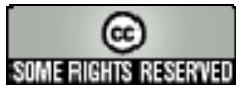


April - 2004

\title{
Technical Evaluation Report
}

\section{Educational Wikis: Features and selection criteria}

\author{
Linda Schwartz, Sharon Clark, Mary Cossarin, and Jim Rudolph \\ Master's of Distance Education Program \\ Athabasca University - Canada's Open University
}

\begin{abstract}
This report discusses the educational uses of the 'wiki,' an increasingly popular approach to online community development. Wikis are defined and compared with 'blogging' methods; characteristics of major wiki engines are described; and wiki features and selection criteria are examined.
\end{abstract}

\section{Defining Wikis}

According to Leuf and Cunningham (2001), creators of the original wiki concept, "a wiki is a freely expandable collection of interlinked webpages, a hypertext system for storing and modifying information - a database, where each page is easily edited by any user with a formscapable Web browser client” (p. 14). Content can be directly linked to that found in other wikis (interwiki) and in Web documents.

Browser-based access means that neither special software nor a third-party webmaster is needed to post content. Content is posted immediately, eliminating the need for distribution with the associated risk of virus transmission. Participants can be notified about new content, and they review only new content. Low graphic use results in pages that load quickly. Access is flexible all that is needed is a computer with a browser and Internet connection. Modular construction means that wikis can be simple or complex to meet user needs and skill levels.

Mattison (2003) states that “a wiki can be a blog, but a blog does not have to be a wiki." Wiki use is often compared with blogging. Blogs, or weblogs, are chronological online journals written mainly by individuals (although group blogs exist), to which readers post comments.

The main differences between the two approaches relate to notification of new content, editing format, and structure. Blogs typically use RSS (Really Simple Syndication) feeds to sort information and alert users to new content. Wikis usually use email notification. For students, an advantage of blogs is the use of 'What You See Is What You Get' (WYSIWYG) editing. Wikis usually employ a simplified markup formatting (although there are also WYSIWYG wikis). A 
disadvantage of using markup is the lack of standardization across various wiki programs (Mattison, 2003).

Blogs are arranged chronologically, while wiki structure can be based on hierarchical subject divisions through new page creation and internal and external hyperlinking. These features make wikis highly suitable for educational use. Blogs are more structured; wikis are more flexible. Most wikis include a search feature; many blogs do not. Once a blog addition is posted, it often cannot be edited. User communities are found at both blog and wiki sites.

\section{Educational Uses}

It is difficult to estimate the number of wikis currently used in university settings, and the range of ways in which they are being used. In order to attempt this, 24 university wikis were examined. The universities using them are located in countries including Canada, the US, Germany, New Zealand, Switzerland, and the UK. A natural tool for distance education (DE), wikis enable instructors to create interactive activities for their students, and to present course information such as resources, external links, project information, and frequently asked questions (FAQs). Instructors may also wish to monitor wiki discussions to determine problem areas for students. University wikis are commonly used as knowledge repositories. Godwin-Jones (2003) suggests that wikis may be ideal for building communities of practice by creating a collective repository of expertise in a subject area, which is refined over time by the contributions and problem-solving of interested individuals. It is this function that distinguishes communities of practice from other online communities, such as chat groups or bulletin boards.

Wikis may also exhibit some of the elements that Wenger (2001) considers fundamental to the creation of successful communities of practice - among them, a virtual presence, a variety of interactions, easy participation, valuable content, connections to a broader subject field, personal and community identity and interaction, democratic participation, and evolution over time. Many wikis also have a core group or individual that takes active responsibility for directing the community. They provide a forum for learners to discuss topics and obtain information relating to courses, extra curricular activities and associations in their fields of interest. Personal home pages and discussion areas help to humanize the learning experience, and to provide social interaction among students.

Typically, universities integrate wikis seamlessly into their main website pages. Many of the wikis surveyed are currently in the early stages of development. Most are purely text-based with few images. In general, university wikis appear to be used more by specific departments or for particular topics, than for campus-wide uses (e.g., institutional information). The use of wikis for administrative scheduling, faculty use, learning support materials, and course management, appears to be rare. Of those we examined, more dealt with activities, events or clubs, than with curricular issues. Project management is a fairly common function, by course/ group projects in particular fields including music and languages. University-based wikis seldom appear to be used for entertainment, student feedback, or journaling purposes. Wikis with a definite purpose and structure appear to be more common than wikis left basically unstructured, or for personal student use. Perhaps the open access to wikis for editing deters regular university use for content that must not risk change. 


\section{Basic Features and Comparison of Major Wiki Engines}

Evaluating wikis is different from evaluating vendor supplied or proprietary programs, which have a fixed set of features. All wikis can potentially adopt all features found in other wikis, simply by accessing and customizing the source code. Rather than attempting to categorize the myriad wiki versions, this report describes the basic characteristics and features of wikis, and attempts to provide an easy approach to selecting wiki features.

According to Meatball Wiki (2003), there are more than 200 wiki programs although only a handful might be considered unique: Dolphin Wiki, Php Wiki, Moin Moin, Swiki Clone, Twiki Clone, UseMod Wiki, Tikki Tavi, Zwiki Clone, and Open Wiki. In addition to these nine core wikis, we compared WikiWiki Web (the first wiki) and Seed Wiki (a WYSIWYG wiki). Feature categories include: source code, wiki management, page formatting, access control, communications, support, and advanced features.

Generally, there were more similarities between them than differences. While written in several different programming languages, each with its own set of formatting rules, most of the wikis used the same basic page formatting functions (i.e., text editing and image, table, list, hyperlink and file insertion). Seed Wiki was the only one with a WYSIWYG text editor. All of these programs are open source. Additional features, such as polling and administrative levels, can be added to Seed Wiki for a fee. Other consistent features included interwiki linking; archiving; a "sandbox" area to practice formatting, and user support. Three of the wikis had spell-check features, and two allowed the insertion of emoticons.

Disparities were evident in access control, and appear to be based on the underlying philosophy of the developers as to the degree of freedom they are willing to pass on to the users. While some wikis provide the ability to password-protect pages, restrict users, and provide various level of administrative control, others allow open access to the entire wiki. Very few of the wikis we examined had advanced features such as blogging, polling, calendars, and the use of RSS. This seems to coincide with research by Leuf and Cunningham (2001) who suggest that a wiki that functions independently of any special add-ons or plug-ins, tends to meet the needs of a fairly broad audience.

\section{Wiki Selection Criteria}

The following list outlines criteria for consideration when selecting a wiki for educational use. (These are consistent with the criteria adopted earlier in this Report series.)

\section{Cost:}

o Open source software vs. financial outlay required

o Licence fees (scaled per user)

o Supportable programming language

\section{Complexity:}

o Online technical support (documentation, manual, FAQs)

o Help by email/ phone/ fax/ online forum

o Plug-in or scripting exchange

o Sandbox

o User community 
Technical Evaluation Report 27 Educational Wikis: Features and selection criteria

o Web-hosted or download required

\section{Control:}

o User registration

o Password protection of core pages

o Levels of user rights to edit

o Active user list

o Participants online

o Easy to restore damaged or deleted pages

\section{Clarity:}

o Index/ site map

o Interwiki - format that facilitates linking content between different wikis; two common formats are are CamelCase, and [free links]

o Back-linking

o Page hierarchy

o History of all versions (revision tracking)

o Archiving of all pages

o New page creation

o Page deletion

o New content identified (version compare)

o Email notification of changes

\section{Common Technical Framework (CTF):}

o Editable by anyone with a forms-compatible browser

o Cross-platform

o Internet and Intranet installation

o Resolution of simultaneous editing conflicts

o Plain ASCII text storage

\section{Features:}

o Editable by major browsers (Internet Explorer, Netscape)

o WYSIWYG editing

o HTML support

o Text editing (italics, font size, colour)

o Image insertion

o Hyperlink insertion

o Tables

o Lists (numbered, bulleted, hierarchical)

o Media insertion (streaming audio/ video)

o Search

o Spell-check

o Emoticons

o Blogging

o Polling

o Calendar

o RSS

o Link checking

o Drawing tools

o Equation editor 
Technical Evaluation Report 27 Educational Wikis: Features and selection criteria

o Synchronous text messaging

\section{Further Educational Considerations}

Although the evaluation team was able to locate numerous examples of the growing wiki trend in education, few were in distance education contexts. Yet wikis can provide an efficient, flexible, user friendly and cost-effective interface for collaboration, knowledge creation and archiving, and student interaction. Lack of standardized formatting across wiki programs makes WYSIWYG editing attractive. The need for minimal technical skills allows users to concentrate on content rather than on the technical process of writing, and reduces the need for student support. For example, while 'bolding' may require HTML tags $(<\mathrm{b}>$ word $</ \mathrm{b}>$ ) in one wiki, it may require three single quotes in another ("'word' "'). Udell (2000) makes the point that most formatting is not mnemonically designed. Clicking the B icon in a toolbar is more familiar and user-friendly.

In some WYSIWYG wikis, users attempting to cut and paste content from word processors should be cautioned to use simple ASCII text to avoid formatting difficulties. With the advent of free tools such as htmlArea (2003), that can turn any text area into a WYSIWYG editor, it is hoped that all wikis will be able to offer WYSIWYG editing. WSYIWYG wikis currently include Seed Wiki, EclipseWiki and some versions of Plone.

Features rarely incorporated in wikis are: equation editor, synchronous text messaging, link checking, and drawing whiteboard (some do have drawing tools). If coursework requires these capabilities, an integrated collaborative software program may be a better choice.

While open source programming may make wiki use cost effective, it may be necessary to have support staff with programming skills in the appropriate language for server maintenance, customization and component creation (Mattison, 2003), particularly for campus-wide use.

Unlike threaded discussions where the writer is identified, it is usually impossible to identify contributions to a wiki. This makes apportioning credit difficult and the authority of the content hard to establish.

\section{Conclusions}

It appears that the full DE potential of wikis remains to be realized. Further evaluation of the contribution of wikis for developing communities of practice in DE education is warranted.

\section{References}

Godwin-Jones, R. (2003). Blogs and wikis: Environments for on-line collaboration. [Electronic Version]. Language, Learning and Technology, 7(2), 12 - 16.

htmlArea (n.d.). Turn any text area into a WYSIWYG editor. Retrieved November 23, 2003, from: http://www.interactivetools.com/products/htmlarea/

Leuf, B., and Cunningham, W. (2001). The Wiki Way: Quick collaboration on the web. Boston: Addison Wesley. 
Mattison, D. (2003). Quickiwiki, Swiki, Twiki, Zwiki and the Plone wars: Wiki as a PIM and collaborative content tool, [Electronic version]. Searcher, 11(4), 32 - 48.

Meatball Wiki (n.d.). MeatBall Wiki FAQ. Retrieved November 21, 2003, from: http://www.usemod.com/cgi-bin/mb.pl?MeatballWikiFaq

Udell, J. (2000). Why not WYSIWYG writing for the web? Retrieved November 20, 2003 from: www.byte.com/column/2000/05

Wenger, E. (2001). Supporting Communities of Practice: a survey of community-oriented technologies. Retrieved November 29, 2003, from: http://www.ewenger.com/tech

The next report in the series reviews Speak2Me, a synchronous audio system used for ESL teaching in Taiwan.

N.B. Owing to the speed with which Web addresses are changed, the online references cited in this report may be outdated. They can be checked at the Athabasca University software evaluation site: http://cde.athabascau.ca/softeval/. Italicised product names in this report are assumed to be registered trademarks.

JPB, Technical Evaluation Reports, Series Editor

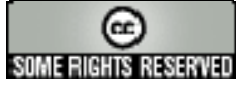


April - 2004

\title{
Technical Evaluation Report
}

\section{Speak2Me: Using Synchronous Audio for ESL Teaching in Taiwan}

\author{
Deborah K. LaPointe \\ Albuquerque Technical Vocational Institute \\ Katherine R. B. Greysen \\ College of Education \\ University of New Mexico \\ Kerrin A. Barrett \\ College of Education \\ University of New Mexico
}

\begin{abstract}
The use of a synchronous audio tool is discussed for teaching English as a Second Language (ESL) in Taiwan. Over several months, a community of practice has formed among teachers and teaching assistants, transcending cultural differences. Exploring the relationship that has developed between teachers and teaching assistants forms the basis of this report. We will also consider the technology underlying Speak2Me's program and its relationship to providing students with quality pedagogy and learning flexibility.
\end{abstract}

\section{Online Content: Articles and cultural perceptions}

The biggest challenge facing English as a Second Language (ESL) learners in Taiwan is their lack of opportunity to practice speaking English. To meet this need, Ladder Publishing Co., Ltd. of Taipei, began an innovative Web-based ESL program in February, 2003, called Speak2Me. The cost of designing, developing, and implementing the project was less than US $\$ 50,000$, making it an affordable distance learning alternative for developing nations. Using an iTalk synchronous platform, American teachers, assisted by bilingual Taiwanese teaching assistants, using voice and chat, teach conversational English based on a brief article on a topic of current interest.

The report proposes that synchronous learning environments provide a richer context than asynchronous environments for online intercultural communities of practice, to develop into engaging and empathetic virtual communities. The use of synchronous voice in teaching ESL has enabled further investigation of cultural practices and norms in Taiwan that could not have been possible in a static, asynchronous environment. Central to the Speak2Me program are the articles, 
taken from Speak2Me's print magazine and placed online in the iTalk window. Teaching assistants and, if present, students, read the articles aloud, paragraph by paragraph. Discussions around each of these current topics have enabled us to understand Taiwanese culture in more depth and to form closer bonds with the teaching assistants.

For example, the article 'Talk Dirty to Me' discussed the issue of online pornography, including vocabulary words such as 'skin flick.' While we, as older female Euro-Americans, were quite taken aback at the article, the younger female Taiwanese teaching assistants had no qualms about teaching it. Their response to teaching what we considered a very controversial article, suggests that our perceptions regarding sex and sexuality are quite different. Another article, 'Play On!' talked about the possible link between violent video games and violent behavior. Again, in our conversations with both male and female teaching assistants, we found that our liberal American views linking video games and violence were quite different from theirs. The teaching assistants to whom we spoke at length, felt there was no connection between playing violent video games and actually committing a violent crime. Other articles on business and culture, for example, have provided additional opportunities for discussion and debate, enabling us to identify and learn more about cultural differences, leading to scaffolding of knowledge.

\section{Social Interaction}

Such social interaction has always been a defining characteristic of education, training, and more generally of learning. In fact, several learning theories rely, in part, on social interaction to explain how learning occurs (Beatty, 2002). Socio-cultural theory, for one, focuses on the causal relationship between social interaction with others and an individual's cognitive development. Vygotsky (1978) wrote that the individual grows into the intellectual life of those around him or her, as more knowledgeable persons act as facilitators, leading the learner beyond where he or she can function without help. Until the learner internalizes society's tool kit of ideas, concepts, and theories, the learner must 'borrow' the knowledge and consciousness of the facilitator to enter a language (Bruner, 1986), discipline, community of practice, or culture.

Acting as facilitators and bridging that gap for the American teachers are the teaching assistants. As the teacher/ teaching assistant community has evolved, the role of the teaching assistants has evolved as well, from an almost silent partner acting only when called upon (e.g., providing translations when necessary), into taking on the active role of co-teacher. This team-teaching relationship facilitates teaching assistants' role in the virtual classroom, which often provides a richer cultural environment, better student interaction, and a more dynamic learning experience for all involved.

Another form of interaction has been through role-playing. When students are absent from the classroom, teaching assistants may role play as students. This enables us to practice our synchronous teaching skills, while at the same time trying out different teaching methods targeted at differing levels of language ability. Often these sessions are quite fun, bringing out everyone's personalities as both sides try to act out their roles.

As the Speak2Me online community has matured, the 'electronic personality' (Palloff and Pratt, 1999) of each teacher and teaching assistant has also emerged. Pratt's work has shown that for an electronic personality to exist certain elements must manifest, including the ability to deal with emotional issues in textual form and the ability to create a sense of presence online through the personalization of communication. Both these elements are present in daily interactions between 
teachers and teaching assistants, who often must cross cultural barriers to understanding between themselves and Speak2Me's students. In the months since Speak2Me was launched, close bonds have been formed with only voice and text chat to create a sense of social presence.

\section{Synchronous Intimacy and Immediacy}

Mayer (1999) asserts: "students are better able to integrate verbal and visual representations when they receive both verbal and visual materials rather than when they receive only verbal [or text] material." In addition, Jelfs and Whitelock (2000) stress that: "sound gives feedback to the user and offers greater levels of reality." The synchronous voice capability of Speak2Me's platform has enabled teachers and teaching assistants to share personal experiences more intimately and immediately than through asynchronous discussions or plain text chat. We believe that the relationships that have grown out of these conversations have developed more rapidly and more deeply, and have been sustained longer, because of the voice capability. For example, one teaching assistant has shared her family's wedding with us; another supplied the recipe for mango ice cream, while another shared her thoughts of loneliness upon moving to a new home. Yet another teaching assistant told us his feelings about entering a mandatory stint in the military. These emotional attachments were felt even more deeply upon hearing of the loss of one of Speak2Me's staff members. Though we never met him face to face, we felt a profound sadness for both him and his family.

Understanding the electronic personalities that have emerged through the Speak2Me classroom and technology suggests the sense of the alternativeness of human possibility (Bruner, 1986). Yet intimacy and immediacy are not a one-way street. As teachers, we share our personal stories as well. As a group, we have shared views on spirituality, comparing Western and Eastern beliefs; talked about New Mexico history and heritage; and even delved into marriage and relationships, offering up experiences and advice when asked.

One teacher had established a personality talking with the teaching assistants about the "little stuff of everyday life" - the daily chitchat. The teaching assistants and teacher talk about day jobs, daily meals, fruits available in Taiwan, vacations and holiday plans, pets' names and personalities, videogames, new recording artists, and family members. Another teacher has established an "intercultural food swap" with the Taiwanese teaching assistants. The teacher mails foods traditional to the New Mexican culture and diet to Taipei, and in return receives menus and examples of traditional Taiwanese cooking. For the most part, all the teachers and teaching assistants have exchanged some form of intimate communication about themselves, which has enhanced the social presences of all participants. This exchange of information has also taken the form of individual and family photos, pet photos, and websites to give each other more information about personal topics. As a result of the exchange of personal information, there is a higher level of familiarity, which leads to a greater degree of intimacy for all involved (Tu, 2001).

\section{Social Presence and Emoticons}

Two key factors in social presence are intimacy and immediacy, both of which are influenced by interactivity, collaboration, and reflectivity. Research by Gunawardena and Zittle (1997) has shown that participants who felt a higher sense of social presence within a conference enhanced their socio-cultural or socio-emotional experience by using emoticons to express non-verbal cues in written form. Teaching assistants and teachers occasionally include emoticons in their text 
messages to each other in the S2M classroom and in the email messages they exchange. During our many voice-chat sessions with teaching assistants, we have encountered a number of unusual and expressive emoticons (e.g. “@@” and “^_^”). The emoticons serve to "warm” and personalize the discussions or messages by greeting each other, showing agreement, clarifying the intent of a message, and suggesting a solution while leaving the discussion open (Fahy, 2003) and generally adding charm to a message. Both the teaching assistants and teachers use emoticons to accomplish similar purposes; however, frequency of use and the shapes of the emoticons vary.

At first, the U.S. teachers infrequently used U.S. emoticons, which are most often built with keyboard characters, producing an image of a sideways face, requiring the reader to tilt his or her head to read the U.S. emoticons. U.S. emoticons seem to emphasize the role of the mouth when conveying the emotional context of a message. Common U.S. emoticons include:

\begin{tabular}{|ll|ll|}
\hline$:-)$ & Happy person & $8-\mathrm{O}$ & Shocked \\
$:($ & Sad person & $--\backslash$ & Undecided \\
$;)$ & Winking person & & \\
\hline
\end{tabular}

The Asian emoticons are read horizontally without tilting one's head. The teaching assistants use emoticons more frequently than U.S. teachers do in their text messages. The Taiwan emoticons emphasize the shape and role of the eyes in portraying an emotion (Sugimoto and Levin, 2000). Frequently used Asian emoticons include:

\begin{tabular}{|c|c|c|c|}
\hline $\begin{array}{l}{ }_{-}^{\wedge}{ }^{\wedge} \text { or }(\wedge \wedge) \\
(\mathrm{l} \quad \mathrm{H})\end{array}$ & $\begin{array}{l}\text { Happy person } \\
\text { Crying person }\end{array}$ & $\begin{array}{l}(@ @) \text { or } \\
(@)\end{array}$ & $\begin{array}{l}\text { Giddy, dizzy, } \\
\text { shocked person }\end{array}$ \\
\hline $\begin{array}{l}><\text { or }>< \\
{ }^{*}\end{array}$ & $\begin{array}{l}\text { Sad or angry } \\
\text { Winking person }\end{array}$ & $(\wedge \wedge ;)$ or $\wedge \wedge^{\wedge \prime \prime}$ & $\begin{array}{l}\text { Cold sweat; writer } \\
\text { is afraid he cr she } \\
\text { is saying something } \\
\text { too strongly }\end{array}$ \\
\hline
\end{tabular}

The use of emoticons has enabled the community to express feelings in textual form. As we have become increasingly friendly with the teaching assistants, we have begun to use emoticons, including the Asian emoticons listed above. We have also begun to create new emoticons. For example, during a discussion about the approaching Thanksgiving holiday and pumpkin pie, one of us typed this emoticon: **_**. It was decided, this emoticon would refer to eating too much pumpkin pie. Likewise, over time the teaching assistants have increased the frequency of their use of emoticons in messages to us. This increased use of emoticons suggests the development of electronic personalities and an increase in social presence.

\section{Speak2me'S Website: Intersection of Technology and Culture}

Supporting these online interactions, the community, and the ESL classes is the Speak2Me website itself. The basic site (http://www.speak2me.net) focuses on text and audio combined with the use of graphics and a chat box. A high-speed modem connection (e.g., cable, DSL) is a necessity for voices to be heard clearly and reliably, without breaking up during transmission. 
This aspect of technology might be a barrier to access for some developing nations, particularly those with large rural populations. However, with the rapid deployment of cellular technologies and the advent of satellite Internet, implementing higher bandwidth applications in rural areas will become increasingly possible.

The synchronous voice technology and the additional equipment required can add technological problems to the classroom. Therefore, the teacher and a bilingual teaching assistant provide learner support during the class period. Although the teacher facilitates each individual lesson plan, the majority of the classroom interaction is based on learner participation and control of the multimedia environment, with primary importance based on functionality of the interface within the overall multimedia design. In this manner, the synchronous Speak2Me learning environment enables the students, teachers and teaching assistants to learn from each other, scaffolding on previous experiences and knowledge to construct new meaning, not only between the different cultures but with regard to the different languages, as well.

Many technical improvements have been made to the virtual classroom since the inception of the Speak2Me program. While some of the changes have focused on basic modifications to the multimedia interface (e.g., color of the background, text size, addition of digital clocks), other revisions have focused on cultural differences and improved communication strategies. Several adjustments made to the classroom to improve communication are the result of teacher/teaching assistant suggestions. For instance, the chat-box was altered to allow for direct text communication between teacher and teaching assistant and/ or the teaching assistant and a student. This chat-box modification allowed for bilingual interpretation for students of technical assistance and clarification of directions when necessary. The direct line chat-box also allows the teacher and the teaching assistant private communication where they can discuss and adjust the lesson plan to match students' level of English fluency.

Many more modifications clearly reflect the Taiwanese culture. As noted by Deubel (2003), the "user interface plays a central role in learning [when] using multimedia.” Indeed, the technology selected by Ladder to facilitate interaction and learning must provide quality pedagogy which (1) allows flexibility of learning; (2) supports diverse learning styles and degrees of learner control; (3) is responsive to learner and teacher support; and (4) affords novelty. Therefore, it follows that the user interface reflects the culture of the students it serves. Some of the cultural modifications include headings and labels in Chinese instead of English and the design of the HELP! icon. Unlike American help icons, which are often friendly and playful animations (i.e., the Microsoft Paperclip), the HELP! icon for Speak2Me is a small green figure with a large head, a distressed look, and waving arms. When students click on the icon, a Chinese question and answer troubleshooting guide is provided.

\section{Conclusion}

The Speak2Me ESL model supports previous assertions that students integrate verbal and visual representations better using verbal and visual materials than when they receive verbal [or text] material only. We conclude that the audio and visual technology driving the Speak2Me synchronous method of teaching ESL bridges cultural differences and establishes tightly knit communities of practice more rapidly than other, asynchronous methods of distance education. Moreover, the iTalk platform is an inexpensive distance education alternative for use by developing nations that seek to improve upon current educational practices, and to put into practice collaborative learning environments able to reach geographically distant populations. 


\section{References}

Beatty, B. J. (2002). A situationalities framework for choosing instructional methods. Dissertation Abstracts International. UMI No. AAT 3054431.

Bruner, J. (1986). Actual Minds, Possible Worlds. Cambridge, MA.: Harvard University Press.

Deubel, P. (2003). An investigation of behaviorist and cognitive approaches to instructional multimedia design. Journal of Educational Multimedia and Hypermedia, 12(1), 63 - 90.

Fahy, P. J. (2003). Indicators of support in online interaction. International Review of Research in Open and Distance Learning, 4(1). Retrieved September 2003 from: http://www.irrodl.org/content/v4.1/fahy.html

Gunawardena, C. N., and Zittle, F. (1997). Social presence as a predictor of satisfaction within a computer mediated conferencing environment. American Journal of Distance Education, 11(3), $8-25$.

Jelf, A., and Whitelock, D. (2000). The notion of presence in virtual learning environments: What makes the environment 'real'? British Journal of Educational Technology, 31(2)145 152.

Palloff, R., and Pratt, K. (1999). Building Learning Communities in Cyberspace: Effective Strategies for the Online Classroom. San Francisco: Jossey-Bass.

Sugimoto, T., and Levin, J. A. (2000). Multiple literacies and multimedia: a comparison of Japanese and American uses of the Internet. In G. E. Hawisher and C. L. Selfe (Eds.) Global Literacies and the World-Wide Web (p. 133-156). New York: Routledge.

Tu, C. H. (2001). How Chinese perceive social presence: an examination of interaction in online learning environment. Education Media International, 38(1), 45 - 60.

Vygotsky, L. S. (1978). In M. Cole, V. John-Steiner, S. Scribner, and E. Souberman (Eds.) Mind and Society (p. 79-91). Cambridge, MA.: Harvard University Press.

The next report in the series reviews a series of integrated learning management systems.

N.B. Owing to the speed with which Web addresses are changed, the online references cited in this report may be outdated. They can be checked at the Athabasca University software evaluation site: cde.athabascau.ca/softeval/. Italicised product names in this report can be assumed to be registered trademarks.

JPB. Series Editor, Technical Evaluation Reports

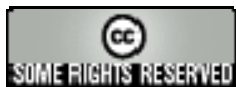


April - 2004

\title{
Technical Evaluation Report
}

\section{Integrated Learning Management Systems}

\author{
Sharon Clark, Mary Cossarin, Harry Doxsee, and Linda Schwartz \\ Master's of Distance Education Program \\ Athabasca University - Canada's Open University
}

\begin{abstract}
Four integrated learning management packages were reviewed: CentraOne, IntraLearn, Lyceum, and Silicon Chalk. These products provide different combinations of synchronous and asynchronous tools. The current report examines the products in relation to their specific value for distance educators and students.
\end{abstract}

\section{Introduction}

Report \#5 in this series has indicated that the ideal learning management systems favour a learner-centred approach, and contain the following features: a range of content tools for synchronous as well as asynchronous collaboration, and student management tools. Four integrated software packages were evaluated according to the selection criteria of cost (institutional and user), complexity (user focus), control, clarity, common technical framework, and features (see Report \#7 in the series).

\section{Product Trials}

\section{CentraOne (v5.2)}

This collaborative platform contains three components: the Agenda Builder, including content creation; the Symposium, or virtual classroom; and the Conference, a virtual meeting-place. The current evaluation concentrates on the DE potential of the first two of these features. Up to 500 participants can interact simultaneously via the platform. The Agenda may contain files, file directories, URLs, and CentraOne tools such as Whiteboard, Web Safari, and AppShare. A presentation created with the Agenda Builder can include a combination of PowerPoint slides, websites, videos, polling and other evaluation tools, and feedback. The content developer creates the presentation and imports it to the platform as a .saz file. The Symposium rooms provide a whiteboard, pointers and other tools for the session leader, and markup tools permitting various types of interaction. The instructor has the ability to enable/ disable tools as needed.

Installation of the CentraOne software is a simple process of downloading browser plug-ins, and the interface is uncluttered and user-friendly. Students access personalized home pages and enter 
the virtual classroom via an ID and password, with the option of perusing the content before the session. Public and private chat tools are available. Students can ask the instructor direct questions, and can click on icons simulating aspects of a traditional classroom (e.g., 'yes' and 'no' responses, a raised hand, 'laughter,' and 'applause'). The instructor receives feedback via a class list, indicating the person speaking, each participant's responses, and group pacing. Participants can view and broadcast live video, with recording and immediate playback options. They can move around the recorded material at will, completing evaluation surveys, etc. Survey results are recorded in the CentraOne database. Technical support for the product is via voice, online help, and easy-to-understand manuals.

In the current evaluation, slight delays were noted as slides loaded for participants to view. One evaluator experienced occasional breaks in audio transmission requiring an exit from and return to the session. CentraOne operates on all current Windows platforms, permitting sharing of Windows applications by the leader and participants. The product makes few demands on users' hardware (requirements are Pentium with $133 \mathrm{MHz}$ speed and $64 \mathrm{MB}$ RAM, or higher), though it does not currently accommodate the Macintosh platform. The application and add-on modules can be licensed separately, or as a complete collaboration environment hosted on an institutional server or on that of the vendor. Pricing models are based on configuration and volume discounts. Hosted on an institution's site, the one-time cost of all real-time components (up to 50 participants) currently starts at approximately CDN \$50,000.

\section{IntraLearn}

IntraLearn is a package of collaborative tools designed for a wide range of users: higher education, K-12 schools, associations, franchise systems, corporations, health care, defense, government, insurance, financial services, telecommunications, and other learning service providers. It provides asynchronous communication by internal email and discussion boards, and synchronous interaction by text-based chat and a simple whiteboard. An optional audioconferencing component is available in the product's high-bandwidth version. Videoconferencing is not provided, but an external video technology can be integrated into the software via add-ons and plug-ins. The interface has a consistent, intuitive and attractive design, and navigation is straightforward. The password-protected course materials can be created outside the IntraLearn platform and uploaded to the server; or an inline editor can be used for direct content creation. The instructor can control course features (e.g., whether exams and whiteboard are turned on, course modules available for the students to view). Screen size, layout, resolution, and audio quality of each course module, can be personalized according to user needs. Banners and pop-up advertisements are not standard features, though users may insert them (e.g., to keep students abreast of important course news). Courses can be linked to other online sources (e.g., electronic textbooks). Search and URL reference features are provided. Attachments can be inserted into the email, chat, and discussion features, and grades displayed in the grade-book. Tests can be incorporated into course modules using self-scored items (e.g., multiple choice, trueand-false, etc.). The administrator can track students' activity in the course via user-friendly tools for registration and report generation.

IntraLearn is Windows NT server-based, for use with the Internet Information Server, Cold Fusion Web Server and Microsoft SQL, and with Internet Explorer. It runs on a TCP/ IP connection. No download/ installation process is required. The platform can be hosted by a certified IntraLearn service provider, or licensed for an internal Intranet behind a firewall. Customers may choose a low- or high-bandwidth version. Hosted courses cost approximately 
\$100 CDN per student, and have technical support. Server purchase includes a negotiated initial fee (approx. \$20,000 CDN) and optional annual support (approx. \$10,000 CDN) providing access to upgrade versions. If the server is purchased, the customer can sell a negotiated number of its portals to other institutions in order to generate revenue.

\section{Lyceum}

Lyceum is the synchronous, collaborative tool developed and used by the British Open University (OU) to enhance its distance-education programs. It comprises a set of text-chat and other workspace tools with audio-conferencing. A free copy of the client software is available via a 30$\mathrm{mb}$ download, or from the OU on a CD. The administrator assigns password-protected access to a subset of work areas, containing a selection of audio and other features for particular work groups. No asynchronous communication tools are provided. Meetings can be public or private. Navigation through the work areas is seamless and intuitive, using a graphical interface resembling rooms in a multi-level building. The interface is attractive and well organized, and the layout of controls for the various functions is user-friendly and consistent from room to room. The display sizes are fully adjustable. If window dimensions are too small, however, the icons controlling the various functions tend to overlap, becoming cluttered, or disappearing altogether. Text and graphics are consistently sharp, though some degradation of quality can occur when images are imported. Import options are currently restricted to digital image and webpage formats. The user can paste an image onto the whiteboard, or can create new images on it via multi-coloured text and drawing tools. Data can be exported in selected proprietary formats. The document window is a simple word processor with collaborative editing capabilities. The 'concept mapper' allows shared contributions to be organized within text-box nodes positioned and linked on a grid to highlight relationships between them. The interface enables collaborative Web browsing. The contents of any of the visual workspace tools can be saved for reloading and reviewing. In the offline mode, users can prepare materials in advance, saving them for later uploading. In most rooms, multiple occurrences of whiteboards, documents, concept maps, and browsers can be created, though window contents cannot currently be printed. All participants can be assembled to focus on a particular screen by pressing the 'gather' button. Audio chat is restricted to a maximum of two users at a time, and users can indicate their wish to speak via 'raised hand' cue. A polling feature is available for the instant assessment of group consensus. Long-term storage of content within the Lyceum environment is not practical. File-sharing among users is not supported.

The client installation package includes a comprehensive tutorial with clear instructions and visuals. Technical support is provided in online and offline HTML formats, and by email and telephone. All parts of the program are modularized to facilitate updates and product reliability. Lyceum is hosted only on the OU's master server, which administers the software updates, authentication of users, and the distribution of resources to users. If the service malfunctions, the event is logged to assist developers in the design of upgrades. Slave servers are responsible for handling events associated with particular virtual rooms. This design enhances the software's scalability, allowing simultaneous access to hundreds of users in multiple groups. The minimal technical specifications to use Lyceum are a PC supporting Windows/98 and, DirectX 8; 64 MB of RAM; 50 MB of free disk space; a 16-bit sound card; and Internet connectivity at 56K or higher. With this particular configuration, there is slight but tolerable latency in the transmission of audio and visual data. 


\section{Silicon Chalk}

Silicon Chalk is an integrated interface designed to enhance student learning via broadcast and archived presentations. The instructor can collate course content featuring slide presentations, instructor audio, Web co-browsing and whiteboard activities, interactive exercises, synchronous text-chat, polling and quizzes using multiple question formats, and applications/ file-sharing. Course access is password-protected; the participant list is displayed during the class; and the instructor can manage student information and tool use. As instruction is delivered, it can be recorded on the student's computer with individualized student questions, comments, and annotations. Notes may be added, edited, and sought by keyword/ phrase. Students may mark questions as private or anonymous. New questions and assignments may be completed for automatic downloading to the instructor the next time the student connects to the course. The instructor can receive live feedback on student pacing, the complexity of activities, and network bandwidth usage. The recording feature enables students to participate in "live or later" instruction, and distance-based students to share the instruction and tools with on-campus students, either synchronously or asynchronously. The software interface is intuitive, though not all tools are displayed. Simultaneous tool use did not affect presentation quality during the evaluation sessions, and recorded audio was consistently clear. The program prioritizes data to ensure highly important data is transmitted first.

The Silicon Chalk software is installed via either a local area network (LAN) or by wireless peerto-peer network. Optional Distance Application Server software is required to enable access for distance-based students. Pilot-test software can be freely downloaded for the creation of one course during a four month period, or be purchased for a four month period at reduced cost. Minimal system requirements include a Pentium III with 256-MB RAM, Windows 2000/XP, a network interface card, and a broadband or wireless network connection. The evaluation team found the download of the trial software file (10-MB) troublesome. Despite three attempts on dial-up (2-4 hours) and broadband connections, the files could still not be extracted. Attempted installation on a networked computer caused the user's entire network to become sluggish as numerous registry files were loaded. Due to these difficulties and limited access to the high-end computers recommended, live instructor-student connection could not be tested. Online demonstrations recorded by the vendor were reviewed instead. This experience suggests that the product may not currently be useable on a wide range of distance-based student hardware platforms. Installation from CD-ROM to a non-networked computer was more successful, and the creation of course activities was easy and intuitive: it took only minutes to create a simple activity including a PowerPoint presentation, audio commentary, and a simple quiz, and to view the recorded presentation adding notes and commentary. Scalability was not tested, although the vendor indicates that the product can accommodate more than 3,000 users/computers. The Macintosh platform is not currently supported. Annual licensing costs are based on per-user or per-computer rates. High-quality technical support for the product is available via toll-free telephone, email, and online forums, tutorials, and white papers.

\section{Conclusion}

In general, these four learning management systems provide rapid, intuitive, user-friendly interfaces and a range of features necessary for online collaborative activities. CentraOne's lower student hardware/ software requirements are appealing for distance education users, though the product's institutional costs are relatively high. IntraLearn provides a user-friendly, structured framework to handle all aspects of course delivery, and can be customized in numerous ways to 
meet the needs of a wide range of clients. Lyceum is an effective synchronous, collaborative tool developed to enhance the specific interactive needs of distance-based students at the British Open University. It provides good audio conferencing and supports it with highly functional visual components. One weakness is its limited capacity to share information with resources outside the Lyceum environment. Silicon Chalk's high-end hardware requirements will make it an expensive interface for distance-based students, although the institutional costs are reasonable. The lack of integrated asynchronous and synchronous communication in Silicon Chalk limits its collaborative potential. Instant messenger and Web-based forum software could be added to enhance interaction among distance students. The four products are thus variously appropriate to different distance-learning situations and should be carefully evaluated in that light prior to purchase.

The next report in the series reviews a vendor-assisted evaluation of a learning management system.

N.B. Owing to the speed with which web addresses become outdated, online references are not cited in this report. They are available, together with updates to the current report, at the Athabasca University software evaluation site: http://cde.athabascau.ca/softeval/. Italicised product names in this report are assumed to be registered trademarks.

JPB, Series Editor, Technical Evaluation Reports

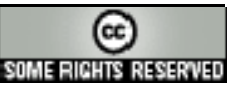


April - 2004

\title{
Technical Evaluation Report
}

\section{Vendor-Assisted Evaluation of a Learning Management System}

\author{
Patricia Fahrni, Jim Rudolph, and Adrienne De Schutter \\ Master's of Distance Education Program \\ Athabasca University - Canada's Open University
}

\begin{abstract}
A product evaluation was conducted of Desire2Learn, an online learning management system gaining popularity in educational institutions. Since an online trial version of the software was not available for evaluation, an inspection meeting with the vendor was arranged. This provided the evaluation team with an opportunity to examine the precautions necessary for ensuring the objectivity of a product evaluation based on vendor-supplied information. The report outlines the team's use of evaluator-driven enquiry and a triangulated approach to information checking. The Desire2Learn product is assessed as a flexible and useful addition to the range of learning management system options.
\end{abstract}

\section{Introduction}

A previous report in this series (\#25) adopted the convention of grouping course and content management systems under the heading Learning Management System (LMS) to avoid confusion between CMS systems. Proliferation of such acronyms is just one example of the types of confusion currently reigning in this rapidly advancing field. Report \#10 in the series described another source of confusion, relating to the lack of objectivity that can arise when software is evaluated with the assistance of its developer/vendor. Often there may be no choice in the matter, when a trial version of the product is not available for inspection. The previous report listed the precautions required when the evaluator is obliged to seek the vendor's assistance in order to gain access to the product. The current study provides a direct example of this situation, in describing an LMS evaluation conducted via a face-to-face demonstration by the vendor in a Vancouver educational institution. The report discusses the precautions taken by the evaluation team in maintaining its objectivity throughout this process, and the outcome of the study.

\section{Methodology}

Desire2Learn (D2L) is an integrated online learning management system (LMS), which provides synchronous and asynchronous interaction between students, teachers, and learning content. Such platforms are usually integrated with administrative databases (e.g., commercial products such as SCT Banner, Peoplesoft, Datatel, and Campus Pipeline). 
Information for possible use in evaluating the product was collected in September and October 2003, from varied sources, including:

- Personal access to existing $D 2 L$ courses

- Interviews with $D 2 L$ users

- An interview with an independent evaluator of $D 2 L$ in a post-secondary institution

- Information on the D2L company's website

- Demonstration of the software by a $D 2 L$ representative at a Vancouver educational institution

Prior to the visit to the $D 2 L$ representative by two of the three-member evaluation team, steps were taken to ensure the depth and objectivity of the information that would be obtained. The caveat emptor recommendations of Report \#10, were followed in this connection. In addition to recognizing the need for independent corroboration of the data collected, the evaluators knew they should request the evidence for unsubstantiated claims and should be prepared, if doubtful of any claims, to challenge the vendor to prove them. Objective technical information was sought, where necessary, to replace merely qualitative product descriptions.

Highlights of the information-gathering process were as follows:

1. The vendor's website provided mission and vision statements, information about external market standards, general information about the product and services, a selective demonstration of features, links to reference sites and adjunct services, and contact information for product representatives.

2. As Fahy (2002) points out in Report \#10, "it is not reasonable to expect vendors to supply complete, objective information on their own products." Prior to the meeting with the $D 2 L$ representative, therefore, the evaluators solicited impartial information about the product from individuals in two major post-secondary institutions. One of these institutions has used D2L for three years, and is doing so currently. The other institution is in the process of assessing whether to transfer to D2L from another LMS platform.

3. During the meeting with the $D 2 L$ representative, the evaluators requested and received a detailed demonstration of specific features of the software in order to verify the qualitative and comparative information provided on the company's website. During the review, they explored several reference sites via the representative's access to them.

4. While the company's website provides technical specifications to externally recognized standards, the face-to-face meeting allowed the team to learn first-hand about the history and evolving functionality of the product. This meeting also provided insight into the organization and management of the company, pricing structures, product support, and software upgrades. At times the discussion with the representative had to be re-focused on the current applications of the product rather than on future development possibilities.

5. The 'forewarned-is-forearmed' approach was considered beneficial, and it is gratifying to report the company responded obligingly to the evaluation team's approach at all times. (In fact, the D2L company's reputation for a high level of customer service had already reached us by word-of-mouth before the evaluation was conducted.) The 
$D 2 L$ representative was open and forthcoming, receptive to feedback and committed to our discussion of educational criteria.

\section{Evaluation of Desire2Learn}

The D2L software has a startup cost based on the number of features, the level of integration with existing systems, and the support needs of the institution. The product has the capability to be used as a course-by-course delivery tool, or scaled up to a larger entity such as a province-wide license. Annual licensing costs are based on a flat fee or on a per-student basis. Users are not required to download any software. The company's servers contain all the software to support their LMS platform with the exception of Java, which is used under the license. This minimal use of third-party software enables the company to give flexible responses to clients' requirements. The vendor provides access to a support person per 5000 students covered by the license.

The product is essentially asynchronous in its approach to online collaboration; at the time of the evaluation, it does not contain synchronous tools such as audio, whiteboard, instant polling, and co-browsing. Its asynchronous conferencing tools are flexible for both administrators and users. The licensing approach allows administrators to assign roles across multiple organizations to facilitate a consortium approach. Administrators can create an unlimited number of customized user roles, with specific privileges for instructors and students. D2L is XML standard-based, and uses a learning-object repository approach that allows instructors to store content (i.e., pages, graphics and test-item banks, etc.). These objects can be shared across any number of courses or programs. (By contrast, other prominent LMS systems use hard-coded HTML pages uploaded to a specific version of a course.) Administrators can assign students the ability to search for specific course content and discussion threads in the learning-object repository. A context-sensitive help feature provides help on each of the major tools for both developers and students. The software is compliant with leading international course-sharing standards including SCORM and IMS, and meets international standards for access by disabled users. D2L databases can be configured to communicate directly with other institutional databases.

The customizable features of $D 2 L$ provide administrators with straightforward means of creating conferences for the members of a class or its sub-groups. Students can be assigned access privileges for system-wide text-chat rooms. Once conferences are created for an individual course, new conferences can easily be created for subsequent offerings of the course. Within a specific course offering, administrators can edit or delete threads, and can control the access privileges of users at different levels, including the right to edit and/ or delete one's own messages. Threaded messages are displayed clearly, and users have control over keyword searches and message sortings by date, topic, and sender. Other options include saving, printing, editing and deleting of postings.

\section{Conclusions}

A primary strength of $D 2 L$ is the breadth and adaptability of its features. It is a fully integrated learning management system that has evidently evolved through close relationships between the software developer and educational institutions. Because D2L is XML standard-based, it is relatively easy to integrate it with other database systems. The product has a high degree of usability. Its course structure and appearance are easy to manipulate, and administrative control over the usage process is broad and easily specified. Owing to its high degree of flexibility and customizability, the product can take many forms. For this reason, the evaluation team recognized 
the vendor's preference for demonstrating its product in person, on an individualized basis rather than via a more generalized online demonstration approach

\section{Acknowledgements}

The authors thank Ben Moore of the Desire2Learn company for his assistance in providing information about this software product; also Bryan Fair, evaluator of Desire2Learn at the British Columbia Institute of Technology.

The next report in the series describes the use of synchronous audio methods in a cross-cultural setting.

N.B. Owing to the speed with which web addresses become outdated, online references are not cited in this report. They are available, together with updates to the current report, at the Athabasca University software evaluation site: http://cde.athabascau.ca/softeval/. Italicised product names in this report are assumed to be registered trademarks.

$J P B$, Series Editor, Technical Evaluation Reports

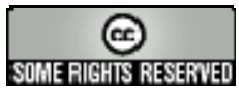

